University of Louisville

ThinkIR: The University of Louisville's Institutional Repository

Electronic Theses and Dissertations

$5-2004$

\title{
An empirical investigation of factors influencing teacher attraction to a career as school counselor.
}

Beverly Cox Keepers 1948-

University of Louisville

Follow this and additional works at: https://ir.library.louisville.edu/etd

\section{Recommended Citation}

Keepers, Beverly Cox 1948-, "An empirical investigation of factors influencing teacher attraction to a career as school counselor." (2004). Electronic Theses and Dissertations. Paper 732.

https://doi.org/10.18297/etd/732

This Doctoral Dissertation is brought to you for free and open access by ThinkIR: The University of Louisville's Institutional Repository. It has been accepted for inclusion in Electronic Theses and Dissertations by an authorized administrator of ThinkIR: The University of Louisville's Institutional Repository. This title appears here courtesy of the author, who has retained all other copyrights. For more information, please contact thinkir@louisville.edu. 
AN EMPIRICAL INVESTIGATION OF FACTORS INFLUENCING TEACHER ATTRACTION TO A CAREER AS SCHOOL COUNSELOR

\title{
By
}

Beverly Cox Keepers

B.A., Western Kentucky University, 1970

M.A., University of Louisville, 1975

\begin{abstract}
A Dissertation Submitted to the Faculty of the Graduate School of the University of Louisville In Partial Fulfillment of the Requirements For the Degree of
\end{abstract}

Doctor of Philosophy

College of Education and Human Development University of Louisville

Louisville, KY 
Copyright () 2004 by Beverly Cox Keepers

All rights reserved 
AN EMPIRICAL INVESTIGATION OF FACTORS INFLUENCING TEACHER ATTRACTION TO A CAREER AS SCHOOL COUNSELOR

$$
\text { By }
$$

Beverly Cox Keepers

B.A., Western Kentucky University, 1970

M.A., University of Louisville, 1975

$$
\text { A Dissertation Approved on }
$$

\author{
April 7, 2004 \\ by the following Dissertation Committee:
}

Dissertation Director 


\section{DEDICATION}

This dissertation is dedicated to my husband, Jerry $\mathrm{C}$. Keepers; our loving daughters, Tiffany Rae and Lauren Kristin; and in memory of my parents, Christine and Raymond Cox. 
ACKNOWLEDGEMENTS

I would like to thank my husband, Jerry, for his continuous support of my educational and professional aspirations. Also, I have been very fortunate to have the support, inspiration, and enthusiasm for my doctoral pursujt with my daughters, Tiffany and Lauren. Also, I would like to acknowledge the unconditional love that was always given to me by my parents, Raymond and Christine Cox, and for their unwavering support and confidence in my endeavors. I would especially like to thank Dr. Paul A. winter, my dissertation chair. His selfless dedication to his students and his unquestionable integrity provided me with the confidence and determination to complete my dissertation. I would also like to thank the other members of my dissertation committee: Dr. P. Diane Ricciardi, Dr. John L. Keedy, Dr. Ann E. Larson, and Dr. Joseph M. Petrosko for their guidance and support of this dissertation. I would also like to thank my program chair, Dr. John L. Strope, for his support, encouragement, and professional support during my coursework and comprehensive 
exams. Special appreciation is also given to Jane Stanford, my cousin, who encouraged me to believe in myself and my goals. I would also like to acknowledge the interest and encouragement demonstrated by the duPont Manual and Youth Performing Arts Schools' faculties, staffs, students, and parents during this project. And finally, I would like to express my appreciation for the members of the Scottish Rites of Kentucky who provided support for my doctoral program and this project. 


\title{
ABSTRACT
}

AN EMPIRICAL INVESTIGATION OF FACTORS INFLUENCING TEACHER ATTRACTION TO A CAREER AS SCHOOL COUNSELOR

\author{
Beverly C. Keepers \\ Apri1 7, 2004
}

This study addressed the administrative task of recruiting school counselors in the largest school district of Kentucky, a state undergoing systemic school reform. The participants $(N=553)$ were elementary $(n=162)$, middle $(n=113)$, and high $(n=278)$ school teachers. The independent variables included personal characteristics of the participants (age, gender, number of dependent children, ethnicity, education, current school enrollment, current school level, current school CATS level, years of teaching experience, years of teaching experience in JCPS, years of teaching experience in Kentucky) serving as control variables. The other independent variables were counselor job facets (predictor variables) and job satisfaction (current, expected). The dependent variable was a two-item composite score for 
applicant rating of a school counselor position as depicted in a simulated counselor job description. The coefficient alpha for the composite rating was .9531 .

This research study utilized a correlation design with hierarchical multiple regression analysis as the primary analytical procedure. The results indicated one control variable (years of experience in JCPS) and four predictor variables (ECE paperwork, administration, testing/assessment, counsel/mentor) explained significant variance in the dependent variable (rating of a school counselor). JCPS experience $(\beta=-.20, p<.01)$ was $a$ negative coefficient indicating as teaching experience in JCPS increased, participant rating of a counselor job decreased.

The full model (adjusted- $R^{2}=.35$ ) explained 35\% of the variance in the rating of a counselor job. Additional statistical procedures included the independent-samples ttest and one-way analysis of variance (ANOVA) to analyze group mean scores with the two-item composite (counselor job rating) serving as the dependent variable. The one-way ANOVA with highest degree serving as the independent variable was significant $(p<.05)$. The participants with a bachelors degree $(M=6.0)$ as the highest degree earned was significantly higher than the mean for participants 
with masters degree +30 hours $(M=5.1)$ as the highest degree earned. The Pearson correlation between age and job rating $(R=-.19)$ was significant $(\mathrm{p}<.0001)$ indicating as age increased, the score for job rating decreased.

Paired t-tests results indicated that teachers rated their current satisfaction with six job factors as teachers higher than they did their expected job satisfaction as a school counselor. The participants completed three openended questions which have implications for counselor recruitment and job restructuring.

Implications for future research might involve casting practicing counselors in the role of simulated applicants for position vacancies. 


\section{CHAPTER}

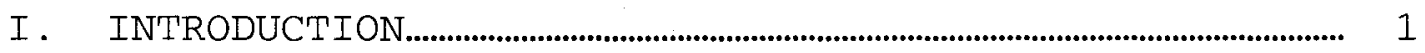

The Job of the School Counselor....................................................... 5

Counselor Recruitment in Kentucky............................................. 11

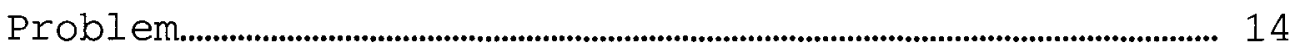

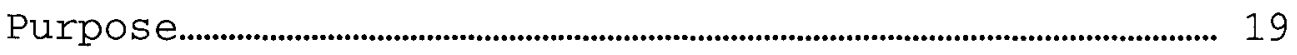

Research Questions.................................................................................. 21

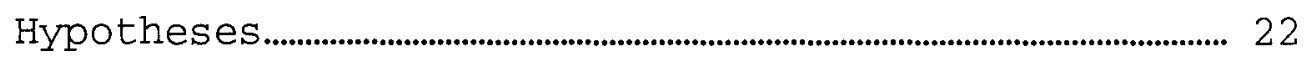

Definitions of Terms............................................................................. 23

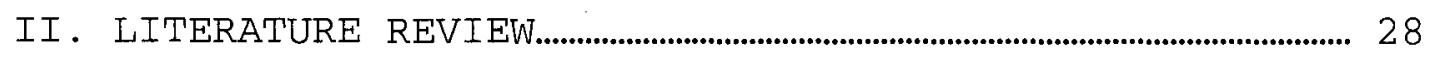

Private-Sector Recruitment Research....................................... 30

Recruiter Effects......................................................................... 31

Recruitment Sources Effectiveness......................................6 66

Realistic Job Previews..................................................................... 89

Person-Organization Fit............................................................. 111

Education Recruitment Research................................................... 140

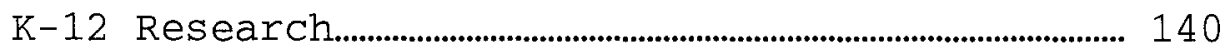


Higher Education Recruitment Research.................. 166

Models and Theories...................................................................... 177

Research Methods........................................................................... 193

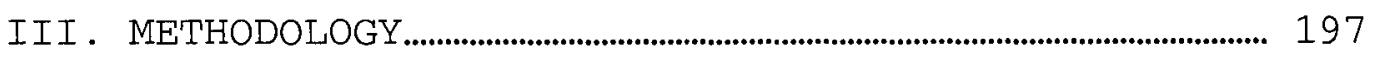

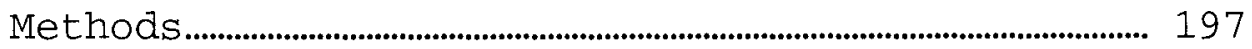

Theoretical Framework........................................................................... 198

Research Advancements............................................................... 198

Participants and Sampling Procedures............................ 199

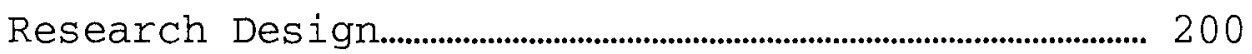

Independent Variables...................................................................... 202

Primary Dependent Variable of Interest........................ 203

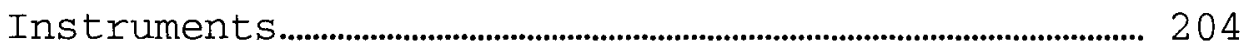

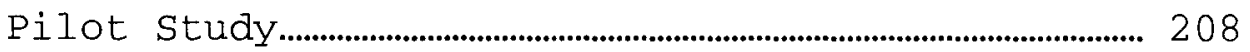

Data collection for This Study........................................... 210

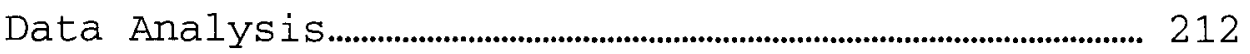

Descriptive Statistics......................................................... 213

Inferential Statistics........................................................ 213

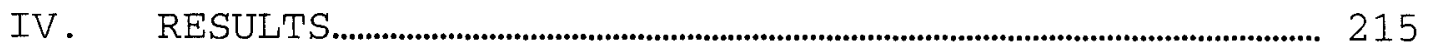

Descriptive Statistics..................................................................... 216

Group Mean Comparisons............................................................ 220

Reliability Analysis.................................................................. 221

Paired t-Test Results................................................................. 223

Correlation and Regression Results................................ 223

Results from Open-Ended Questions...................................... 230 
V. DISCUSSION, IMPLICATIONS, AND CONCLUSION...................... 235

Administrative Practice..................................................................... 236

Descriptive Statistics...................................................................... 237

Group Mean Comparisons...................................................................... 240

Paired t-Test Results.................................................................... 241

Hierarchical Multiple Regression........................................ 244

Open-Ended Questions........................................................................... 248

Future Research.............................................................................. 250

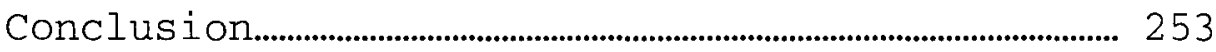

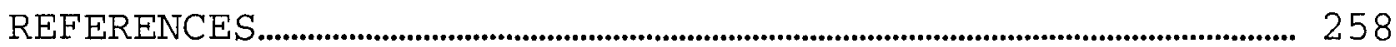

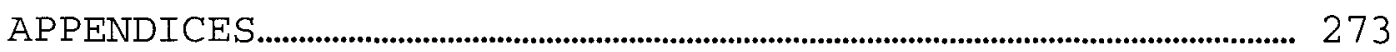

A. Counselor Performance Responsibilities

B. Counselor Survey Instrument

C. Data Collection Script

D. Test-Retest Reliability Analysis

E. Revised Instruments

F. Responses to Open-Ended Questions

G. Data Collection Sites 


\section{LIST OF TABLES}

TABLE

PAGE

1. Descriptive Statistics for Pilot Participants.................... 211

2. Reliability Analysis - Pilot Study................................................. 212

3. Descriptive Statistics for Participants..................................... 217

4. Descriptive Statistics for Attending a

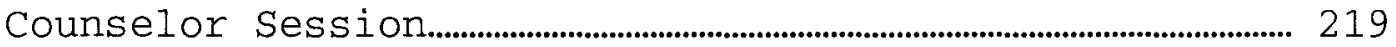

5. Reliability Analysis for Participants.......................................... 222

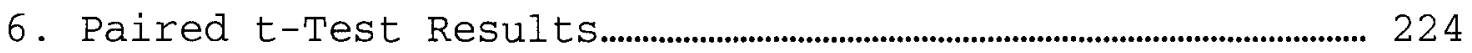

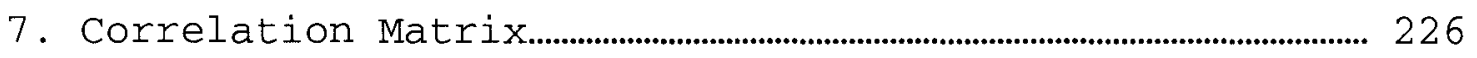

8. Reliability Analysis for Current Job Satisfaction Composite Score................................................................... 228

9. Hierarchical Multiple Regression of Control Variables and Predictor Variables on Counselor Job Rating. 
CHAPTER I

INTRODUCTION

This study addressed the administrative task of recruiting school counselors in the largest school district of Kentucky, a state undergoing systemic school reform according to the mandates of the Kentucky Education Reform Act (KERA) of 1990. KERA increases the demands and responsibilities of school counselors, who often are responsible for the organization and administration of school-wide testing, and are required to maintain student assessment records and interpret these records for students and parents. Recruitment of school counselors is an important topic because of the "shortage of highly qualified school counselors prepared to deal with a wide range of students, from those who are gifted to those who are in pain" (Schwab, 2001).

"Recruitment includes those practices and activities carried on by the organization with the primary purpose of identifying and attracting potential employees" (Barber, 1998, p. 5). Recruitment has been traditionally viewed as 
a process of employee selection, and organizational success in recruiting is defined by the applicant population from which the organization selects an employee (Guion, 1976). A more recent perspective is that recruitment involves decisions made both by the organization and the job applicant (Young, Rinehart, \& Heneman, 1993; Young, Rinehart, \& Place, 1989; Maūrer, Howe, \& Lee, 1992; Winter, 1996). Rynes (1991) defines recruitment as encompassing "all organizational practices and decisions that affect either the number, or types, of individuals who are willing to apply for, or to accept, a given vacancy." This definition leads to a wide-range of recruitment activities, processes, and outcomes which do not occur in isolation from each other (Rynes, 1991).

High school guidance counselors are in short supply, and those currently employed struggle with large numbers of students to serve and with increased administrative responsibilities (Klaus, 2003). Little more than half the number of secondary school counselors is available to meet the American School Counselor Association recommendation of one counselor for every 250 students (Klaus, 2003; Davis \& Craig, 1986).

In Kentucky, the site for this study, the position of school counselor is classified as an administrative 
position. Yerkes and Guaglianone (1998) cite job difficulties often expressed by high school administrators in literature reviews and interviews: (a) time (60-80 hour week); (b) workload and complexity of job; (c) supervision of "unending" nighttime activities; (d) minimal pay differential between top teacher and administrator; (e) feeling bombarded between parents, students, teachers, and employer; (f) state and district mandates resulting in relentless paperwork; ( $g$ ) increased social problems; and (h) difficulty in helping secondary teachers become more collaborative. Administrative responsibilities are more diverse, complex, and time consuming than they have ever been.

The need for more, better-prepared school counselors is evident in schools (Davis \& Craig, 1986). Yerkes and Guaglianone (1998) summarize four reasons cited by human resources administrators for the lack of applicants for school administrative positions: (a) job complexity, lack of support, (c) paperwork demands, and (d) time commitment. In addition to the overall shortage of administrators, the lack of minority applicants for all levels of school administration is one of the real problems in education leadership (Tirozzi, 2001). 
School districts nationwide are reporting difficulty in recruiting and retaining school administrators. About half of these districts are finding a shortage of qualified applicants, with rural districts reporting higher percentages (National Association of Elementary School Principals and National Association of Secondary Principals 1998). Pounder and Merrill (2001) summarized from recruitment literature that "the perceived shortage of applicants for administrators in public high schools is not simply a matter of having adequate numbers of certified applicants to fill expected vacancies. The issue appears to be one of perceptions of quality as well as quantity" (p. 29). Reasons for shortages of quantity and quality in the administrative pool include: job pressures, demands for special programs, long hours, collaborative decision making, and accountability for students success through state mandated reform initiatives (Howley \& Pendarvis, $2002)$.

Finding solutions to the problem of administrator shortages often becomes the responsibility of the human resources department. The human resources administration is challenged with the responsibility of designing and implementing personnel recruitment programs. Effective management of human resources began in the 1970's and grew 
in importance in the 1980's. The concept of organizational entry became the focus of human resources management and included the "wide variety of events occurring when new members join organizations" (Wanous, 1980, p. 1). Organizations desire a qualified applicant pool from which to select new members. The factors influencing applicant decisions to choose organizations emerged in the recruitment literature as applicant reactions to job attributes and applicant reaction to the employment interview (Powel1, 1984). "Attraction strategies do not operate in isolation from other human resource policies and practices" (Rynes \& Barber, 1990). An organization operationalizes job attraction strategies with human resource practices to generate a qualified applicant pool. The Job of the School Counselor

The school counselor is a professional who "focuses on the relations and interactions between students and their school environment with the expressed purpose of reducing the effect of environmental and institutional barriers that impede student academic success" (The Education Trust, 2001). Stone (2003) defined the role of the counselor in this century as one who:

attacks barriers to student success and tackles the task of changing attitudes and beliefs about students and their ability to learn. Counselors take on 
institutional and environmental barriers that stratify students' opportunities. The new counselor embraces an agenda of social justice and will not hesitate to kick dirt in the eye of inequality. (p. 45)

The school counseling profession has migrated from one where students received counseling advice on relationships and continued education, to a profession that has transitioned to a broad-based structure of assisting children and their caregivers (Sink \& Stroh, 2003). School counselor roles require leadership which is necessary to meet the academic expectations of state mandated reform initiatives. To produce effective school counseling programs, counselors must provide leadership to school reform efforts (Hughley, 2001). The context of counseling leadership would include building comprehensive counseling programs, being visible and accessible, being politically astute by linking the school, district, and state, and using symbols and metaphors that communicate the vision of the school (Dollarhide, 2003).

Leadership in school counseling programs requires the contemporary counselor to be effective at problem-solving, leadership, professional relationships, school and district politics, school reform, and resourcefulness. The pressure on school counselors to see that students meet state reform performance standards despite significant student 
emotional, social, and personal needs has contributed to the complexity of the school counselor roles and responsibilities (School Counselors: Emerging Vanguards of Student Safety and Success, 2000).

School counselors feel overwhelmed and intimidated by the recent focus on accountability (Paisley \& McMahon, 2001). As with other personnel in a school reform, individuals are held accountable for program outcomes which contribute to student success. Paisley and McMahon (2001) propose that site-based accountability will require counselors to: (a) understand student needs by interpreting qualitative and quantitative data; (b) design the school counseling program based on those determined needs; (c) determine relevant data and regularly monitor (e.g., test scores, attendance, course offerings, etc.); and (d) implement, evaluate, and revised the program based on reviewing the data (p. 113).

The changing role of the school counselor involves leadership, advocacy, and change. School counselors are joining other school leaders to establish a belief in the development of high aspirations for every child. The school counselor joins the leadership team to ensure that all students succeed (Stone, 2003). In joining the team, counselors must possess the necessary skills to guide and 
support academic development. However, many counselors report that they are unable to focus on student academic achievement because they are burdened with paperwork, clerical record keeping, state mandated testing administration, test (Comprehensive Test of Basic Skills [CTBS], Preliminary Scholastic Aptitude Test [PSAT]) proctoring and supervision of students such as lunchroom duties and after-school activities (McCormick, 2003).

This research project was conducted in the Jefferson County Public School System (JCPS) located in Jefferson County, Kentucky. In 1990, the state legislature passed the Kentucky Education Reform Act (KERA). As a part of this law, school staffs are held accountable for the success of their students on statewide mandated tests. School staffs may receive rewards or sanctions as the extremes of the testing accountability. As a result, school administrators, faculty, and staff are accountable for student success. With KERA, came new roles and responsibilities for all school personnel including counselors. Counselors are now held accountable for students meeting new graduation standards, scoring proficient on state tests and writing portfolios, and for meeting non-cognitive standards. 
The Kentucky Education Professional Standards Board adopted Experienced School Counselor Standards (Standards 1-9) and New School Counselor Standards (Standards 1-7) (February, 1996). The standards address the following nine areas :

1. Program Management, Research, and Evaluation.

2. Developmental Guidance Curriculum.

3. Individual/Small-Group Counseling.

4. Consultation/Collaboration.

5. Coordination.

6. Assessment.

7. Adherence to Professional Standards.

8. Demonstration of Professional Leadership.

9. Engagement in Professional Development.

JCPS uses the Kentucky standards as a "process for the delivery of services in implementing a comprehensive, student results-oriented guidance program" (JCPS, 2000). However, the National Standards (ASCA, 1996) shape the Jefferson County Comprehensive Guidance Program Standards which radically differ from state standards. Jefferson County leads the state in developing standards which reflect programs of structured experiences designed to support students in three areas of skill development (JCPS, 2000): 
(a) Academic Development

1. Students will acquire the attitudes, knowledge, and skills that contribute to effective learning in school and across the life span.

2. Students will complete school with the preparation essential to choose from a wide range of substantial post-secondary options, including college.

3. Students will understand the relationship of academics to the world of work and to life at home and in the community.

(b) Career Development

1. Students will acquire the skills to investigate the world of work in relation to knowledge of self and to make informed career decisions.

2. Students will employ strategies to achieve future career success and satisfaction.

3. Students will understand the relationship between personal qualities, 
education and training, and the world of work.

(c) Personal/Social Development

1. Students will acquire the attitudes, knowledge, and interpersonal skills to help them understand and respect self and others.

2. Students will make decisions, set goals, and take the necessary action to achieve goals.

3. Students will understand safety and survival skills (JCPS, 2000).

According to the 2002 JCPS Human Resources Manual (Eckels, 2002), there are specified performance responsibilities for elementary, middle, and secondary school counselors. The performance specifications are in Appendix A .

Counselor Recruitment in Kentucky

To be employed as a counselor in the Jefferson County Public Schools (JCPS), one must meet three minimum qualifications: (a) hold a masters degree with a major in guidance and counseling, (b) hold a certificate in guidance and counseling from the Kentucky Department of Education, and (c) complete three years of teaching experience for 
elementary and middle school counselor positions and one year of teaching experience for the high school counselor position.

JCPS Human Resources Department generates an applicant pool by publishing internal and external advertisements. The Joblist is both an internal and external publication which lists job vacancies at specific schools and anticipated vacancy positions in the district. The Career File is distributed to all JCPS cost centers and is available online through the JCPS website. In addition, brochures advertising JCPS administrator and counselor positions are distributed at national education conferences and to colleges and universities with counselor education programs.

Once the minimum qualifications are met, applicants for counselor vacancies must complete a JCPS screening process at central office. This screening process consists of an on-site writing sample (usually a response to a parent in letter format) and a series of intensive interviews which address counselor job responsibilities (exceptional child education, interpretation of student test scores and records, student issues, and counseling techniques and strategies for student success). Following these screening activities, the applicant receives scores 
for each one of the areas as well as an attendance score (based on the past five years of applicant work records). The JCPS Director of Administrative Recruitment and Development and her staff rank applicants based on their cumulative scores. Screening scores, references, work record, and applicant materials are considered in creating the applicant pool from which local schools select applicants for counselor vacancies.

When the Director of Administrator Recruitment and Development determines which candidates have the highest scores, she publishes a list of counselor applicants who qualify for interviews at the schools with counselor vacancies. The principal with a counselor vacancy has the opportunity to review personnel files including screening scores of the applicants in the counselor pool. Counselors placed in the pool are categorized by their certification and school level interest (elementary, middle, high). The principal then interviews candidates adhering to local Site-Based Decision Council (SBDM) policies. Most SBDM policies require a site-based interview committee for the selection process. When a counselor is selected, the principal consults with the SBDM Council prior to the recommendation for hiring to the JCPS Director of Administrator Recruitment and Development. 
The Jefferson County Public Schools (JCPS) uses four job performance standards for evaluating counselors: (a) managing the counseling organizational unit (e.g., making appropriate decisions in crisis situations, planning programs, creating a climate conducive to counseling, chairing special education committee meetings, etc.); (b) providing student services (e.g., provides personal, social, and educational developmental counseling; maintains accurate student records, etc); (c) providing informational services to staff, parents, and community; and (d) completing professional responsibilities (Eckels, 2002).

$$
\text { Problem }
$$

The problem addressed in this study was the shortage of K-12 counselors, and the lack of empirical research about counselor recruitment. The need to recruit school counselors was based on the increased retirements indicative of the current "baby boom" generation reaching retirement age and the perceived ambiguous role identity and the job complexities of counselors resulting from school reform initiatives. Because recruiting is a "welldeveloped specialized field" (Davis \& Craig, 1986, p. 5), educators must develop recruitment programs that address the quantity and quality of school counselor job applicants. 
The increased demand for school counselors is resulting in increased numbers of school counselor job positions. In 1991, the American School Counseling Association (ASCA) reported 105,962 counselors in the United states, and in 1994 the number grew to 115,000 counselors (Bureau of Labor Statistics, 1996). TownerLarsen, Granello, and Sears (2000) made this projection in their study of supply and demand of school counselors:

The Bureau of Labor Statistics (1996) reported that employment of school counselors is expected to increase more rapidly than the average of all occupations through the year 2005. This translates to a projected increase in employment of approximately $21 \%$ to $35 \%$. Employment of school counselors was expected to grow as a result of: (a) increasing enrollments (particularly in secondary schools); (b) state legislation requiring counselors in elementary schools; (c) national emphasis on the role of school counselors in preventing school violence; (d) projected retirements of current school counselors; and (e) the expanded responsibilities of school counselors. (p. 271)

The often undefined role of the school counselor also contributes to the shortage of applicants for school counselor positions. Most educational administrators and classroom teachers have little understanding of the job of school counselor (Johnson, 2000). Aubrey (1993) reported that counselors suffered from low visibility and role ambiguity, and that there existed no clear-cut sense of a counselor job description. Johnson (2000) reported that 
the recent trend in public school organizational management is to eliminate central office guidance leadership and place the school counselor supervision under the local building administrator such as the assistant principal. This arrangement has the potential to increase supervision and administrative responsibilities and decrease time spent on student counseling services.

The role of the school counselor has become more complex due to school reform initiatives to address societal factors affecting $\mathrm{K}-12$ students. Increasing poverty, diversity, violence in schools, numbers of at-risk students, and emphasis on academic achievement contribute to the job responsibilities of the school counselor. To address role ambiguity and improve school counseling programs, professional school counselors published the National Standards for School Counseling Programs (ASCA, 1996) which defined effective program responsibilities as engaging in individual counseling, group counseling, consultation, school-wide guidance activities, case management, and program evaluation.

Pérusse, Goodnough, and Noel (2001) found in their study of counselor integration of the national standards that "the National Standards for School Counseling Programs are not used in any consistent fashion by school counseling 
education programs" and "only $30 \%$ of counselors responding to the survey used them minimally or not at all" (p.53). Burnham and Jackson (2000) conducted a study of actual job practices of school counselors. The results indicated that counselors spend from $13 \%$ to $65 \%$ of their day on nonguidance duties including the following most highly ranked nonguidance activities: student records, scheduling, transcripts, office sitting, clubs and organizations, bus duty, attendance, hall and lunch duty, averaging grades, and homeroom (p.46).

Many new school counselors find the actual counseling role responsibilities to be "disconcerting and/or disappointing" (Good, 1992, p. 85). The counseling profession must transform the school counselor role from one of nonguidance responsibilities to one that is shaped by the national standards. If not, administrators wanting to hire school counselors "may well find a shortage of qualified candidates and may be forced to hire less qualified individuals to fill these positions" (TownerLarsen, Granello, \& Sears, 2000, p. 275).

Dr. Diane Ricciardi, Director of Administrator Recruitment for Jefferson County Public Schools articulated counselor recruitment complexities from her job perspective: 
The position of counselor is sometimes more difficult to fill than that of principal or assistant principal. We have a shortage of counselors-particularly at the elementary level and have limited male and minority applicants coming from university certification programs. Several factors complicate staffing counselor positions. First, the counselor's role is somewhat misunderstood since it is in a state of fluxchanging from a traditional slant of mental health intervention. Instead, the role is evolving into one of leadership-as a leader for student achievement and a catalyst for removing learning barriers that exist for students in the school or home environment. Expertise in counseling services, knowledge of current curriculum and instruction, coupled with understanding of student learning theory and learning needs-becomes the content for counselor leadership in the new role.

Sometimes, counselors are unsettled with new leadership roles because of their prior training and personal experiences. Finally, counselors learn that guidance jobs aligned with ASCA standards are not in place in all schools due to informal job performance expectations set by building principals. Even counselors who are ready to accept and flourish with new counselor leadership responsibilities have limited success when the principal is not on board with the new job expectations and instead fills counselor time with low-level non-counseling tasks. Assignment of excessive paperwork, removal from instructional improvement and curriculum activities in the school, and lack of structuring the counselor's role as one responsible for overall student achievement, dilutes the potential influence of today's counselors (P. D. Ricciardi, personal communication, December 1, 2003).

Although research indicates an increasing need for

qualified school counselors and a decline in the number of applicants, there are no empirical studies to date about counselor recruitment. This study is a first step towards filling this gap in the existing recruitment literature. Also, this study responded to the call by Whiston (2002): 
...there is a significant dearth of research in school counseling... Unless more emphasis is placed on documenting the effectiveness of school counselors, school counseling programs can easily be eliminated in these times of budgetary constraints. I believe more research is needed..... (p. 154)

This study also responded to the need for empirical research about administrator recruitment from pounder and Young (1996): "Given the importance of recruitment, it is disappointing that few, if any, empirical studies exist which bear specifically on the attraction of individuals to public school administration positions" (p. 288). This study is unique in that it contributes knowledge about counselor recruitment so that school administrators may establish more effective counselor recruitment programs.

\section{Purpose}

The purpose of this study was to address factors that may influence teacher attraction to a career in school counselor recruitment. This study had three objectives. The first objective was to determine if teachers differed in their ratings of a counselor position with respect to their demographic characteristics. Characteristics of interest included gender, ethnicity, and school assignment level.

The second objective was to evaluate $\mathrm{K}-12$ public school teachers' satisfaction with job facets in their 
current position compared to expected satisfaction with the same job facets in the position of school counselor. The purpose of the satisfaction analysis was to identify (a) job factors that discourage teachers from considering a job as school counselor and (b) job factors that may attract teachers to a job as school counselor. Information from this analysis may be used to improve the content of counselor recruitment media (e.g., positive advertisements, recruitment videos); provide data useful for planning and implementing teacher orientation sessions to inform teachers about a career as school counselor; and inform district officials about ways to restructure the job to make counseling a more attractive position.

The third objective was to determine which teacher demographic variables and counselor job facets are the most salient predictors of teacher rating of a school counselor position. The independent variables for this phase of the Jefferson County Public Schools study were counselor job facets and teacher demographic variables. The job facets were the predictor variables of interest, and the demographic variables (age, gender, ethnicity, number of dependent children, highest degree earned, school level, teaching specialty, years of teaching experience, and years of teaching in current assignment) served as control 
variables. The dependent variable was a two-item composite rating of a school counselor position depicted in a counselor job description. Information about predictor variables would also inform the planning and implementation of recruitment practices, teacher orientation sessions, and counselor job restructuring.

\section{Research Questions}

The research questions for this study were as follows:

1. Which teacher demographic characteristics (e.g., gender, ethnicity) impact teacher ratings of a school counselor position?

2. Which work facets do teachers find more interesting or less interesting than their current teaching position as compared to their perceived interest in those same work facets in the position of school counselor?

3. Which teacher demographic variables (e.g., age, gender, ethnicity) are significant predictors of teacher ratings of a school counselor position?

4. Which counselor work facets are significant predictors of teacher ratings of a school counselor position?

5. Which interactions between counselor work facets and demographic variables (i.e., school level, school classification, years of teaching experience) serving 
as control variables are significant predictors of teacher ratings of a school counselor position?

The teacher demographic variables and the work facets addressed by the above research questions appear in the school counselor survey instrument (Appendix B).

\section{Hypotheses}

The research questions, articulated as formal null hypotheses, appear below. The first null hypothesis addressed the impact of demographic variables such as gender and ethnicity.

The second null hypothesis addresses differences between teacher job satisfaction in the current position and expected teacher satisfaction in the job of school counselor.

$\mathrm{H}_{1}$ : There is no difference in teacher mean rating of a counselor position associated with teacher demographic variables.

H2: There is no difference between teacher mean rating of teacher work facets in the current position and teacher mean rating of job facets in the job of school counselor.

The third, fourth, and fifth null hypotheses related to the control variables and predictor variables assessed by a multiple regression procedure. 
H3: There is no difference in teacher mean rating of a counselor position associated with teacher demographic variables serving as control variables.

H4: There is no difference in teacher mean rating of a counselor position associated with counselor work facets serving as predictor variables.

H5: There is no difference in teacher mean rating of a counselor position associated with interactions between school level, school classification, and years of teaching experience (control variables) and the predictor variables.

\section{Definitions of Terms}

The following section provides a definition of terms which will be used in the study:

1. Applicant - a "job seeker" who submits a formal notification (letter of interest, application, résumé) (Judge \& Cable, 1997).

2. Applicant attraction - the positive reaction of the applicant to the organization which treats the applicant as a customer (Smither, Reilly, Millsap, Pearlman, and Stoffey, 1993) 
3. Applicant perspective - a recruitment approach emphasizing the applicant's reaction to the recruitment process (Powell, 1984).

4. Counselor - a certified teacher and counselor who focuses on the relations and interactions between students and their "school environment with the expressed purpose of reducing the effect of environmental and institutional barriers that impede student success" (Scheel, 2003).

5. Interview - a series of questions from the organizational representative and responses from the job applicant. Interviews function to recruit and select employees (Wanous, 1980).

6. Interviewer - a representative from an organization who obtains information about the applicant, evaluates the data, and makes a prediction about applicant potential value to the organization. In addition, the interviewer must present the information in a favorable light so the applicant might accept an job offer if one is given (Alderfer \& McCord, 1970).

7. Job choice theory - job applicant organizational choices are influenced by both job and organizational attributes that vary by job attribute categories such 
as objective, subjective, and critical contact (Young, Rinehart, and Place, 1989).

8. Job message - the information about a job vacancy the organization communicates to potential job applicants.

9. Job offer - the final stage of the recruitment process where a position in the organization is offered to the job applicant.

10. Kentucky Education Reform Act - in 1990, the General Assembly passed HB 940 which created for all public schools curriculum standards, assessment, accountability, rewards, and sanctions (Legislative Research Commission, 1994).

11. Organizational entry - the process that occurs when new members enter the organization (Wanous, 1977).

12. Organizational perspective - the recruitment strategies are from the point-of-view of the goals, mission, and needs of the organization (Herriot \& Rothwe11, 1981).

13. Person-organization fit (P-O fit) - the congruence of the personality traits beliefs, and values of the employee with the culture, strategic needs, norms, and values of the organization (Rynes \& Gerhart, 1990).

14. Recruitment-as-job-marketing theory - a recruitment theory that acknowledges the dual decision-making 
process by both the applicant and the organizational representative during the recruitment process (Maūrer, et al., 1992).

15. Recruitment - "recruitment includes those practices and activities carried on by the organization with the primary purpose of identifying and attracting potential employees" (Barber, 1998, p. 5).

16. Recruitment medium - the method to communicate organizational recruitment information (Schwab, 1982).

17. Recruitment sources - the origin from where an individual was recruited such as college placement office, newspaper advertisement, referral, etc. (Decker \& Cornelius, 1979).

18. Realistic job previews - the organization stresses in the interview efforts to communicate what organizational life will be like on the job, giving both positive and negative information (Wanous, 1975).

19. School counseling - a process of helping students to make decisions and change behaviors (Kindergarten Through Grade Twelve Comprehensive Guidance Program, $2000)$.

20.Selection - the decision to accept or reject a candidate for a position in the organization (Alderford \& McCord, 1970). 
21. Traditional job preview - an approach to recruitment and selection where the applicant is only given positive information about the organization (Wanous, 1975).

A review of the literature that framed this study is in the next chapter. 
CHAPTER II

LITERATURE REVIEW

The focus of this literature review is recruitment from both the organization's and job applicant's perspective. Traditionally, organizations hired job applicants based on the information gathered. Recently, organizations have directed attention to the applicant's need for job information and how that information is delivered in the decision-making process for job acceptance/rejection (Fisher, Ilgen, \& Hoyer, 1979). Rynes and Miller (1983) proposed that hiring decisions are now a "two-way selection process" where applicants and employers make decisions about prospective employment. Recruitment has become a process of seeking applicants for job vacancies. Taylor and Bergmann (1987) defined recruitment as "a wide variety of activities and characteristics, ranging from the dispensing of organizational literature to the characteristics and behavior of organizational recruiters" (p. 261). Rynes (1991) conceptualized the scope of organizational recruitment as follows: 
"Recruitment encompasses all organizational practices and decisions that affect either the number, or types, of individuals who are willing to apply for, or to accept, a given vacancy" (p. 429).

Recruitment emerged as the organization's most effective method for attracting applicants with predicted labor shortages persisting into the $21^{\text {st }}$ century (Rynes \& Barber, 1990). The importance of organizational recruitment has recently received attention by organizations, including school systems, in their attempts to hire qualified and competent school administrators. Organizations recognize that recruitment programs are the most important component of an organization's staffing process (Rynes, Heneman, and Schwab, 1980). Recruitment research has linked recruitment effects to post-hire outcomes such as tenure and job performance (Breaugh, 1981). Pounder and Merrill (2001) reported concerns regarding the shortage of high school principal candidates, as the issue relates to both quality and quantity of applicants. Winter and Morgenthal (2002) highlighted the need for qualified principals to meet the challenges of current school reform initiatives including state standardized assessments and school accountability. 
This literature review addresses empirical studies from both the private and education sector. The purpose of this review is to meet the following overall objectives:

(1) To review recruitment research from the private sector which guided the education research literature relative to theory, methodology, and experimental designs.

(2) To review recruitment research from the educational sector,

(3) To analyze recruitment models,

(4) To analyze recruitment theories.

Sections of this chapter will address: (a) recruiter effects, (b) recruitment sources effectiveness, (c) realistic job previews, (d) K-12 education research, (e) higher education research and (f) summary of reviewed literature.

\section{Private-Sector Recruitment Research}

Most recruitment research in the private sector has focused on three topics: recruiters, recruitment sources, and realistic job previews (Rynes, 1991). Alderfer and McCord (1970) had one of the earliest research studies which investigated the impact of perceived interviewer traits, attitudes, and behaviors on job candidates. They theorized that as interviewers' behaviors changed, so would 
the job candidates' attitudes change and their likelihood of accepting a job position. Recruitment sources effects emerged as a variable in the recruitment literature relative to formal sources, informal sources, and walk-ins (Quaglieri, 1982). Realistic job preview addressed the accuracy of job information included in recruitment messages which, according to Rynes (1991), has generated more attention than the other recruitment topics. Recruiter Effects

Research on recruiter effects focused on the effects of recruiter characteristics on the applicant's decision to accept or not to accept a job offer (Rynes, 1991). The importance of the interview in the organization's attempt to recruit top candidates motivated researchers to investigate interviewer behaviors such as personableness, competence, informativeness aggressiveness, and gender, relative to the applicant's expectancy of receiving a job offer and probability of accepting the job offered (Harris \& Fink, 1987). Rogers and Sincoff (1978) found a significance in the recruiter's age, title, and manner of presentation on applicant decisions to accept a job offer. However, Powell (1984) found that when controlling job attributes, perceptions of recruiters were not significantly associated with job acceptance decisions. 
Rynes (1991) speculated that recruiters do have a large effect on applicant job decisions but that effect diminishes somewhat when applicants move further along in the recruitment process.

Alderfer and Mccord (1970) studied various perceived recruitment interviewer traits, behaviors, and attitudes on job candidates during the interview process. The researchers hypothesized that as interviewer behaviors changed, the job candidates' attitudes changed, as did their probability of accepting a job if offered. The study participants $(N=112)$ were first-year and second-year Business and Public Administration graduate students at Cornell University. The participants were second-year students ( $n=65$ ) looking for permanent jobs, and the first-year students $(n=47)$ looking for summer jobs. The independent variables were: (a) recruiter willingness to answer questions, (b) recruiter interest in the applicant, (c) recruiter understanding of the applicant perspective, (d) recruiter trustworthiness and likeability, (e) recruiter familiarity with applicant background, appearance of recruiter competence, and (g) recruiter not making the applicant comfortable. The dependent variable was applicant reaction to the interview measured as 
applicant expectancy of receiving an offer and probability of accepting an offer.

The researchers operationalized the independent variables on a survey questionnaire by asking the participants to respond to two lists of job attributes by rating and ranking those attributes as to what constituted an ideal job. In Part II of the questionnaire, the participants rated their best, worst, and average interviews by responding to 17 questions on 6-point Likerttype scales that measured applicant reaction to the interview. The researchers used Pearson product-moment correlations to compare responses of the participants to items on the questionnaire. Also, independent t-tests assessed group mean differences between best and worst interviews.

Results of the study supported the hypothesis that perceived satisfaction of a candidate's interpersonal needs was related to a positive evaluation of the recruitment interview. Also, the study revealed that the interviewer's positive, interested behavior resulted in a job applicant's positive reaction to a job if offered. The researchers also noted that the more the recruiter addressed the interpersonal needs of the job applicant, the more favorably the applicant rated the interview. There was 
also a correlation between the candidate's positive reaction to the interview and the interviewer asking the candidate to assess his own strengths and weaknesses.

The researchers interpreted this positive reaction as being key to the interviewer's positive approach toward the candidate. However, it was not related to accepting the job offer. Best interviewers demonstrated interest and concern for the candidate, asked candidates to assess their strengths and weaknesses, described interviewers as young, successful men, and described the job as one with a high salary. The highest correlation related to expectancy of being offered a job and probability of accepting a job if offered occurred with ratings provided for the best interview.

Schmitt and Coyle (1976) investigated the validity of the employment interview as a selection device for organizational recruiters. The researchers conducted a field study using a post-interview questionnaire to examine the interviewer effects on applicants. The purposes of the study were: (a) to determine through factor analytic procedures the dimensionality of job applicant impressions of the interview process, (b) to relate those dimensions to the applicant overall impressions of the interviewer and the organization and the likelihood of receiving and 
accepting a job offer, and (c) to determine the importance of each of these dimensions in the decision of the applicant. The participants were business and engineering undergraduate students $(N=237)$ at Michigan State University. The sample consisted of $68 \%$ male and $51 \%$ business or management majors and $28 \%$ engineering majors. Responses to mailed questionnaires determine the sample size which was $1 / 3$ of the total mailed surveys $(N=711)$. Questionnaires, which instructed the participants to recall their last interview as a frame of reference for responding, operationalized the independent variables for recruiter behavior. In Part I of the questionnaire, participants responded to 74 items on 5-point Likert-type scales which measured their impressions of the interviewer. In Part II, the participants responded to nine statements that assessed the participant impressions which might have resulted from the interview. In Part III, participants responded to demographic data (age, sex, parent occupation, expected income, major field of study, and past work experience) .

Schmitt and Coyle performed factor analysis using a varimax rotation to reduce the factors from 74 to 6 . The six factors became the independent variables which were: (a) interviewer warmth and thoughtfulness, (b) interviewer 
manner of delivery, (c) interviewer aggressiveness, (d) interviewer correctness in presentation and delivery, (e) interviewer presentation of job information, and ( $f$ ) interviewer expression of opinion and willingness to ascertain the opinion of the candidate.

The researchers used these six independent variables in a multiple regression analysis with recruiter warmth and friendliness predicting nine dependent variables:

(likeliness of job, likelihood of job acceptance, receipt of job offer, acceptance of job offer, perception of performance in interview more or less favorable to company, perception of interviewer competence, perception of interviewer pleasantness, and likelihood of exploring further job possibility with this company). Recruiter information about the job predicted seven out of nine dependent variables. Measurement of the other two items was as follows: (a) receipt of job offer (yes, uncertain, no) and (b) student accepted a job offer (yes, no). The researchers used Pearson's correlations to compare means, standard deviations, and intercorrelations of the nine dependent variables. Results indicated that "overall perception of the interviewer's competence" and "overall perception of the interviewer's pleasantness" received the strongest correlation. 
Schmitt and coyle (1974) performed a series of multiple regression analyses to assess the influence of applicant perceptions of the interviewer (independent variables) on the nine dependent variables. The researchers divided the sample $(N=237)$ into two groups: an estimation sample $(n=162)$ and a cross-validation or holdout sample $(n=75)$. The researchers ran a multivariate regression analysis with the estimate sample. The multivariate $F$ based on the estimate sample indicated that the six factors were significantly related to the dependent variables $(F=4.33, \mathrm{P}<.0001)$. Then, the researchers performed univariate regression analyses on each of the dependent variables. Schmitt and Coyle (1976) applied the regression coefficients to the cross-validation sample $(N=75)$ to estimate the shrinkage in multiple- $R$ for each of the dependent variables. Results indicated little shrinkage in multiple $R$ except for overall perceptions of interview competence. The researchers combined the estimation and cross-validation samples and conducted multiple regression analyses for each of the dependent variables. The results of the analysis indicated that the first regression equation (estimation sample) measured the relationship between the independent and dependent variables fairly consistently. 
The study results indicated that interviewers influenced applicant ratings of (a) the interviewer, (b) the organization, (c) the probability of receiving a job offer, and (d) the probability of accepting a job offer. Factor 1, interviewer warmth and thoughtfulness, significantly related to all nine dependent variables. The participants responded more favorably to interviewers perceived as being warm and thoughtful. Factor 5, interviewer presentation of job information, was significantly related to seven of the nine dependent variables.

Applicants perceived interviewers as more favorable when they presented detailed job information. Interviewer manner of delivery (Factor 2) and interviewer correctness in presentation (Factor 4) significantly related to two (estimate of likelihood of job acceptance immediately after interview) and five (interviewee perception of his performance in the interview) of the dependent variables respectively. Applicants perceived interviewers who presented information with clarity and without redundancy more favorably. Not significantly related to any of the dependent variables were the interviewer forcefulness and self-confidence (Factor 3 ) and the interviewer expression of opinion and willingness to ascertain the opinion of the 
candidate (Factor 6). This study indicated that the interviewer's personality, manner of delivery, and presentation of job information had a significant effect on the applicant's decision to seek/accept employment in that organization.

Rogers and Sincoff (1978) determined if the impressions made by college recruiters affected students' job choice decisions. The study assessed the effects of three independent variables: (a) the age of the interviewer $(20,30,50) ;(b)$ the stature (position title) of the interviewer (title, no title); and (c) the quality of the interview presentation (good, poor). The participants were freshmen communication students $(N=376)$ enrolled at ohio University. The researchers operationalized the independent variables with two prerecorded interviews. Good recruiter presentations were smooth and fluent. Poor recruiter presentations included 50 performance difficulties with hesitations, mispronunciations, and extended pauses. To hold other variables constant, the recruiters were males of similar physical appearances (height, weight, eyeglasses) and used the same name. The recruiters were introduced as having a specific job title or no job title. The participants listened to one of the two audio taped interviews which operationalized the 
quality of the recruiter's presentation. One of the three recruiter photos operationalized age $(20,30$, and 50).

Rogers and Sincoff (1978) operationalized the dependent variable, applicant perception of the recruiter, by having the participants complete a semantic differential credibility scale (Berlo, Lemmert, and Mertz, 1969) which provided a composite score for applicant impression of the recruiter. The statistical procedure used was a $3 \times 2 \times 2$ factorial analysis of variance (ANOVA) to determine if significance existed among treatment groups. Results showed significant main effects for each independent variable: age, job title, and manner of presentation. To determine the source of the main effects from the analysis of variance, the researchers performed three post-hoc tests: the Newman-Keuls Sequential Range test, Duncan's Multiple Range test, and the t-Test for Differences Among Several Means. Results revealed that recruiter job title accounted for greater differences than did either age or manner of presentation. Participants reacted most favorably to 30-year-old recruiters and had a slight preference for the 50-year-old-recruiter compared to the 20-year-old recruiter. The participants also reacted more favorably to fluency than non-fluency in the recruiter's presentation. 
Fisher, Ilgen, and Hoyer (1979) examined the effects of job source information and the favorability of information on applicant rating of source credibility and job acceptance. The participants were seniors from the business school at Purdue University $(N=90)$ who roleplayed as applicants for jobs depicted in written job descriptions. The independent variables were: source of information about the job (interviewer, friend, job incumbent, and professor) and favorability of job information (positive, negative). To operationalize the independent variables, the participants read a statement which contained six questions and answers which presented information as though it came from one of the four information sources. The researchers created two statements, one answered positively and one answered negatively. The information in the questions related to opportunity for skill use, promotion, working conditions, salary, job variety, and autonomy. Mailings to students provided 90 usable surveys for a $40 \%$ response rate. The researchers attributed this low response rate to mailing the surveys near the end of the semester.

The researchers piloted the instrument with 100 students from an introductory psychology class. Students rated favorability of each statement about the job on a 7- 
point Likert scale. The anchors were: 1 = very favorable, $4=$ neutral, and $7=$ very favorable. The researchers classified the answers as positive if the mean was between 4.5 and 5.5 and as negative if the mean was between 2.5 and 3.5 .

The dependent variables were: (a) trust in the source, (b) expertise of the source, (c) liking for the source, and (d) interest in the company. The researchers used a 5point Likert-type scale to measure the dependent variables and formed a composite score of the 13 items which assessed participants' attitudes towards the job and company $(1=$ strongly disagree, 2 = disagree, 3 = uncertain, 4 = agree, 5 = strongly agree). The items measuring trust in source were: (a) "I feel this person is extremely trustworthy", (b) "I believe this person is telling me the truth as he sees it", and (c) "I feel this person is not being honest with me" (reverse scored). Coefficient alpha for these items was .68. The items measuring expertise of the source were: (a) "This person really knows a lot about this company", (b) "I consider this person to be an extremely credible source of information about the job", and (c) "This person really knows what he is talking about". Coefficient alpha for these items was .81. The items measuring credibility of the source were: (a) "This person 
seems like a very nice person", (b) "I believe I would really like this person", and (c) "I really don't care to get to know this person any better" (reverse scored). The researchers measured choice-of-company scale (based on information and source) with items: (a) "I am very interested in pursuing my application with this company", (b) "I would be very willing to accept a job with this company if offered one", (c) "I would really like to work for this company", and (d) "I feel I know enough about this company to no longer be interested in it except as a last resort" (reverse scored). Coefficient alpha for this scale was .83 .

Intercorrelations among the four dependent variables ranged from .17 to .58 with the median being .45. The researchers performed a 2 x 4 multivariate analysis of variance (MANOVA) because the dependent variables were correlated. The MANOVA test was significant, so the researchers performed univariate analysis of variance (ANOVA) and Newman-Keuls post-hoc tests to identify the precise significant group mean differences.

For trust in source, there was a significant main effect for source of information $(F=3.08, p<.05)$. A post hoc test revealed that the most trusted people were job incumbents and friends, and the least trusted was the 
interviewer. The participants rated trust more significant when information sources gave negative as well as positive information about the job. There was a significant main effect for source by favorability interaction with applicant ratings of perceived job expertise. The participants viewed a friend as the expert regardless of information favorability level while they viewed other sources as experts only when the information presented contained negative information as well as positive. The only significant main effect for liking the source was source of information. The interviewer was the least liked of the four sources. The main effects for choice of company were significant. The participants were less likely to accept a job if the source of information was the interviewer, and they were more likely to accept a position if the job information was positive. This study confirmed that favorability and source of job information affect source credibility and job offer acceptance.

Herriott and Rothwell (1981) investigated the effects of recruitment practices of employers on applicant attraction to a job. Two experiments assessed the effects of employers' brochures and selection interviews on student intentions to accept a job. The researchers intended to provide experimental support for decision-making theory 
which involves the assessment of individual beliefs about the outcomes of chosen alternatives (instrumentalities) and the evaluations of those outcomes (valences).

In Experiment 1, second-year engineering students $(N=$ 96) served as participants to assess the effects of employer literature on students as job candidates. The independent variables were: (a) brochure type (employer, control group); (b) pretests (yes, no); (c) post-test (immediate, delayed); (d) quantity of information about research and work variety (high, low); and (e) company type (nationalized industry, large private organization). The dependent variable consisted of applicant composite score ratings measuring seven recruitment outcomes: (a) intentions to pursue the job, (b) beliefs (instrumentalities) regarding the outcomes of entering the job, (c) evaluations of the outcomes (valences), expectancies of obtaining the job, (e) applicant perceptions of the beliefs of referring others regarding the job, and (f) motivation to comply with organizational requests. Questionnaires containing Likert-type scales operationalized the dependent variables.

The researchers utilized six groups to manipulate the five independent variables. Each design group received a different treatment. Within the six-group manipulations 
included independent variable a (brochure type); independent variable b (pre-test); and independent variable $c$ (brochure content). Independent variables $d$ and $e$ were repeated measures variables and were applied across all groups. The researchers assigned students to one of the six groups and then paired each group to form the three groups. The researchers analyzed the factors using univariate three-way analysis of variance (ANOVA) with unequal cell sizes.

The results of Experiment 1 indicated that company brochures with many mentions of the opportunity to do research and experience work variety received significantly higher applicant ratings for intention to apply for the job than did brochures with few mentions of research and work variety. Mention of research and variety (high, low) interacted with post-test (immediate, delayed). Applicants' intentions to apply for the job decreased over time. Multiple regression analysis revealed that only applicant expectations for obtaining the job (multiple-R = .45) was a significant predictor of applicant intention to apply for the job.

Experiment 2 in the Herriott and Rothwell (1981) study investigated interview effects on final-year university students $(N=72)$ whom the researchers placed into five 
groups: engineering $(n=15)$; social sciences $(n=17)$; math and computing $(n=14)$; pure sciences $(n=12)$; and other disciplines $(n=14)$. Experiment 2 research design replicated the first with the exception of additional factors entering the analysis to address the interview issues as the independent variable. The independent variables were: interview status (interviewed, not interviewed); order of questions about ideal versus actual interview outcomes (ideal order, real order); and post-test (immediate, delayed). The researchers again created six experimental treatments and paired them into three groups. A three-way analysis of variance (ANOVA) revealed that experiencing an actual interview lowered applicant ratings of intentions to accept a job, and intentions to accept a job further decreased when there was a delay in the posttest. The researchers again re-cast the dependent variables used in ANOVA as predictors in a multiple regression analysis. Applicant beliefs about the job (instrumentalities), applicant perceptions of the beliefs of referent others concerning the job, and applicant expectancies of obtaining the job were significant predictors of applicant probability of accepting the job (multiple-R $=.57)$. 
Although the effects were small and inconclusive for supporting decision-making theory as a framework for assessing job applicant decisions, the ANOVA results had practical implications for recruitment. Recruitment brochure content seems to positively impact the size of the applicant pool. Engineering recruitment brochures showcasing the opportunity to do research and to experience a high degree of work variety received a more favorable rating than those which contained a small degree of research opportunity and work variety content. Also, applicants who interviewed for the job reacted to the job less favorably than did applicants who had not interviewed for the job. The researchers theorized that this might be a result of the failure of the recruiters to fulfill applicant expectations for the interview. The researchers recommended that further research might focus on interviewer effects on recruitment practices.

Rynes and Miller (1983) conducted two experiments to study the influences of recruiter behavior and job attributes on job applicant decisions. Both studies involved an experimental design with simulated videos that portrayed two types of recruiter behaviors and two types of job attributes to assess the recruiter message and medium simultaneously. The independent variables in study 1 were 
recruiter behavior (positive, negative) and recruiter information about the job (high information, low information). Positive recruiter behaviors included consistent eye contact, frequent smiles and nods, verbal recognition of applicant's responses, and positive reactions to applicant's attempts at humor. Negative recruiter behaviors included little smiling, no verbal recognition of applicant's responses, ignoring applicant's attempts at humor, and giving the appearance that the interview should terminate. The recruiter portrayed job knowledge as emphasizing highly specific knowledge of the job (salary, fringe benefits, promotional opportunities). The recruiter depicted low job knowledge as vague information regarding the position and/or the company. Rynes and Miller (1983) operationalized the dependent variables with participants viewing one of four videotapes and responding to nine questions using 4- and 5-point Likert-type scales. The dependent variables were: (a) impressions of the recruiter as a representative of the company, (b) likelihood applicant will receive a second interview or job offer, (c) attractiveness of the job and organization, (d) likelihood the applicant would pursue the job offer after the interview. The participations in study 1 were undergraduates at a large mid-western university ( $N$ 
= 133) and were likely to participate in job interviews in the following year.

The researchers used a multivariate analysis of variance (MANOVA) which revealed statistically significant effects for recruiter behavior and recruiter job knowledge. Positive recruiter behavior was significant for all dependent variables. High recruiter job knowledge was significant for recruiter impressions, expectancies of receiving a job offer, job attractiveness, and the applicant's likelihood to pursue the job offer after the interview. The two independent variables revealed no interaction effects, and MANOVA analysis of covariates revealed no significant effects.

Rynes and Miller (1983) conducted a second experiment using four simulated recruitment interview videotapes in a $2 \times 2$ between-subjects design. In this study, the independent variables were recruiter behaviors and job attributes. The dependent variables were the same as in Study 1 and were operationalized in the same manner. The high level for job attributes emphasized high starting salary, excellent benefits and working conditions, and possible choice of work location operationalized highly attractive job attributes while the low level of job attributes emphasized low starting salary, fewer benefits, 
less vacation, and no choice of initial work location operationalized highly unattractive job attributes. Applicant reactions to eight items on 4 - and 5-point Likert-type scales operationalized the same four dependent variables used in study 1.

Using MANOVA again to analyze the data, the researchers found significant positive recruiter behavior for recruiter impressions and expectancies of job offer. In contrast to Study 1, Study 2 revealed no significant effects for recruiter behavior on job attractiveness or pursuit intentions. High attractiveness resulted in significance for job attractiveness, perceptions of how well the company treats employees, and intent to attend a second interview and to accept a job offer. Results of Study 1 and 2 revealed that recruiter job knowledge and job attributes influenced applicants more than recruiter behaviors.

Powell (1984) examined the simultaneous effects of job attributes and recruiting practices on the likelihood of applicants accepting a job. Previous research had focused on applicants' reactions to job attributes and on applicant reactions to recruiting practices. No research studies had been done on the relative impact of job attributes and recruiting practices in the applicant's decision making 
process for job acceptance. The researcher hypothesized that both job attributes and recruiting practices would have a significant effect on applicant likelihood of job acceptance.

The study participants were graduating college students $(N=200)$ at a state university who participated in employment interviews for one year at the university's placement center. Time periods for interviews were randomly selected, and scheduling data was recorded by placement center personnel. The participants received a survey prior to the interview and asked to complete it after the interview and return it to the sealed box at the placement center within one week. The researchers surveyed 510 participants who returned 200 usable surveys for a $39 \%$ response rate.

The independent variables were: applicant's perception of recruiter affect, recruiter responsiveness, and job attributes. The dependent variable was the applicant likelihood of job acceptance. Applicant responses to 15 job attribute descriptors measured on 7-point Likert-type scales $(1=$ very weak, 7 = very strong) operationalized the independent variable job attributes. The researchers performed factor analysis using varimax rotation, to validate three categories of job attributes: (a) the job 
itself, (b) compensation/security, and (c) company/work environment. Measures for recruiting practices were participant responses to 11 items using 7-point Likert-type scales asking them to respond to attitudes and behavior of the interviewer $(1=$ strongly disagree, 7 = strongly agree). The researchers used factor analysis with varimax rotation to extract two recruiter factors, recruiter positive affect and recruiter responsiveness/knowledge.

Powell (1984) used path analysis to test the hypothesis concerning the relationships between the latent variables (job attributes, recruiting practices, and likelihood of job acceptance) and the six measured variables as indicators (the job itself, compensation/security, company/work environment, positive affect, recruiter responsiveness/knowledge, and likelihood of accepting a job offer). Results showed that each indicator's loading on the appropriate latent variable was significant indicating that the latent variables explained their assigned indicators adequately. The coefficient for the path from job attributes to likelihood of job acceptance was significant providing support for the hypothesis that job attributes influence the likelihood of job acceptance. However, path analysis revealed no significance for recruiting practices and the likelihood of 
accepting a job. In fact, job attributes accounted for more variability than did the combined model of job attributes and recruiting practices. The study results indicates that applicants are influenced by job attributes based on their likelihood of accepting a job if offered. However, importance of recruiting practices on applicant likelihood of accepting a job may be overstated in the related literature.

Harn and Thorton (1985) conducted a study which focused on the job applicant's impression of the recruiter based on a previous study by Schmitt and Coyle (1976) who theorized that recruiter warmth and thoughtfulness influenced an applicant's willingness to accept a job offer. The purpose of this study was to identify behaviors that might influence an applicant's perception of recruiter warmth and thoughtfulness, and to identify those behaviors such as smiles, head nods, and eye contact which might impact an applicant's willingness to accept a job offer. The study participants were 105 graduating college students (44 business majors, 42 engineering majors, and 19 various other majors) which consisted of 85 males and 36 females. The independent variables were: (a) recruiter behaviors indicating the applicant was suited for the job, (b) recruiter informativeness, (c) recruiter interpersonal 
sensitivity, and (d) recruiter listening skills. The researchers operationalized the independent variables by having participants complete five-part questionnaires following employment interviews. The five-parts included: (a) demographic information; (b) statements regarding counseling behaviors measured on 7-point Likert-type scales; (c) statements regarding counseling behaviors using dichotomous responses (true, false); (d) statements regarding recruiter warmth and thoughtfulness measured on 5-point Likert-type scales; and (e) two statements regarding the willingness to accept a job offer and the organizational representativeness of the recruiter.

Harn and Thorton (1985) used varimax rotation factor analysis to reduce counseling behaviors to fewer items. Factor analysis yielded the five independent variables mentioned earlier which factor analysis further defined as: (a) recruiter nondirective counseling behaviors included understanding, acceptance, genuineness, communication skills, and rapport building; (b) recruiter indications of applicant suitability for the job included the recruiter stating job requirements explicitly and specific postinterview contact, (c) recruiter listening included smiling, and other positive nonverbal actions; (d) recruiter informativeness included defining technical 
terms, giving company background information and company career paths; and (e) recruiter interpersonal insensitivity included the use of rehearsed statements and impatience with applicant indecisiveness.

The dependent variables were: (a) perceived warmth and thoughtfulness of the recruiter and (b) applicant willingness to accept a job offer. The applicants responded to 20 items on 5-point Likert-type scales describing impressions of the recruiter $(1=$ strongly agree, 2 = disagree, 3 = neither agrees nor disagree, $4=$ agree, and $5=$ strongly agree). The researchers operationalized the dependent variables, applicant willingness to accept a job offer and the perceived representativeness of the recruiter, with 7-point Likerttype scales anchored with $1=$ strongly disagree and $7=$ strongly agree. The applicants responded to: "If I were offered a job by the company I would probably accept it" as a measure of willingness to accept a job offer. They also responded to: "The recruiter was representative of the employees in this company" as a measure of recruiter representativeness.

The researchers performed a multiple regression analyses. With warmth and thoughtfulness as the dependent variables, significant variance was found in: (a) non- 
directive counseling behaviors, (b) communicated applicant suitability, and (c) listening skills. For willingness to accept a job offer, significance was found in only listening skills. The results confirmed the hypothesis that recruiter counseling behaviors would be related to both recruiter warmth and thoughtfulness and applicant willingness to accept a job offer. The first hypothesis was more strongly supported than the second. The researchers found no significance for age and applicant sex. The researchers suggested that training college recruiters in counseling and listening skills may improve the chances of applicants accepting job offers as a result of these acquired skills.

Liden and Parsons (1986) investigated applicant reactions to job interviews and their intentions to accept a job offer. Applicant sex and race, and interviewer sex were variables in the study. The study purpose was to consider factors that related to applicant intentions to accept a job if offered and to consider how the race and sex of applicants and interviewers affect interviewer and applicant behaviors. Liden and Parsons (1986) offered three hypotheses: (a) Applicant perceptions of the interviewer's behavior is related to applicant affect concerning the interview, the job, and to job acceptance 
intentions; (b) Applicant affect concerning the job is related to job acceptance intentions; and (c) The relationship between the variables is moderated by alternative job possibilities.

The participants $(N=422)$ were applicants seeking seasonal employment at a large amusement park in the Southeast. Demographics, by sex and race, included: 106 Black males, 132 Black females, 100 white males, and 81 White females. The participants volunteered to complete a post-interview questionnaire. Likert-type scales measured applicant responses to brief statements describing interviewer behaviors by assessing: (a) applicant's perception of the interviewer, (b) general affect concerning the interview, (c) general affect concerning the job, (d) external influences, and (e) intentions of accepting a job offer. On 5-point scales, the anchors were: 1 = Does not describe the interviewer's behavior very well and 5 = Describes the interviewer's behavior very well. A varimax rotation factor analysis yielded three factors: competence, personable, and informative. These three factors were the independent variables along with recruiter sex. The dependent variables were: (a) affect toward interviewer, (b) affect toward job, and (c) intention to accept a job offer. 
Liden and Parsons performed correlations to measure feelings about the interview, general job affect, external influences, and job acceptance intention. Also, demographic variables were correlated and showed linear effects. Correlations revealed significance between applicant race, applicant sex, interviewer sex, and perceptions of the interviewer. A multivariate analysis of variance (ANOVA) revealed that applicant perceptions of interviewer personableness influenced applicant affect regarding the interview most strongly. Also, perceptions of the interviewer did not strongly influence applicant affect concerning the job, and Black applicants perceived the White male and white female interviewers as less competent than did White applicants.

The study presented important practical implications in the recruitment process with regard to racial differences in applicant reactions to interviewers. Differences in applicant ratings based on race revealed that perceived interviewer competence could be indicative of perceived fairness of the employment process (Liden \& Parsons, 1986).

Harris and Fink (1987) reviewed previous research on recruitment and determined that recruiting procedures research was minimal. The researchers conducted a field 
study to investigate recruiter characteristics using preand post-interview questionnaires to assess the effects of recruiter characteristics on applicant perceived job attributes and intentions to accept a job. The purpose of the study was to: (a) determine more precisely whether recruiter characteristics were related to perceived job attributes and intentions to accept a job by using a preinterview-postinterview design and (b) test potential moderator variables to determine whether the impact of the recruiter depended on the applicant, job, and interviewer variables.

The participants were graduating college students at a university placement center $(N=145)$ which facilitated pre and post interview opportunities. Following an actual interview, the participants volunteered for a position in their field of study. The independent variables were applicant impressions of: (a) recruiter personableness, recruiter competence, (c) recruiter informativeness, recruiter aggressiveness, (e) recruiter sex, and (f) personnel vs. line recruiter. The researchers operationalized the independent variables with 33 brief descriptions on 5-point Likert-type scales ( $1=$ strongly disagree, 5 = strongly agree). 
A factor analysis with varimax rotation identified four recruiter factors which became the independent variables: (a) personableness, (b) competence, (c) informativeness, and (d) aggressiveness. The dependent variables were: (a) applicant perceived job attributes, applicant expectancy of a job offer, (c) applicant intention to accept a job offer, and (d) applicant regard for the company. The researchers operationalized the dependent variables with 25 items measured on 5-point Likert-type scales $(1$ = very unlikely, 5 = very likely) . The 25 items were divided into four categories: (a) the job itself, (b) work/company environment, (c) compensation/job security, and (d) minor fringe benefits.

The applicants responded to six items to measure job acceptance intentions with these items and scales: (a) likeliness of receiving a job offer $(1=$ very unlikely, $5=$ very likely); (b) overall job attractiveness ( 1 = very unattractive, 7 = very attractive); (c) regard for company (1 = hold in low regard, $5=$ hold in high regard $)$; intention to accept a job if offered ( 1 = very unlikely, $5=$ very likely); and (e) intention to accept an offered job immediately ( 1 = definitely not, 5 = definitely would). The researchers examined the effects of moderator variables which they theorized may influence recruiter effects. The 
moderator variables were: (a) applicant work experience, (b) applicant prior interviews, (c) applicant gender, (d) applicant perceived alternatives, (e) applicant perceived job attractiveness, (f) recruiter gender, and (g) recruiter function.

Harris and Fink (1987) used a two-stage multiple regression analysis to analyze the data. In the first analysis, recruiter characteristics were positively related to perceptions of the job itself, compensation/job security, and work/company environment. Effects of recruiter on minor fringe benefit was not significant. The second multiple regression revealed that recruiter characteristics had a positive impact on job ratings, expectancy of receiving a job offer, and applicant likelihood of accepting the job. Recruiter competence and informativeness had a significant positive impact on participant regard for company. The third multiple regression analysis revealed that when controlling job attributes, the recruiter characteristic personableness had a significant positive effect on intention to accept a job. Hierarchical set regression analysis analyzed moderator variables for each of the eight dependent moderator variables. Previous work experience had a positive effect on applicant rating of job, salary and job security, 
intention to accept the job, and regard for the job. No significant effect was found for recruiter sex or recruiter function (personnel vs. line).

Taylor and Bergmann (1987) investigated the relationship between recruitment activities and job attributes using a field setting and a cross-sectional correlation design. This study, however, differed from previous ones in that the researchers utilized a longitudinal study which investigated diverse recruitment activities across a five-stage recruitment program. These stages included: (a) campus interview, (b) post-campus interview, (c) site visit, (d) job offer, and (e) job offer decision.

The participants $(N=1,286)$ were actual job applicants for a large, national manufacturing firm and its subsidiaries. At each of the five stages, the participants completed questionnaires. Sample sizes were 910 applicants at the campus interview stage, 507 applicants at the post campus stage, 95 applicants at the site visit stage, 91 applicants at the job offer stage, and 38 applicants at the job offer decision stage. The declining number of participants at each successive stage was attributed to an unforeseen recession causing the company to reduce recruitment and cut jobs. 
The independent variables were: (a) recruiter

demographic information, (b) recruiter self-descriptions of the campus interview behavior, (c) applicant descriptions of the interview and the behaviors of the recruiter, (d) information regarding organizational communication, (e) treatment of the applicant by the organization during the non-interview stages, (f) and perceived job attributes of the organization. The dependent variables were: (a) applicant reactions to the recruitment process and (b) applicant reactions to the perceived job attributes. The following measured the dependent variables: (a) company attractiveness, (b) probability of offer acceptance, (c) job offer decision, and (d) tenure intentions. The highest intercorrelation was between company attractiveness and probability of job offer acceptance (.62) while job offer correlated (.28 and .39) with company attractiveness and tenure intentions, respectively. Tenure intentions correlated with company attractiveness (.53).

Taylor and Bergmann (1987) used hierarchical multiple regression analysis to measure the effect of job attributes and recruitment practices on applicant job ratings. A varimax rotation factor analysis reduced the data to a smaller set of predictors. Results indicated that recruitment practices accounted for a significant amount of 
variance in applicant job ratings only at the campus interview stage of the recruitment process. Other significant findings at this stage include: (a) applicants interviewed by female recruiters, older recruiters, or recruiters from the personnel department rated the company as less attractive; (b) applicants interviewed by recruiters with masters (or higher) degrees were preferred over those with only bachelors degrees; (c) female applicants interviewed by female recruiters rated the company as less attractive; (d) applicants who perceived the recruiter as empathetic rated the company as attractive; and (e) recruiter reports of high interview structure predicted high probability of job offer acceptance. The researchers did not find significance for recruiter affect at any of the stages other than the campus interview.

Results showed that job attributes accounted for most of the variance in applicant job ratings at later stages of the recruitment process. Also, recruitment activities influenced applicant reactions when applicants received perceived unknown information about job attributes. The study results did not support the relationship between recruitment activities and applicant comparisons to other 
job offers, applicant years of full-time work experience, and applicant labor market opportunities.

\section{Summary}

Private sector research on recruiter effects identified several independent variables to have significant effects on dependent variables (impression of recruiter and the organization, intentions to accept a job offer). The independent variables in this review include: recruiter demographics (age, race, sex, title); recruiter job knowledge; recruiter behaviors (warmth, responsiveness, sensitivity, listening skills); and recruiter presentation. The literature supports the theory that recruiters influence applicant ratings of the interview, the job/organization, the probability of receiving a job offer, and the probability of accepting an offer. Other studies supported the influence of the recruiter, but limited that influence to the interview stage of the recruitment process. If organizations do not succeed in the interview stage, applicants may self-select out of the recruitment process and pursue jobs with other organizations. Recruitment Sources Effectiveness

Recruitment sources emerged as an important variable in the private-sector recruitment research. Rynes (1991) identified this research as focusing on "employer 
preferences for various sources and on differences in posthire outcomes among individuals hired through various sources" (p. 402). These recruitment sources have been identified in the literature as referrals from current organizational employees, direct applications or walk-ins, newspaper or professional journal advertisements, rehires, and employment agency referrals. The research indicated that recruitment sources impact tenure, performance, and absenteeism.

Ullman (1966) investigated the theory that direct employee referrals are a more reliable source of quality employees. Ullman (1966) based his theory, in part, on a three-year study of the Chicago labor market. He limited this investigation to the recruitment of female clerical workers. The participants were female clerical works $(N=$ 258) from two different organizations. The purpose of the study was to investigate which recruitment source resulted in the most satisfied workers. The researcher identified recruitment sources as the independent variable with three levels: employee referrals, newspaper advertisements, and private employment agencies. The dependent variable was the employee turnover rate 24 months after the initial hire date. Attrition rate data collected was completed after 
each of the following number of months: 1, 2, 3, 6, 9, 12, 18, and 24 .

Ullman (1966) used a descriptive method of comparison of turnover, or attrition, rates from the three different recruitment sources as his data analysis. Results revealed that there was a lower turnover (attrition) rate among employees hired through employee referrals in both organizations. The second lowest turnover was for workers hired through employment agencies. Workers hired through newspaper advertisements had the highest turnover rate (Ullman, 1966).

Rather than measuring employee referrals by attrition rates, Hill (1970) conducted a study to assess employee referrals and non-referral methods of employee hires relative to their performance ratings. The study's purpose was to determine if participants hired through employee referrals had higher performance ratings than those hired with non-referral methods (walk-ins, employment agency, newspaper advertisements). The participants $(N=203)$ were clerical workers in three insurance firms (referred to as Company A, Company B, and Company C). The researcher theorized that referrals who had accurate pre-hire information about the company and who did, in fact, have a close relationship with the referral source, would have a 
higher mean performance rating than those hired through non-referral methods.

The independent variables were: (a) employment channel or job sources (referral, non-referral); (b) pre-hire information (accurate, inaccurate); and (c) relationship with intermediary friend (close, casual). The dependent variable was performance ratings, measured as employee quality and desirability. Company records provided data for performance ratings. The researcher performed independent samples $t$-tests to identify differences between referrals and non-referrals. Results revealed no significant differences on job performance. Although results from all three companies revealed no significant effect on performance for referral versus non-referral sources, referred employees had a higher overall mean rating than non-referral employees.

Hill (1970) conducted further investigations with Company $\mathrm{B}$ and Company $\mathrm{C}$ due to their larger number of employees. The remaining independent variables pre-hire information (accurate, inaccurate) and relationship with intermediary friend (close, casual) formed the comparison for the second analysis. Independent samples t-test were again used to compare groups. As in the first analysis, 
statistically significant. However, in Company B the mean for accurate information and close relationship group was higher than the mean for inaccurate information and casual relationship group. Also, referred employees in Company B tended to be above average in quality as compared to nonreferred employees. In contrast, Company $\mathrm{C}$ employees in the accurate information and close relationship referral group had substantially lower ratings as compared to the inaccurate information-casual relationship group. From this last analysis, Hill (1970) reasoned that referrals may depend on the morale of the employees, the accuracy of prehire information, and the closeness of the employee to the intermediary friend.

Gannon (1971) investigated employee turnover by hiring sources. He hypothesized that recruiting patterns or source of referral predict employee turnover. The participants were New York bank employees $(N=6,390)$ hired during a four-year period (1961-1964). The bank personnel department supplied the data. The department categorized employee referral sources as: (a) newspaper advertisement, (b) major hiring agency under bank contract, (c) hiring agencies not under bank contract, (d) referral to bank by current employee, (e) employee reemployment after time 
away, (f) referred by high school, and (g) other methods such as walk-ins.

Gannon used descriptive statistics to create $2 \times 2$ contingency tables for sources of referral and number of employees hired and those who quit. The researcher used chi-square to analyze differences between recruitment sources and employee quit rates after 12 months. Four sources of referral were uniformly and significantly different from the other three: (a) employee rehires, employee referrals, (c) high school referrals, and (d) walk-in applicants. Of the four, walk-ins were the least effective recruitment source. Employee referrals had the lowest quit rates, and referral by current employees was a less effective method than high school recommendation. The three sources of high employee turnover were: (a) major hiring agency under bank contract, (b) hiring agencies not under bank contract, and (c) newspaper advertisement. The study results indicated that employee turnover can be reduced by utilizing the four most effective recruitment sources.

Decker and Cornelius (1979) tested the generalizability of the findings from previous research on employee referral sources and turnover such as those of Gannon (1971). The participants $(N=2,466)$ were from a 
bank $(n=514)$; an insurance company $(n=1,753)$; and an abstracting service $(n=199)$. Personnel records provided referral information which was recorded in one of five categories. Referral information served as the independent variable with five levels: (a) newspaper advertisements, (b) employment agency, (c) employee referral, (d) walk-in, and (e) other. The dependent variable was place of employment with three levels: (a) bank, (b) insurance company, and (c) abstract service. The dependent variable was the quit rate after 12 months employment.

Descriptive statistics and chi-squared analysis identified significance between referral source and place of employment. Employee referrals were consistently a good recruiting source with the lowest quit rate across all places of employment. Employment agencies were consistently a poor recruiting source. Newspaper advertisements and employment agencies had the highest quit rate across all three work places. Chi-squared analysis also revealed that referral source was significantly related to lower quit rates in the bank and insurance company. The study's findings were consistent with previous research (Gannon, 1971) which indicated the significance of recruiting sources on employee quit rates. 
Breaugh (1981) conducted a field study to assess if employee recruitment sources had an effect on subsequent employee job performance, absenteeism, and work attitudes. The study participants $(N=112)$ were research scientists (70 males, 42 females) who held degrees in biology or chemistry. The researcher gathered data on employee performance, absenteeism, recruitment source from personnel files. Supervisory performance on four performance dimensions (quality, quantity, dependability, job knowledge) operationalized employee performance with ratings on a 5 -point continuum ( 1 = unsatisfactory to $5=$ exceptional). Days absent in the previous 12 months operationalized absenteeism. Employee questionnaires operationalized biographical data and work attitudes. The three work attitudes assessed were: (a) satisfaction with work, (b) satisfaction with supervision, and (c) job involvement.

The independent variable was recruitment source with four levels: (a) newspaper advertisement $(n=30)$; college placement office $(n=24)$; (c) professional journal/convention advertisement $(n=26)$; and (d) selfinitiated $(n=26)$. This study did not include employee referrals because only three subjects reported this as a recruitment source. The dependent variables were: (a) 
absenteeism, (b) performance ratings, and (c) employee work attitudes. Breaugh (1981) also used demographic information as dependent variables to determine differences in the four recruitment sources related to demographic variables.

Breaugh (1981) used univariate analysis of variance (ANOVA) to assess group differences. Results showed no significant effects for demographic variables (employee age, sex, years of education, years with the company, years in current position, and years under the current supervisor) and the four recruitment sources. Multivariate analysis (MANOVA) simultaneously analyzed eight dependent variables (quality, quantity, dependability, job knowledge, absenteeism, work satisfaction, job involvement, and supervisory satisfaction) with the recruitment source serving as the independent variable. MANOVA results revealed significant effects on employee performance and worker attitudes. The researcher computed a post-hoc Duncan Multiple Range Test which indicated strong recruitment source differences. Employees recruited through newspaper advertisements resulted in higher absenteeism, and those recruited through college placement resulted in employees with low performance ratings and lower job involvement and satisfaction with supervisor 
(work attitudes). Self-initiated and journal/convention advertisement recruitment sources produced more employees with better work performance, less absenteeism, and better work attitudes.

Quaglieri (1982) investigated applicant perceptions of job information among recruitment sources. The participants were recently employed business school graduates $(N=64)$ with an average tenure of six weeks. On mailed questionnaires, participants described the first source of job referral and rated that source's information on its specificity and accuracy in describing their current job position.

The independent variable was recruitment source with four levels: (a) formal source (newspaper advertisements, employment agencies, professional journal advertisements); (b) informal source (referrals by friends or relatives who either did or did not work for the organization); and (c) walk-ins. The dependent variables were applicant perceptions of recruitment source accuracy and applicant perceptions of source specificity in the referral job description. The researcher measured the dependent variable source accuracy of information on 5-point Likerttype scales $(1=$ very accurate, $5=$ totally inaccurate) . The participant rated specificity on similar 5-point 
Likert-type scales $(1=$ all specific, $5=$ all general $)$. The participants also responded to demographic items including sex, age, tenure with company, and work tenure.

Quaglieri (1982) performed two separate one-way analyses of variance (ANOVA) to measure differences among sources for accuracy and specificity of information. ANOVA results indicated significant differences among referral sources in terms of the accuracy and specificity of the information offered. The researcher then used independent samples t-tests to analyze the differences for accuracy and specificity of information between the pairs formal versus informal, formal versus walk-in, and informal versus walkin. Results revealed that informal sources of referral and walk-ins received more specific and accurate information about a job than formal sources of information. Quaglieri (1982) concluded that formal sources of information did not provide as accurate and specific job descriptions as did informal ones.

Caldwell and Spivey (1983) advanced the previous research on recruitment sources and employee tenure by conducting a study to examine the relationship between recruitment source, employee race, and employee success. The purpose of this study was to investigate the impact of recruiting source on overall employee success while 
providing a separate analysis by race. The participants were store clerks $(N=1,400)$ hired during 1979 by a national retail chain. The racial makeup of the participants was: (a) White $(n=832)$; (b) Black $(n=370)$; (c) Asian ( $n=76)$; (d) Native American ( $n=20)$; and (e) Hispanic $(n=102)$. Asians, Native Americans, and Hispanics were labeled 'other'. Company files provided the information.

The independent variable was recruitment source which had four levels: (a) employee referrals, (b) response to in-store notices, (c) referrals from employment services, and (d) response to media advertisements which were mostly newspapers. The dependent variables were measures of job success (satisfactory, unsatisfactory) and job tenure (long-term, short-term). The researchers defined categories of employee tenure. Employees were unsatisfactory if terminated for cause (theft, excessive absenteeism, tardiness), or if their supervisor evaluated their performance so low they did not warrant rehiring. Employees were satisfactory if voluntarily terminated or evaluated as eligible for rehire. Employees were long-term if on the job for at least 30 days and short term if on the job less than 30 days. Employees were successful if they had been categorized as satisfactory and long-term. 
Caldwell and Spivey (1983) used a chi-squared statistical analysis to determine the job success of employees recruited through different sources. The results did not support pervious findings. The more formal recruiting source of media announcements (newspapers) was more effective than the informal source of employee referral. Another chi-square analysis revealed a significant relationship between recruiting source of satisfactory employees by race. Media announcements were successful in recruiting successful Black employees while in-store notices were more successful in recruiting successful White employees.

The researchers conducted another chi-square analysis to determine the relationship between employee job success and recruiting source for each racial group. Results revealed that employee referrals for white employees were less effective in recruiting satisfactory employees, but they did tend to be long-term. Also, media announcements effectively recruited white employees, but they tended to be short-term. For Black employees, results were similar to those of Whites. Media announcements effectively recruited satisfactory Black and white employees; however, they tended to be short-term. The analysis revealed that all agencies were ineffective sources for recruiting 
successful employees. The results of this study indicated that recruiting source can have an impact on employee job performance and tenure, but this impact may not be the same across racial groups.

Taylor and Schmidt (1983) conducted a study to examine the causes of differences in recruitment source effectiveness based on the realism of job information provided and the characteristics of individuals recruited. Taylor and Schmidt (1983) proposed three hypotheses. Hypothesis 1 predicted differences in sources utilized to recruit employees measured by employees' job performance, job tenure, and attendance. Hypothesis 2 predicted that job applicants from various recruitment sources believed to provide more realistic job information (employee referrals and rehires) will have longer tenure from sources less likely to yield realistic job information. Hypothesis 3 predicted better job performance and better attendance differences in employees recruited from more and less effective sources with regard to individual characteristics related to job success. Also, the researchers predicted that if personal characteristics are held constant, there will be no significant differences in employee tenure, performance, and attendance across a diversity of recruitment sources. 
The study participants were randomly sampled seasonal workers $(N=293)$ at a packaging plant who were employed as either: (a) forklift drivers, (b) packers, or (c) runner craters (line suppliers of packaging materials). The independent variable was recruitment source with seven levels: (a) employee referrals, (b) newspaper advertisements, (c) public employment office referrals, (d) radio advertisements, (e) rehires from the previous season, (f) television advertisements, and (g) walk-ins. Individual characteristics was the other independent variable with six levels: (a) height, (b) weight, (c) date of birth, (d) sex, (e) previous rate of pay, and (f) shift preference (first, second, third, any). The dependent variables were: (a) job performance, (b) organizational tenure, and (c) attendance. An additive composite score consisting of 4-point Likert-type scales $(1=$ below average, 4 = above average) operationalized the dependent variable job performance. The categories of job performance were: (a) quantity of work, (b) quality of work, and (c) attitude. Days present out of total possible days worked for the season operationalized employee tenure. Supervisor ratings of employees on 4-point Likert-type scales operationalized attendance. 
To test Hypothesis 1, Taylor and Schmidt (1983) used a multivariate analysis of variance (MANOVA) which revealed a highly significant multivariate effect and significant univariate effects for performance, tenure, and attendance. Therefore, the first hypothesis was supported. Rehired employees received the highest ratings of all sources for all employee outcomes.

To test Hypothesis 2, the researchers used the Duncan Multiple Range Test to examine differences between all possible pairs of means. The analysis revealed no significant differences among sources for performance. However, the rehires did yield longer tenure than those recruited by other sources. Also, rehires were significantly more effective in regards to attendance than other recruitment sources.

To test Hypothesis 3, Taylor and Schmidt (1983) used canonical correlation between the individual characteristics and dependent variables use to produce an individual characteristic variate. Computation between the six individual differences and the three effectiveness measures (performance, tenure, absenteeism) resulted in a positive effect. Results revealed that employee effectiveness variables accounted for the greater variance in the date of birth variable. Thus, age of employees 
recruited by different sources had an effect on job effectiveness. ANOVA analysis and subsequent post-hoc Duncan Multiple Range tests included the individual characteristic variate. Results revealed that rehires differed significantly from employees recruited by other sources. Therefore, the results supported Hypothesis 3 which proposed that employees recruited with more or less effective sources would differ on personal characteristics. Two groups of hierarchical multiple regression equations computed on the three effectiveness variables (attendance, performance, tenure) tested personal characteristics differences. Results revealed support for individual differences as causes of differential recruitment source effectiveness with respect to absenteeism, tenure, and partial support for performance.

Breaugh and Mann (1984) investigated recruitment source effects in a study that examined two explanations for source differences: realism and individual differences. The study purpose was to investigate source differences in information provided to applicants and to determine if individual differences might be a variable in the performance findings. The participants in the study were social service workers $(N=98)$ with a demographic makeup of 65 females, 33 males, 18 minorities and 80 
nonminorities. The recruitment sources included: newspaper advertisements $(n=33)$; employee referrals $(n=42)$; and direct applicants/walk-ins $(n=23)$. Research questionnaires and personnel records provided information for the study.

The independent variable in the study was source of recruitment with three levels: newspaper, employee referral, and direct application. The dependent variables were: (a) six ratings of realism of information, demographic information, (c) three ratings of employee ease of movement, (d) employer ratings of employee ability, (e) employer ratings of employee performance, and (f) employer ratings of employee retention. A survey questionnaire required the participants to rate realism of job information provided by source, give demographic information, and rate their ease of movement in finding alternate employment. The above factors were independent variables. Employee personnel records relating to employee ability, performance, and retention operationalized the other independent variables. Six ratings of realism of information in responses to realism statements using 7point Likert-type scales $(1=$ disagree strongly, $7=$ agree strongly) operationalized the dependent variable for 
realism ratings. A composite of the five ratings identified the realism index.

The individual differences variables included demographics and perceived ease of movement. The demographic variables included: sex, race, education level, and age. Participant responses to statements measured perceived ease of movement. The first response $(1=$ yes, 2 = no) was to this question: "Were you employed elsewhere when you accepted employment with this department?" The other measure were responses using 7-point Likert-type scales $(1=$ very hard, 7 = very easy) to questions such as: "When you first came to work here, how easy would it have been for you to find a job as good as the one you took here?" Personnel specialists rated employee education levels and prior work experience $(1=$ underqualified, $2=$ qualified, and 3 = overqualified). They also rated employee performance using 7-point Likert-type scales $(1=$ poor performance, 7 = excellent performance). Retention data included those employees retained after one year and those terminated after one year.

Breaugh and Mann (1984) used analysis of variance (ANOVA) to analyze the realism of information data. All of the realism items were significant (including the index) except for information on job content. Post-hoc Duncan 
Multiple Range Tests revealed that employee referrals provided more realistic job information than either newspaper advertisements or direct applications. ANOVA also analyzed individual differences (demographic, ease of movement, quality). Results revealed significance for only age and sex variables. Newspaper ads tended to recruit older males than those recruited form other sources. Other analysis of means indicated that employees who made direct applications received higher performance ratings than employees recruited from other sources. In addition, employees recruited by referrals were less likely to be terminated than those recruited from other sources.

Swaroff, Barclay, and Bass (1985) investigated the relationships between recruiting source, employee tenure, and employee productivity. The two-year study involved newly hired male technical sales trainees $(N=618)$ in a large corporation. All participants were college graduates, mostly business majors. The means for demographic data included subject age (25 years); length of service (17.2 months); approximate marital status (50\%); and previous experience by number of jobs held prior to this position ( 1.18 jobs). Personnel records were the source for data collection. 
The researchers investigated four hypotheses.

Hypothesis 1 proposed that newly hired

technical/professional employees recruited through informal methods tend to remain with an organization longer than such applicants recruited by more formal methods.

Hypothesis 2 proposed that employees with varying length of service, the longer the length of service, the smaller the probability of finding significant differences among referral sources for employee tenure. Hypothesis 4 proposed that when the effects of age, previous experience, and marital status are statistically removed from referral source-tenure relation, referral source accounts for no significant variance in turnover. Hypothesis 4 proposed that employee referral source and employee productivity will be significantly related.

The independent variables in the study were: (a) referral source (employee referral, friend-relative or self-initiated, newspaper advertisement, employment agency, college recruitment); (b) age; (c) marital status (married, unmarried); and (d) number of previous jobs $(0,1,2,3,4$, or more). The dependent variables were: (a) employee tenure (0-3 months, 4-6 months, 7-12 months, 12-24 months) and (b) employee productivity (percentage of first year quota, percentage of second year quota, supervision 
rating). Five-point Likert-type scales $(1=$ exceptional, 2 = very good, $3=$ satisfactory, $4=$ needs improvement, $5=$ unsatisfactory) operationalized the dependent variables which also included supervisor evaluation of overall employee performance.

Swaroff, Bass, and Barclay (1985) performed separate statistical analysis for each hypothesis. They used both analysis of variance (ANOVA) and multivariate analysis of variance (MANOVA) followed by Scheffe's post-hoc test. For Hypothesis 1, the researchers used ANOVA to test whether employees hired through informal recruitment methods stayed longer than those hired through more formal recruitment methods. Tenure at the end of 24 months was the measure. Results revealed no significant statistical differences in employee tenure based on formal or informal recruitment sources. Therefore, Hypothesis 1 was not supported.

For Hypothesis 2, the researchers compared employees terminated during time intervals of three months. Again, there were no significant statistical differences found between employee tenure and recruitment source. Hypothesis 2 was not supported.

Analysis of Hypothesis 3 was not necessary because Hypotheses 1 and 2 showed no referral source-tenure effect for any time interval. However, the researchers performed 
a multivariate analysis of variance (MANOVA) to assess group mean differences between referral sources relative to three demographic variables. The results indicated that all three demographic variables (age, marital status, number of previous jobs) were related to referral source, but the only significant univariate difference between referral sources was with applicants hired through informal recruiting methods and who were more likely to be married. Univariate post-hoc also revealed that employees hired through newspaper advertisements were significantly older, and employees in the college recruitment group were significantly younger. The researchers then conducted a test using three different productivity measures in three independent univariate analyses. The results revealed no support for Hypotheses 4, because the analysis revealed no relationship between three separate measures of productivity and recruitment source.

Summary

The studies reviewed above indicated that recruitment sources affect employee behaviors and attitudes. The research documents the importance of organizations carefully selecting recruitment sources in order to recruit the best candidates for the job vacancy. Employee referrals emerged in the literature as the most effective 
type of recruitment source. Employees recruited by referrals had longer tenure, less absenteeism, and better performance reviews. Organizational rehires and private employment absences were good recruitment sources while college placement offices were not effective sources. The least effective recruitment source was newspaper advertisements. Two important theories relating to employee performance emerged from the recruitment sources effects literature. Realistic job information and individual differences theories further define the differences in employee performance. Formal sources (newspaper advertisements, employment agencies) are less effective means of realistic job information than informal sources (employee referrals, rehires). The more realistic job information a candidate receives, the better the employee performance. Individual differences (sex, age, race) of recruitment sources and job candidates impact employee performance in that these differences may result in more successful employees. Realistic Job Previews

Realistic job preview research emerged from research studies investigating recruitment source effects. John Wanous emerged as the leading researcher in the study of realistic job previews as a recruitment strategy. Wanous 
(1973) defined a realistic job preview (RJP) as a description of a job vacancy that presents both positive and negative (realistic) information about a particular job. RJPs relate to recruitment studies because they are job messages which impact recruitment outcomes such as the decision to apply for a job and post-hire outcomes (e.g., turnover) by lowering initial job expectations and increasing employee trust and skills to resolve difficult work situations. RJPs contrast with traditional job previews (TJPS), which are job messages that present only positive information about the job.

RJP research focused on change in employee behavior rather than attitude change and emphasized employee turnover as the dependent variable (Popvich \& Wanous, 1982). Research studies supported that behavioral changes resulted because realism fosters a better match between individuals and jobs through the process of self-selection of jobs based upon applicant needs (Wanous, 1980). Also, employee behavior resulted in a reduced turnover rate when realistic information enabled applicants to have pre-hire expectations match the actual job experiences after job acceptance (Wanous, 1980).

Wanous (1974) investigated individual differences and variables in the job search process. Using his previous 
research study (1973), Wanous conducted follow-up investigations to assess three different methods for measuring individual differences relevant for employee reactions to job characteristics. The participants $(N=$ 80) were the same female telephone operators as in the previous study. The independent variables, designed to measure individual differences, were: (a) applicant background (urban, rural); (b) belief in Protestant work Ethic (strong, weak); and (c) strength for higher order needs (high, low). Responses to multiple items on a questionnaire operationalized the independent variables. To identify applicant background (urban, rural), participants responded to the item "Describe the area where you lived most of the time when you were growing up".

Response selection included (a) urban (large size city with a population of 200,000 , medium size city with a population of at last 10,000 ) or (b) rural (small-sized city or rural area). Responses to the following four items measured Protestant Work Ethic: (a) "Hard work makes you a better person"; (b) "Wasting time is as bad as wasting money"; (c) "A good indication of a person's worth is how well he does his job"; and (d) "If all other things are equal, it is better to have a job with a lot of responsibility than one with little responsibility". The 
researcher operationalized higher order needs by having the participants rate preferences for specific job

characteristics: variety, autonomy, task identity, task feedback, management feedback, challenge, meaningfulness, and use of valued skills.

The dependent variables were applicant ratings of specific task characteristics and applicant rating of job characteristics. Four core dimensions (feedback, variety, autonomy, task identify) and several other items measured job characteristics of the participants' current jobs. Applicant ratings identified three reactions: (a) satisfaction with a specific job characteristic, (b) global job satisfaction, and (c) job behavior. Wanous (1974) then used the Minnesota Satisfaction Questionnaire (MSQ) to measure participant satisfaction with job characteristics. Participant responses to the following questions measured job satisfaction: (a) "Generally speaking, how satisfied are you with your job?" and (b) "How characteristic is this statement of you? Taking everything into account I am very satisfied with my job" (p. 618).

Wanous (1974) analyzed the data using a correlation design and one-tailed independent samples t-tests. Results indicated that the higher order need strength individual differences measure was the most effective in measuring 
individual differences with 8 of the 12 relationships as significant. Results indicated only 4 significant relationships with Protestant work Ethic and only 1 significant relationship using urban and rural backgrounds of employees. The correlations between the four task dimensions (variety, autonomy, task identify, and feedback) and overall job satisfaction revealed similar results as the correlation between job satisfaction measures and individual differences. Results indicated that the only significant correlation with type of task characteristic and individual differences was with higher order need strength. Variety and autonomy revealed significance at the .05 level. Results indicated no significance at the .05 level for Protestant Work Ethic or urban-rural background and type of task characteristic. The study supported the fact that higher order need strength is the most effective of the three individual differences as moderators of job characteristics-job behavior relationships.

Wanous (1976) conducted a two-part study to investigate how employee perceptions of organizations change during the job entry process. The participants in the first part of the study were MBA students $(N=861)$ from three New York business schools. The participants in 
the second part of the study were telephone operators $(N=$ 46) who had participated in previous studies by Wanous (1973, 1974). MBA students responded to the same questionnaire at three intervals in the entry process (prior to enrollment, early fall after enrollment, late spring after enrollment). Participant responses to 15 items on 5-point Likert-type scales measured individual perceptions at each period in the entry process. The researcher used factor analysis with varimax rotation to analyze the 15 items. The two variables accounting for the most variance were intrinsic (e.g., quality of teaching) and extrinsic (e.g., tuition and scheduling).

The independent variable was organizational entry points (prior to enrollment, early fall after enrollment, late spring after enrollment). The dependent variables were applicant perceptions of the intrinsic or extrinsic work aspects of the organization. The researcher used a cross-sectional research design using one-way analysis of variance (ANOVA) to assess participant perceptions during the organizational entry process for intrinsic and extrinsic factors. Results revealed that organizational entry influenced outsider expectations for the intrinsic factor, but not the extrinsic factor. To analyze mean differences, Wanous (1976) conducted Scheffe post-hoc tests 
among the three groups to determine when the effects due to entry occurred. Results showed that the decline occurred between the newcomer and the insider stages.

In the second part of the study, telephone operators completed questionnaires at various organizational entry stages (following initial contact with the company, following one month of work experience, following three months of work experience). The independent variable was organizational entry point. The dependent variable applicant perception of the organization was operationalized by participants responding to 11 items measuring job and task focus using 7-point Likert-type scales which formed a composite score. The participants also completed the Short Form of the Minnesota Satisfaction Questionnaire (MSQ) with the researcher modifying the survey instructions to focus on "expectations" instead of "satisfaction" for each of the 20 items. The researcher used analysis of variance (ANOVA) to analyze the dependent variables (11 item task composite, MSQ intrinsic and extrinsic composites).

Results revealed a significant effect for intrinsic and extrinsic MSQ scores with a decline in intrinsic expectations being greater for the insiders than for organizational newcomers. There were no significant 
effects found for organizational entry on the job and task composite. For both studies, wanous (1976) found that outsiders had more inflated expectations of the organization as compared to the more realistic beliefs of the insiders. Organizational expectations declined significantly with entry to the organization. Wanous (1976) called for future research studies using the expectancy theory to predict which applicants might join specific organizations.

Reilly, Tenopyr, and sperling (1979) investigated the effects of realistic job previews on job acceptance and survival (turnover). The participants $(N=325)$ were applicants for telephone operator positions in three different companies. The researchers hypothesized that applicants receiving RJPS would have a lower rate of acceptance and higher survival rate than applicants who did not receive RJPs. The researchers randomly assigned participants to one of three conditions: (a) realistic (applicant given a script with balanced job information); (b) favorable (applicant given script with only favorable or neutral job information); and (c) control (applicant given no information). The three groups served as the independent variables (realistic, favorable, control). The 
dependent variables were job acceptance (yes, no) and turnover rate (one month, six months).

Reilly et al. (1979) used a 2 x 3 chi-squared analysis to assess the relationship between the number of jobs accepted and the type of job preview applicants received. This statistical procedure also analyzed job survival rates for applicants who remained with the company after one month and six months. Results revealed support for only the first hypothesis. Applicants who received RJPs had the lowest percentage of job acceptance (56.1\%). The researchers speculated limitations in the study such as differences in job complexities (telephone operators versus West Point cadets in a former study), definitions of realistic job previews, and identification of variables such as job preview media and job applicant expectations. Dugoni and Ilgen (1981) investigated the effects of RJPs on organizational turnover rates. The researchers hypothesized that RJPS reduced turnover through: (a) lower expectations and increased job satisfaction, (b) improved ability to cope with unpleasant job circumstances, and (c) the creation of a perceptual set of greater openness and honesty within the company. The participants were employees $(N=249)$ in the customer service department of five retail outlets of a large midwest retail food chain, 
a11 of whom were either checkers or baggers. The participants were randomly assigned to three groups: (a) employees $(n=130)$ who had been with the company from six to 12 months (to provide realistic job preview information); (b) a control group ( $n=70)$; and (c) an experimental group $(n=49)$.

The first group provided realistic job preview information by responding to the questions: (a) "Describe in your own words, something that happened while working that made you feel very good about your job. I felt very good about my job when....", and (b) "Now, describe in your own words, something that happened while working that made you feel very bad about your job. I felt very bad about my job when...." Raters sorted responses into two categories and identified five areas of concern: customer relations, co-workers, supervision, duties/policies, and hours. This data became the basis for providing RJPs in the study. The participants in the control group and the experimental group were recent hires who had not reported to work. Both group participants attended a required orientation session prior to beginning work.

The control group received the company's standard orientation session which emphasized company policy, procedures, and information. The experimental group 
received the same information as the control group plus an additional 30-minute presentation emphasizing the five areas of concerns and the RJP survey results from the first group. The participants completed a 35-item survey assessing initial expectations of the job related to the five areas of concern (customer relations, co-workers, supervision, duties/policies, hours). The participants responded using 6-point Likert-type scales ( 1 = never true, 6 = always true). Sample items included: (a) "It is unlikely that you will have to work later than your scheduled time", and (b) "Checkers cannot be required to work as baggers."

The independent variable in the study was group membership (control, experimental). The dependent variables were: expectations (customer, co-workers, supervisors, duties/policies, hours); (b) perceptions (customers, co-workers, supervisors, duties/policies, hours); (c) satisfaction; (d) coping (handled, upset); and (e) openness.

Dugoni and Ilgen (1981) assessed post-hire attitudes after employees were on the job for two months. The same 35-item instrument used in the pre-hire survey perceived job situation. The participants completed a similar set of items measured on 5-point Likert-type scales to assess job 
satisfaction. In addition, the participants completed the short form of the Minnesota Satisfaction Questionnaire (MSQ). The researchers measured coping ability (handled, not handled) by presenting the participants with a sample critical incident and asked them to respond using 5-point Likert-type scales. The researchers measured openness and honesty (climate) by having the participants respond to 11 items using 6-point Likert-type scales. Employee quit rate measured turnover in the organization.

The researchers used multivariate analysis of variance (MANOVA) to analyze the data. Results showed no strong support for any of the three hypotheses. However, expectations were significantly lower in the experimental group. The researchers concluded that RJPS lowered initial job expectations. There was no statistical difference in overall job satisfaction and turnover between the two groups. There was a significant difference between the two groups on ability to handle difficult situations (coping). However, the control group demonstrated more effective coping skills than the experimental group. There were no significant differences in the two groups for openness and honesty. The researchers identified study limitations as conditions at the research site (large number of layoffs and terminations during the first month), the sample size 
(small sample size of permanent part-time employees), and the verbal presentations of RJPs (less effective than films and pamphlets).

Reilly, Brown, Blood, and Malatesta (1981) conducted a field study to investigate the effects of realistic job previews (RJPs) on job acceptance, met expectations, job commitment, and turnover. The participants $(N=842)$, telephone service representative applicants, received either an RJP before a formal job offer, or no RJP at all. The independent variable was job preview (film preview, job visit, control). The treatment group $(n=260)$ for film preview viewed a 21-minute film depicting service representative training and work. For job visit, the participants $(n=240)$ visited the actual job site observing service representatives on the job. The control group ( $n=217)$ received no RJPs. The dependent variables were: (a) job acceptance (yes, no); (b) met expectations; (c) job commitment; and (d) turnover. The participants in each treatment group received a RJP prior to job acceptance. After two months on the job, all participants received a questionnaire for data collection.

Reilly et al. (1981) used a 2 × 3 chi-square test to analyze the data. Results found no significant differences in job acceptance rates for the three groups. Additional 
chi-squared analysis indicated no significant differences between turnover rates for the two RJP groups and the control group. Analysis of variance (ANOVA) revealed no significant differences among the three groups for both met expectations and commitment. The researchers concluded that RJPs are not effective in reducing turnover which contradicted previous studies of Wanous (1977, 1980) and others.

Reilly et al. (1981) examined the data from 11 previous RJP studies. The researchers selected the 11 studies based on the following criteria: (a) conducted in a realistic setting, (b) reported turnover data, and (c) had a clearly identifiable RJP preview group and a clearly identifiable control group. The researchers pooled data in various ways and analyzed data using $z$ values and chisquared procedures. Results indicated that organizations that did not use RJPs had a turnover rate $28.32 \%$ higher than organizations who did use RJPs in their recruitment process.

Based on the research study and the review of previous RJP studies, Reilly et al. (1981) concluded that: (a) RJPs are unlikely to have any beneficial effect on selfselection of job applicants; (b) even with limited data, no evidence exists that RJPs affect met expectations; (c) 
effects of RJPs on turnover are unlikely to be effective on entry level jobs or jobs with simple, repetitive tasks; (d) RJPs may lead to more positive attitudes either by communicating a favorable organization image (Wanous, 1977) or through a social information processing of realistic information and choice behavior.

Zaharia and Baumeister (1981) investigated the effects of realistic job previews (RJPs) on employee turnover among staff at a large residential care facility for mentally retarded people. Because turnover rates in the facility exhibited an annual rate of over $60 \%$ for the preceding two years, the researchers hypothesized that misalignment of initial job expectations of the inductee was a major contributor to the large turnover rate.

The participants $(N=278)$ were applicants for positions as technicians, which was the primary workforce of the company. Actual job acceptance rates were $40 \%$ for applicants $(n=60)$ for the treatment group and $39 \%$ for the control $(n=50)$. The researchers used two interventions to assess RJP effect on job turnover. The first intervention was a six-page brochure with candid descriptions of work at the institution based on a replication of Weitz's (1956) realistic written job preview. Over a nine-month period, 149 applicants received 
the candid descriptions, and the 129 in the control group received no RJP. The second intervention required applicants to view a 12-minute color videotape based on Wanous' (1973) approach of translating the written handout to a videotape. Over a four-month period, 38 applicants viewed the videotape, and the 82 applicants in the control group received no RJP. The independent variables were the two RJP interventions (brochure, videotape) and the two control groups (no brochure, no videotape). The dependent variable was employee turnover rate.

After nine months of study, $40 \%(n=16)$ of the control group and $46 \%(n=25)$ remained on the job. Chisquared analysis revealed no significant statistical differences for the two groups. The retention rate was $36 \%$ for the participants $(n=54)$ who received the brochure preview and $31 \%$ for those in the control group $(n=40)$. None of these differences was statistically significant. The retention rate was $64 \%$ for the participants $(n=14)$ who received the videotape preview and $51 \%$ for those in the control group $(n=27)$. This difference was not statistically significant. The researchers analyzed the length of service between groups with t-tests. For the treatment groups, the length of services was 11.1 weeks, 
and for the control group, it was 6.8 weeks. This difference was statically significant $(t=2.02, p<.05)$.

The researchers concluded that neither intervention (brochure, videotape) was effective in reducing employee turnover. However, a small but insignificant improvement in employee retention was observed in the groups receiving RJPs. Also, length of service was significant for those employees who received RJPs. Also, the researchers theorized that considerable self-selection did occur with the treatment group as evidenced by relatively low acceptance and hire rates.

Breaugh (1983) critiqued selected RJP research studies over a ten-year period and concluded that results were inconclusive about their effectiveness. He proposed directions for future research. The researcher critically examined three recent RJP research studies. According to Breaugh (1983), previous research studies of Dugoni and Ilgen (1981), Reilly (1981), and Wanous (1980) identified four psychological processes which provided a conceptual framework on which to base future RJP research: (a) met expectations (lowers initial job expectations which influences job satisfaction and turnover); (b) ability to cope (reduces anxiety with job demands which influences job satisfaction and turnover); (c) air of honesty (increases 
degree of freedom in organizational choice); and selfselection (increases applicant accuracy in job decision making) .

Breaugh (1983) proposed that RJPs ignored "boundary conditions" which must be met for maximum effects of RJPs. The researcher suggested boundary conditions which limited previous RJP research studies: (a) high selection ratio (limited availability of job candidates); (b) position is non-entry level; (c) high unemployment exists. These research studies failed to assess job applicant perceptions prior to the interview stage. Boundary conditions for more effective RJPS included when the applicant; (a) can be selective about accepting a job offer, (b) exhibited unrealistic job expectations, (c) would have difficulty coping with job demands without an RJP.

Wanous (1983) concluded that future research studies should focus on both the content in which RJPs can be effective and the psychological processes which create the boundary conditions. He proposed three additional variables for future studies: (a) the timing of the RJP, (b) examining the effects of RJPs on other variables than turnover, and (C) conceptualizing RJPs as a persuasive communication. 
Vandenburg and Scarpello (1990) investigated the validity of the Wanous (1980) matching model as a framework for the processes of explaining the role of realistic job previews (RJPS) in influencing positive work adjustment and employment stability. The researchers were the first to test the wanous matching model in its entirety. Wanous based the model on the Minnesota Theory of Work Adjustment (TWA) which proposes a match between individual preference for job rewards (needs) and perceptions of available job rewards (rewards) results in job satisfaction and employment stability. The framework included RJPs as a staffing procedure for increasing the need-reward match process. Wanous theorized that job satisfaction and organizational commitment increased when applicants received a job offer and an RJP. Based on this theory, Wanous extended the TWA model to include: (a) comparison of present job to others; (b) organizational commitment (employee turnover); and (c) accuracy of job information $(\mathrm{RJP})$.

Vandenburg and Scarpello (1990) used a cross-sectional design to assess the matching model to the data of newcomers and of more tenured employees. The participants $(N=393)$ were information systems personnel from nine major insurance companies. Responses to four 
questionnaires operationalized the constructs: (a)

accuracy, (b) comparison, (c) need-reward match, (d) job satisfaction, (e) organizational commitment, and (f) intentions to quit. The researchers measured accuracy by asking participants to reflect back to when they accepted their current job and if the company portrayed the job realistically as to job responsibilities, career opportunities, and job descriptions. Usefulness of current job relative to similar jobs in other organizations identified responses for the construct comparison. Likerttype scales measured the first two constructs.

The Minnesota Importance Questionnaire (MIQ) measured employee needs, and the Minnesota Job Description Questionnaire (MJDQ) measured employee perceptions of rewards. The short form of the Minnesota Satisfaction Questionnaire (MSQ) measured job satisfaction, separated with summed scores for intrinsic and extrinsic factors. The Organizational Commitment Questionnaire (OCQ) assessed perceived organizational commitment. The researchers measured intention to quit with participants indicating their probability of leaving their organization in the next six months with (a) $0 \%$ to $20 \%$, (b) $21 \%$ to $40 \%$, (c) $41 \%$ to $60 \%$, (d) $61 \%$ to $80 \%$, and (e) $81 \%$ to $100 \%$. 
Vandenburg and Scarpello (1990) used multiple statistical analyses to assess the six constructs on employee adjustment and stability. The researchers divided the sample into two groups: newcomers (less than one year in the organization) and tenured (more than one year in the organization). The newcomer group was a small sample size, $n=55$. The tenured group consisted of 338 participants. The researchers used LISREL VI and canonical correlation analysis to correlate composite scores. The results supported the wanous matching model to be a better fit for the newcomer data but not for the tenured employees. However, in the need-reward match, RJPs predicted job satisfaction for both newcomers and tenured employees. Also, the results indicated that tenured employees related job satisfaction to job search intentions rather than to turnover intentions. The researchers suggested that organizations might retain tenured employees with rewards and job enhancements to reduce turnover.

Meglino, Ravlin, and DeNisi (1997) investigated the effects of realistic job previews (RJPs) on job applicant acceptance and the impact of prior job exposure on this process. The participants $(N=1,117)$ were applicants for a state correctional officer position. The independent variables were: (a) job exposure (correctional experience, 
no correctional experience) and (b) realistic job preview (preview, no preview). The dependent variables were: (a) an additive composite score of expected danger and injury and (b) percentage of job acceptance rate.

The researchers randomly assigned the participants two groups: one received traditional job information and the other received realistic job information. The participants in the second group received the RJPs by watching a 22minute videotape containing both positive and negative aspects of the job. Both groups responded to a questionnaire focusing on job expectations with two items assessing applicant perceptions of noxiousness (danger) involved on the job. Participants responded on 5-point Likert-type scales ( 5 = very dangerous, $1=$ no danger $)$. The participant responses created an overall measure of expected danger and injury.

Descriptive statistics and two-way analysis of variance (ANOVA) assessed RJP effect on job acceptance. Results indicated that applicants with no prior job exposure and received a RJP had an $8.1 \%$ increase in job acceptance rate $(\mathrm{p}<.001)$. The participants who received prior exposure and a RJP revealed a $9.8 \%$ decrease in the rate of job acceptance $(p<.05)$. The researchers concluded that it was appropriate to provide RJPs to 
applicants who had no previous job exposure. Providing RJPS to applicants who experienced previous job exposure increased applicant frequency and intensity to distort negative information. Meglino et al. (1997) suggested that employers "should think twice" about providing realistic job previews when applicants have prior job exposure. Summary

Research indicated that RJPS affected both job satisfaction and tenure. Studies showed that organizations that used RJPs during the recruitment process lowered applicants' initial job expectations. With lowered expectations, most studies indicated an increase in employee job satisfaction, performance, tenure, selfselection, and organizational commitment. The researchers called for future studies to investigate the realistic recruitment process, potential moderator variables, realistic recruitment messages, and applicant perceptions prior to the applicant stage. Person-Organization Fit

Most of the private recruitment literature focused on the job applicant recruitment and selection process from the perspective of matching individual knowledge, skills, and abilities to job requirements. The idea of how applicant skills and abilities might be congruent with 
organizational culture, climate, and goals developed into recruitment approaches in which as individual "fits" a particular organization. Adkins, Russell, and Werbel (1994) defined person-organization (P-O) fit as the "congruence of the personality traits, beliefs, and values of the employee with the cultures strategic needs, norms, and values of the organization" (p. 605-606). Researchers shifted their focus to P-O fit because of the belief that a variety of consequences result from this congruence. Bretz, Rynes, and Gerhart (1993) identified some of these positive consequences to be higher job involvement, greater organizational commitment, improved personal health, adaptation to the organization, and lower turnover rates. Recognizing that most of the research literature on organizational entry focused on entry from an organizational viewpoint, Wanous (1977) reviewed organizational entry literature from the individual's perspective. The 40 reviews were of quantitative research studies from 1956-1977. The reviewer proposed that the differences in perspectives stems from two conflicting goals: (a) the newcomer seeks to satisfy personal needs through membership in an organization and (b) the organization is concerned with the ability and competence of the newcomer to perform satisfactorily. From these 
contrasts, Wanous (1977) proposed three contrasts between the individual and organizational perspectives of the entry process: (a) the extent to which human needs are measured and considered, as opposed to abilities; (b) the extent to which participation in an organization (i.e., joining and remaining) is important, as opposed to job performance; and (c) the extent to which job satisfaction (or other attitudes) is examined, as opposed to the satisfactoriness of a newcomer (p. 601).

Wanous (1977) defined two entry processes (organizational, occupational) and defined their differences. The reviewer separated the two entry processes with these contrasts: (a) occupational entry precedes organizational entry, (b) organizational entry is a choice and an event, and (c) organizational entry is a personal choice which is grounded in cognitive dissonance theory; whereas occupational entry is grounded in economic, sociological, and cultural theories.

Wanous (1977) reviewed the four different theoretical models used to assess results in the studies: (a) unprogramed decision-making model, (b) cognitive dissonance theory, (c) self-image theory, and (d) expectancy theory. The unprogramed decision-making theory views individuals as using only a few criteria to screen alternatives and make 
an implicit choice, then rationalize their decisions with more comprehensive criteria after organizational choice decisions. The cognitive dissonance theory is concerned with post-choice rationalizations where individuals justify their choices and may change their beliefs about the organization selected. This theory best distinguishes the differences in organizational or occupational entry. In the self-image theory, individuals make occupational and organizational choices based on their own self-image (identity). These individuals select organizations similar to their own beliefs and profiles.

Most of the studies Wanous (1977) reviewed used the expectancy theory which suggests that people make expected value calculations about all job alternatives. With this theoretical framework, it is important to distinguish among the attractiveness of an organization (i.e., the preferred one), the amount of effort directed toward joining one, and the final choice of the organization. Wanous (1977) gives two considerations in determining these areas of attractiveness: (a) expectations about the characteristics of the organization and (b) the valence, or desirability, of each characteristic for each person (p. 608).

Wanous (1977) arrived at five conclusions from his literature review: (a) Organizational choice is a 
cognitive decision (in contrast with occupational); (b) Cognitive dissonance effects seem to follow the act of choosing an organization; (c) Outsiders almost always hold inflated expectations about organizations; (d) As the newcomer experiences the organization, he develops a less favorable view of it; and (e) The use of realistic job previews in the recruitment of new members reduces newcomer turnover.

Rynes and Gerhart (1990) conducted a two-year longitudinal study to examine interviewer assessments of job applicants in terms of both general and firm-specific person-organization (P-O) fit. The researchers differentiate between general and firm-specific P-O fit as when the recruiter searches for "apple pie" attributes (e.g. leadership, motivation intelligence, warmth) versus attributes that are tailored to a specific organization. Interviewer evaluations of applicant general employability included the relationship between applicant knowledge, skills, and abilities (KSAs) and job requirements. Interviewer evaluations of firm-specific (P-O) employability involved identifying applicant characteristics above and beyond the KSAs required for a job. 
The participants $(N=346)$ were graduating MBA students at an Ivy League business school. Campus interviews provided data from post-interview ratings of the participants. Interviewers rated applicants following each interview on three kinds of assessments: (a) ten specific trait scales (e.g., general knowledge, demonstrated leadership, warmth); (b) overall employability; and (c) employability in the interviewer's firm (P-O fit). The participants responded on 5-point Likert-type scales $(1=$ not favorable, 5 = most favorable). Business school data bases provided information on grade point average, gender, years of business experience, and major. Two placement officials assessed applicant physical attractiveness using 3-point Likert-type scales $(1=$ average, $3=$ significantly above average).

Rynes and Gerhart (1990) used three different statistical analyses to assess the data. The researchers performed $t$-tests on average ratings for the two evaluations, computed and compared variances, and estimated interrater reliabilities for the two evaluations based on calculated average ratings. Using regression analyses, the researchers then identified significant characteristics as independent variables: (a) objective characteristics, (b) physical characteristics, and (c) interviewer assessment of 
traits. The dependent variables were the 10-trait rating scales which measured interviewer perceptions of $\mathrm{P}-\mathrm{O}$ fit.

Results indicated evidence of differences between general and firm-specific assessments of employability: (a) recruiters appeared more rigid in evaluations of firmspecific employment (P-O fit) than of general employment; (b) firm-specific evaluations exhibited greater variability across interviews that did general employability assessments; and (c) higher within-firm interrater reliabilities for assessments emerged as compared with across-firm interrater reliabilities for assessments of the same applicant. There was no significance for objective characteristics and recruiter assessment of applicant fit. O'Reilly, Chatman, and Caldwell (1991) developed and validated an instrument, the Organizational Culture Profile (OCP), for assessing person-organization (P-O) fit. The purpose of the study was to examine person-culture fit and its implications for work attitudes and behavior. Previous research posed difficulties with assessing relevant aspects of both person and culture for validation purposes. o'Reilly et al. (1991) proposed a solution to this validation with measurements of Q-sorting, or templatematching to resolve measurement issues. With the Wanous' (1977) theory of accurate job understanding enhancing 
employee adjustment to a job, O'Reilly et al. (1991) postulated that positive responses by job applicants for positions will occur when individuals understand the realistic description of the organization, and they fit or match the requirements of the organization with their own situation or personality.

The researchers developed value statements based on extensive review of academic and practitioner-oriented writings on organizational values and culture. From an initial pool of 110 items, the researchers asked the participants to identify redundant items and those items which did not describe an organization's culture. The participants were university seniors $(N=38)$ majoring in business administration and four university faculty members. The result was the OCP instrument comprised of 54 value statements designed to capture individual and organizational values.

The participants sorted the 54 items into nine categories ranging from most to least desirable or from most to least characteristic with descriptive statements in each category. Then, the participants sorted the 54 value statements according to the extent to which the items were characteristic of the organization to form a profile of the organization culture. The researchers had the participants 
sort the value statements according to personal preferences for each value in an ideal organization to develop the construct for individual preferences. Person-organization fit scores were then assessed for each participant using correlations between the individual preferences profile and the organizational profile.

O'Reilly et al. (1991) identified eight factors representing individual organization culture preference: (a) innovation, the degree of individual preference for organizations that encourage risk taking, experimentation and that fail to emphasize being careful, stable, or secure; (b) attention to detail, the degree of individual preference for organizations that are analytical, attend to details, and are precise; (c) outcomes orientation, the degree of individual preference for organizations that are achievement-oriented, are demanding and results-oriented, and promote high expectations; (d) aggressiveness, the degree of individual preference for organizations that emphasize aggressiveness, competition, and opportunities; (e) supportiveness, the degree of individual preference for organizations that are supportive, promote sharing information, and recognize good performance; (f) emphasis on rewards, the degree of individual preference for organizations that value high pay for performance and 
professional growth; $(\mathrm{g})$ team orientation, the degree of individual preference for organizations that are teamoriented and promote collaboration; and (h) decisiveness, the degree of individual preference for organizations that value decisiveness, predictability, and low conflict.

Seven factors emerged as descriptors of organizations: (a) innovation, describes organizations that focus on opportunities, experimenting, risk taking, rule oriented, and carefulness; (b) stability, focuses on organizational predictability, security, and no rules; (c) respect for people, involves organizational fairness and tolerance; outcome orientation, describes organizational emphasis on achievement, action, high expectations, and results; (e) attention to detail, focuses on organizational precision and analytical abilities; (f) team orientation, involves collaboration and people orientation within the organization; and (g) aggressiveness, focuses on competition and social responsibility that exists within the organization.

Contributing to the understanding of the role of values in both the job choice process and P-O fit, Judge and Bretz (1992) used a policy capturing design to investigate the effects of work values on job choice decisions. The participants $(N=67)$ were enrolled in four 
professional degree classes at a northeastern and midwestern university. The researchers used a mixed experimental design incorporating within-subject and between-subjects factors. Because the research question focused on decision-making, the research design is "policy capturing" for the decision-making process.

The independent variables were: (a) pay, (b)

promotional opportunities, (c) type of work, (d) achievement, (e) concern for others (f) honesty, and ( $g$ ) fairness. The seven within-subject independent variables were manipulated with four value variables (achievement, concern for others, honesty, fairness) from the Ravlin and Meglino (1987) study. The seven independent variables were completely crossed resulting in 128 job choice descriptions. The between subjects design assessed personal characteristics (e.g., married, male, grade point average, age, work experience, and value fairness). The dependent variable was the probability of accepting a job offer measured by the item: "Indicate the extent to which you would accept an offer possessing the above characteristics." The participants responded on 7-point Likert-type scales $(1=$ highly unlikely, $7=$ highly likely). 
Judge and Bretz (1992) used Pearson Product Moment Correlations to analyze each of the seven independent variables effects on the participant job choice decisions. An overall multiple regression procedure assessed the combined effects of job factors, personal characteristics, and the interaction between job factors and the applicant decision to accept a job. Results indicated that organization attraction and job choice decisions rated at the time of the interview significantly correlated with acceptance of job offer. The within-subjects analysis revealed that concern for others, achievement, and fairness had more influence in the decision to accept a job with an organization than did pay and promotional opportunities. Judge and Bretz (1992) concluded that subjective fit (applicant perception of fit) and P-O fit (congruence between the recruiting organization culture and applicant culture preference) influenced organizational attraction and probability of accepting a job offer.

Recruitment strategies shifting emphasis on applicant fit to broader organizational characteristics initiated an investigation by Bretz, Rynes, and Gerhart (1993) of how organizational recruiters assess applicant personorganization (P-O) fit at the pre-hire stage of the recruitment process. Because little empirical research on 
P-O fit exists in the pre-hire stage of the recruitment process, the researchers chose to examine applicant fit in a non-directive manner. Recruiters conducted their own interviews without intervention from the researchers. Then, the researchers interviewed the recruiters using structured interview questions.

The participants $(N=54)$ were recruiters conducting on-campus interviews within four colleges at a northeastern university: arts and sciences $(n=9)$; business $(n=14)$; engineering ( $n=14)$; and industrial relations $(n=17)$. Forty recruiters were male and 14 were female. Following the interviews, Bretz et al. (1993) asked the recruiters to describe specific characteristics of good-and-poor-fitting applicants through the structured interview questions format. The responses intended to elicit examples of fit and lack of fit (best fit, worst fit, changes in fit, assessment, general versus specific fit). The researchers designed coding schemes for interpreting the tape-recorded comments of the recruiters. Content analyses identified 45 different characteristics as indicators of applicantorganization fit. Identification of most often mentioned characteristics produced 13 attributes for further analysis: (a) job related work experience, (b) articulateness, (c) job related course work, (d) 
appearance, (e) general communication skills, (f) perceived cognitive ability, (g) teamwork/cooperative attitude,

focus, (i) work ethic, (j) leadership activities, (k) wellroundedness, (1) self-confidence, and (m) grade point average. Correlations identified significant relationships: (a) leadership correlated with teamwork and work ethic, (b) experience, articulateness and general communication skills tended to be mentioned together, (c) focus correlated with work experience, (d) grade point average correlated with work ethic and coursework, and (e) confidence correlated with appearance.

Bretz et al. (1993) analyzed the data using two multivariate analysis of variance (MANOVA) to determine differences in recruiter perceptions of organizational fit associated with perceptions of applicant characteristics. The independent variables were the type of college and recruiter sex. The dependent variables were the $13 \mathrm{fit}$ attributes. Results indicated significant differences between recruiters in different colleges. Post-hoc tests revealed significant differences on three attributes: (a) grade point average indicated a fit between engineering and business recruiters, (b) work experience was more important to recruiters in arts and sciences, and (c) teamwork/cooperative attitude was more important to 
recruiters in the business area. Univariate analysis of variance (ANOVA) indicated that male recruiters mentioned work experience as an indicator of applicant fit nearly twice as often as did female recruiters. Female recruiters mentioned work ethic more frequently than did male recruiters.

Bretz et al. (1993) performed a final analysis of differences in variation across the $13 \mathrm{fit}$ attributes by examining the Coefficient of Variation. Results indicated that job-related work experience, articulateness, and jobrelated coursework were the most generalizable applicant attributes. Grade point average, leadership, focus, and self-confidence were the least generalizable applicant attributes. The study results indicated that recruiters placed more emphasis on job-specific fit and general fit (i.e., universally, desired characteristics) than a personorganization fit. The researchers concluded that organizational fit may be important, but may not be important in assessing in the pre-hire process. The researchers also mentioned the additional finding that recruiters look for specific attributes of demonstrated achievement such as grade point average, work experience, and leadership activities (team sports, extracurricular/community organization officers, military 
experience). Bretz et al. (1993) suggested that successful job search initiatives needed to occur long before the actual job interview.

Adkins, Russell, and Werbel (1994) investigated the effects of work values congruences on recruiter perceptions of person-organization (P-O) fit. The researchers defined work-value congruence as the congruence between the work values of the employee and the dominant work values of the organization. The participants $(N=44)$ were corporate recruiters (31 male, 13 female) from 37 companies. The recruiters conducted 353 interviews at a large university placement center with applicants $(N=171)$, some participating in multiple interviews.

The researchers used the Comparative Emphasis Scale (CES) developed by Ravlin and Meglino (1987) to assess : (a) recruiter personal work values and (b) recruiter perceptions of organizational work values. The recruiters first completed the CES to reflect their personal beliefs in behaviors important for the job. Then, the recruiters completed the CES to reflect perceived behaviors important by the organization. The CES measures four work values: achievement, fairness, honesty, and concern for others. Adkins, et al. (1994) then assessed applicant general employability and P-O fit using a six-item instrument. Two 
items measured P-O fit: (a) "Given your overall impression of the candidate, how good a 'fit' do you think there is between the candidate and your organization?" and (b) "Do you think other people in your organization will think this candidate fits well in the organization?" The applicants responded on 7 -point Likert-type scales $(1=$ Poor fit, $7=$ Good fit). Four items measured general employability: (a) "Given your overall impression of this candidate, how 'employable' do you think this candidate is?"; (b) "Do you think other people in your organization will feel this candidate is very employable?"; (c) "Regardless of the candidate's qualifications, how likeable was the candidate?"; and (d) "Do you think other people in your organization will find this candidate likeable?" The applicants responded on 7-point Likert-type scales $(1=1$ ow employability, 7 = high employability).

Job applicants responded to the CES identifying personal work values and to a behavioral friendship subscale to identify interpersonal behaviors. University placement records provided demographic data, employment history, grade point averages, and involvement in campus activities. The researchers contacted the recruiters four months later to identify which applicants were invited to participate in a second interview. 
The independent variables were: (a) the congruence between applicant work values and recruiter perceptions of the organizational work values, (b) the congruence between applicant and recruiter personal work values, (c) the congruence between applicant work values and "universal" set of work values. The dependent variables were recruiter ratings of (a) applicant employability and (b) personorganization fit. The control variables were: (a) grade point average, (b) employment history, (c) involvement in campus activities, (d) gender, (e) minority group membership, and (f) behavioral social skills.

Multiple regression procedures and t-tests analyzed the relationship of value congruence to recruiter assessment of general employability and P-O fit. Results indicated that recruiter ratings of employability and P-O fit were significant predictors of employability. Applicant and organization work value congruence did not predict employability.

Additional multiple regression procedures analyzed the relationship between assessment of fit, employability, work value congruence, and the invitation to interview a second time. This time, general employability and P-O fit were additions to the independent variables. The dependent variable was invitation to a second interview. Results 
revealed that recruiter ratings of employability and $\mathrm{P}-\mathrm{O}$ fit were significant predictors of invitation for a second interview. However, applicant and organization work value congruence had no impact on invitations to a second interview. The researchers concluded that organizational work values and judgments of applicant fit do not influence the personnel selection process in the early stages of the recruitment process, but may do so at later stages when final selections are made.

Cable and Judge (1996) investigated the subjective person-organization ( $\mathrm{P}-\mathrm{O}$ ) fit for job seekers and new employees. P-o fit, job choice, and organizational entry research formed two research questions for this study: (a) What are the determinants of P-O fit perceptions of job seekers and new employees? and (b) How important are P-O fit perceptions in job-choice decisions and work attitudes relative to job attributes? The participants $(N=96)$ were job applicants who completed questionnaires at three different time periods.

In the Time 1 period, the participants interviewed for paid internship positions at a large northeastern university. Immediately following the interviews, the participants completed questionnaires assessing attractiveness of job attributes (e.g., location, salary); 
perceived fit with the organization and the job; and perceptions of the values of the organization. The researchers used the Organizational Culture Profile (OCP) to assess P-O fit by having the participants sort values into nine categories ranging from most to least characteristic. The applicants responded on 5-point Likert-type scales $(I=$ not at all, $5=$ completely) to a question of value congruence between applicants and organizations: "To what degree do you feel your values 'match' or fit this organization and the current employees in this organization?" and "To what degree do you believe your skills and abilities 'match' those required by the job?" assessed how job applicants perceived their personal abilities met a job requirement. The applicants responded on 5-point Likert type scales $(1=$ not at all, $5=$ completely). "Please evaluate the aspects of this job to the best of your knowledge" assessed the participants' ratings of the attractiveness of job attributes. The applicants responded on 5 point-Likert-type scales $(1=$ very unfavorable, 5 = extremely favorable).

Following the completion of the spring recruiting cycle, the Time 2 period began. The participants completed a survey assessing individual differences (e.g., demographics, values, grade point averages); the importance 
of P-O fit in the job search and choice decision; and the final job choice decisions. The researchers used a reduced OCP (from 54 to 40 items) to assess and sort applicant values. The participants responded to the question: "How characteristic is this attribute of me?" Two items assessed the importance of P-O fit in applicants job choice decisions: (a) "In general, when you evaluate a job, how important is fit (values, personality interests and goals match current organizational employees?" and (b) "To what degree is your job search based upon the 'match' or interpersonal fit between your values, personality, and goals and those of the current employees in the organization?" The applicants responded on 5-point Likerttype scales $(1=$ completely unimportant, 5 = extremely important; $1=$ not at all, $5=$ completely).

Approximately six months later, the Time 3 period study participants responded to surveys assessing perceived fit with the organization and job, participant job attitudes, attractiveness of job attributes, and perceptions of company values. Again, the OCP instrument assessed the participants' values of the organization. Two additional items to the same scale used in the Time 1 period assessed employee perceptions of P-O fit: (a) "MY values match those of the current employees in the 
organization" and (b) "Do you think the values and 'personality' of this organization reflect your own values and personality?"

During the Time 3 period, the researchers also measured four additional elements: (a) a 12-item scale of organizational commitment (O'Reilly and Chatman 1986) and (b) three items measured general or overall job satisfaction (Gallop Poll). A 4-item scale by O'Reilly et al. (1991) measured: (a) employee intentions to leave the organization and (b) employee likelihood of recommending the organization to a friend as a good place to work. Cable and Judge (1996) used multiple regression analyses to assess the data. For applicant subjective P-O fit perceptions, the independent variables were: (a) congruence between values of job applicants and job applicant perceptions of organizational values, (b) job applicant race, (c) job applicant gender (d) demographic similarities between job applicants and recruiters, (e) job seeker age, and (f) full-time position. The dependent variable was job choice intention. Results revealed that perceived value congruence between applicants and organizations predicted applicant P-O fit perceptions.

To predict job choice, the multiple regression analysis used the following independent variables: (a) P-O 
fit perceptions, (b) person-fit perceptions, (c) organizational rewards perceptions, (d) organizational imagery perceptions, (e) organizational security perceptions, (f) grade point average, (g) work experience, (h) perceived job opportunities, (i) applicant race, (j) applicant gender, and (k) full time position. The dependent variable was job choice intention. Results indicated that P-O fit perceptions of applicants significantly predicted choice intentions.

To predict $\mathrm{P}-\mathrm{O}$ fit of employees, the multiple regression analysis used these independent variables: (a) congruence between values of job applicants and job applicant perceptions of organizational values, (b) importance of P-O fit in the job search, (c) perceived job opportunities, (d) job applicant race, (e) job applicant gender, (f) job applicant age, and ( $g$ ) full time position. The dependent variable was employee P-O fit perception. Results indicated that perceived values congruence between job applicants and the chosen organization positively influenced employee perceptions of P-O fit. Job applicants who placed greater emphasis on P-O fit in job choice decisions experienced greater P-O fit after organizational entry than job applicants who placed less emphasis on P-O 
fit. Results also indicated that males experienced more Po fit than females.

Four separate multiple regression procedures analyzed organizational commitment, job satisfaction, organizational recommendation, and turnover intentions. The independent variables were: (a) P-O fit perceptions, (b) person-job fit, (c) organizational rewards perceptions, (d) organizational image perceptions, (e) organizational security perceptions, and (f) full-time position. The dependent variables for each procedure were: (a) organizational commitment (b) job satisfaction (c) willingness to recommend the organization, and (d) turnover intentions. Results indicated that perceived P-O fit of employees significantly predicted organizational commitment, job satisfaction, willingness to recommend the organization and turnover intentions. Person-job fit perceptions positively and significantly predicted job satisfaction and turnover intentions but not organizational commitment or willingness to recommend the organization. The researchers concluded that job seeker and employee subjective P-O fit perceptions mediate the effect of perceived values congruence on job choice intentions and work attitudes. 
Judge and Cable (1997) investigated job applicant cultural preferences and how those preferences interacted with recruiting organizations' cultures. The researchers conducted a three-tiered investigation: (a) to investigate the relationship between applicant personality traits and organizational culture preferences, (b) to compare those job applicant culture preferences to the culture of the organizations with which they interviewed, and (c) to examine the relationships between person-organization ( $\mathrm{P}-\mathrm{O}$ ) fit, organizational attractiveness, and actual job choice decisions.

The participants $(N=182)$ were from the three largest professional degree programs (engineering, business, industrial relations) at the large university in the Northeast. The researchers collected data over a fourmonth period. In Time 1 , the participants completed a self-reported survey of their personality and organizational preferences. In Time 2, which occurred three weeks later, the participants completed a survey of the culture and attraction to the next organization with which they interviewed. In Time 3, which occurred three months later, the participants evaluated the organization with which they interviewed in Time 2. The evaluation items were: (a) the attraction toward the company, 
whether or not they received a job offer from that company, and (c) if so, whether they accepted or not. Judge and Cable (1997) selected the Five Factor Model of personality, often called the Big Five (Goldberg, 1990), as the unifying framework for the study. The factors comprising the Big Five are: (a) extroversion (tendency to be social, assertive, active, and directive); (b) agreeableness (tendency to be likeable, cheerful, adaptable and cooperative); (c) conscientiousness (combination of achievement and dependability); (d) neuroticism (tendency to demonstrate poor emotional adjustment and to experience negative effects such as fear, anxiety, and impulsivity); and (e) openness to experience (tendency to be curious, creative, nonconforming, and autonomous).

The independent variables were applicant personality (the Five Factor Model) and P-O fit. The dependent variables were organization attraction, perceptions of organization culture by job applicants, and job choice decisions. The researchers identified control variables from past research indicating relevance in job choice contexts: (a) demographics (race, gender); (b) human capital (education level, experience); (c) labor market success (number of interviews, and (d) whether or not the 
applicant received a job offer from the recruiting organization.

Judge and Cable (1997) used various measures to assess the data. The NEO personality inventory (Costa \& McCrae, 1992) measured personality traits with 12 statements for each of the five traits. The participants responded to the statements on 7-point Likert-type scales $11=$ strongly disagree, 7 = strongly agree). The Organizational Culture Profile (OCP)) assessed the participant values: (a) by reporting their own values and (b) by reporting the values of the organization from their last organizational interview. Two methods analyzed P-O fit: (a) objective P-O fit (congruence between applicant culture preferences and an organization's culture by computing both the selfreports of the applicants and other applicant reports of the organizational culture from which they interviewed); and (b) subjective P-O fit (the direct perception of fit by the applicant). Again, 7-point Likert-type scales measured the participant responses $(1=$ not at all, $7=$ completely $)$. The participants responded to a 3 -item scale on 7point Likert-type scales to measure organizational attraction: (a) "Rate your overall attraction to this organization" ( 1 = not attracted, $7=$ very attracted $)$; "Rate the likelihood that you would interview again with 
this organization, if they offered you a second interview (1 = very unlikely, $7=$ very likely); and (c) "Rate the likelihood that you would accept a job offer from this organization, if it were offered" (1 = very unlikely, $7=$ very likely). The participants rated overall attraction to the organization using a 5-point Likert-type scale $(1=$ very unattracted, 5 = very attracted.)

Judge and Cable (1997) used multiple regression as the statistical method to predict organization culture preferences with applicant personality traits. Results revealed that the Big Five personality traits generally related to culture preferences. Specifically, men preferred innovative and decisive cultures, women preferred detail-oriented cultures, business majors preferred innovative and aggressive cultures, engineering majors preferred supportive cultures, and white job applicants preferred decisive cultures. Hierarchical multiple regression analysis revealed that objective $\mathrm{P}-\mathrm{O}$ fit and subjective P-O fit related to organization attraction; however, neither subjective nor objective P-O fit correlated with job offer acceptance.

\section{Summary}

P-O fit between individuals and organizations research contributes to the importance in the recruitment, hiring, 
and retention of employees. In the P-O fit recruitment literature, job applicant goals, values, needs, interests, and personalities have been compared with organizational cultures, pay systems, sizes, structures, and values (Judge \& Cable, 1997). The newcomer seeks to satisfy personal needs through organizational membership, and the organization seeks competent and committed employees (Wanous, 1977). Interviewers who evaluate applicants for firm-specific P-O fit rated applicants more favorably when identifying those traits (Rynes \& Gerhart, 1990). Because applicants develop most job-specific traits (job-related experience and course work, communication skills, work ethic, leadership activities, grade point average, selfconfidence) long before the interview, the search for $\mathrm{P}-\mathrm{O}$ fit is determined from both the individual and organizational perspectives (O'Reilly, Chatman, \& Caldwell, 1991). The dependent variable in most of these studies was person-organization fit (Rynes \& Gerhart, 1990; O'Reilly, Chapman, \& Caldwell 1991; Bretz, Rynes \& Gerhart, 1993; Adkins, Russell, \& Werbel, 1994 ; Cable \& Judge, 1996; Judge and Cable, 1997). Researchers demonstrated that work value congruence between applicants and organizations is a significant predictor of P-O fit. 
K-12 Research

As in private-sector research, education (K-12)

recruitment research became an important resource in school systems' search for qualified teachers and administrators. Early research studies were primarily about teacher recruitment; however, with the growing shortages of school administrators (Pounder \& Merrill, 2001), recruitment studies about the principalship emerged. As in private sector recruitment studies, some $\mathrm{K}-12$ educational recruitment studies focused on recruiter characteristics (e.g., sex, race, age) and job attributes (e.g., subjective, intrinsic, critical contact). Recruitment researchers explored the relatively new medium of recruitment videos. Also, organizational characteristics emerged as a significant recruitment effect for school location (urban, rural), size, pay, and school type.

Rynes and Lawler (1983) used expectancy theory to frame a study about how individuals combine information about job characteristics and probabilities of receiving job offers in decisions to pursue job vacancies. The expectancy theory (Vroom, 1964) proposed that the motivation to pursue job alternatives is a multiplicative function of job attractiveness (valence) times job seeker 
estimate of its attainability (expectancy). Rynes and Lawler (1983) used policy capturing (e.g. multiple regression) and narrative self-reports to assess how applicants combined and processed information concerning job characteristics and probabilities of receiving job offers (expectancies).

The participants $(N=10)$ were female, third-year college students who were elementary education majors at a large midwestern university. The participants read hypothetical job descriptions for elementary teaching positions. The job attributes investigated came from a pretest sample of individuals. The four independent variables were: (a) geographical location (Midwest, Northeast, Southeast, Northwest); (b) type of school (inner city, suburban, small city); (c) grade taught (primary, middle); and (d) probability of receiving a job offer/expectancy $(5 \%, 35 \%, 65 \%)$. The dependent variable was the decision to seek a job interview.

Each participant performed three tasks. First, they completed 7-point Likert-type scales assessing the job attractiveness based on the certainty that they would receive a job offer. Second, each participant rated the probability of pursuing the job if (a) the probability of receiving a job offer was either $5 \%, 35 \%$, or $65 \%$ and (b) 
the job pursuit included traveling to the geographical location at the expense of the applicant. Third, each participant gave a written description of the process used in deciding whether or not to pursue the job.

Rynes and Lawler (1983) used 10 separate analyses of variance (ANOVA) to analyze the job attributes influence on applicant decision to seek a job interview. The researchers used logistical regression analysis to test the use of additive or multiplicative expectancy-valence models. Results indicated that job attributes influenced teacher job choice decisions. Geographical location, type of school, and the interaction between the two were more important factors in the interview decision than grade taught or any other attribute interactions. Analysis of means indicated that applicants preferred jobs in the Midwest and not in inner city schools. The researchers concluded that their research was consistent with previous empirical studies which did not support the expectancy theory. Rynes and Lawler (1983) theorized that the nonsupport was due to unknown factors such as (a) variables affecting job seeker expectancy perceptions, (b) the degree those perceptions correspond with probabilities of job offer, and (c) whether or not a minimum expectancy 
threshold must be met before applicants will devote resources to job pursuit.

Young and Heneman (1986) conducted a laboratory simulation study to assess reactions of teachers as job applicants to the interviewer in the recruitment interview process. The participants were educational administrators $(N=44)$ and classroom teachers $(N=66)$ who were graduate students at a midwestern university. The researchers randomly assigned the administrators to role-play the interviewer while classroom teachers role-played either a faculty member assisting the administrator or the applicant seeking a position. The researchers used the critical contact theory which suggests that specific interviewer characteristics influence applicant decisions in the recruitment process.

The independent variables were: (a) the chronological age of the interviewer (self-reported); (b) interview format (single, group); (c) perceived interviewer personality (as assessed by interviewees on 6-point Likerttype scales); and actual personality of the interviewer (as assessed on a Myers-Briggs indicator). The dependent variable was teacher perception of the interview process. An additive composite score measured teacher responses to the interview process on 4-point Likert-type scales (4 
being more favorable than 1). The two additive composite items were (a) perceived probability of the position being offered and (b) perceived probability of accepting the position.

Young and Heneman (1986) used stepwise multiple regression to assess the covariance between the independent variables and the dependent variables. Results indicated that interviewer characteristics accounted for substantial variance in teacher reactions. The applicant reactions were more positive when the interviewer seemed more aware of the feelings of the interviewee, and when the interviewer projected more personal warmth toward the applicant. Also, the interviewer who tended to work through the entire interview before reaching a conclusion had a positive significant effect on teacher applicant decision-making.

Hudson (1994) investigated the informal job contact practice as organizational employment discrimination in recruiting women and minorities for public school superintendent positions. Almost two-thirds of all public school superintendents learn about their jobs through informal contacts (Hudson, 1991). When the job search behavior of minorities (women and African-Americans) is compared to the majority (White men), all job contract 
channels (formal and informal) are basically closed to minorities and opened to the majority (Hudson, 1994). Organizations which fail to develop recruitment programs that encourage and support women and minority applicants will continue to exclude these groups from superintendent positions .

The researcher used a stratified random sampling (Black women, Black men, White women, White men) of school superintendents $(N=404)$. All participants received a $10-$ page questionnaire which had a return rate of $77.8 \%$. Also, the researcher conducted 13 personal interviews with selected superintendents. Chi-square tests analyzed the data for statistical significant differences. Also, an analysis of variance (ANOVA) measured mean score differences. The results revealed no statistically significant differences existed in the use of informal job contacts between men and women or between Blacks and Whites. However, a statistically significant portion of all school superintendents (61.6\%) learned about their positions through informal job contacts $(p=.000)$. Also, when controlling for minority (women and Blacks) superintendents and majority (men and white) superintendents, minority superintendents (69.3\%) were more likely than majority superintendents (54.2\%) to use 
informal sources to learn about their jobs $(p=.000)$. These results indicate that the few minority candidates who are hired use informal contacts channels.

The researcher concluded that almost all school superintendents (90\%) received some form of pre-employment assistance through informal sources. However, Hudson (1994) theorized that school superintendent jobs are filled based on the context of the race of school board members and the demographics of students served. Also, recruitment through word-of-mouth suggests that the White males will be hired more due to sheer numbers than minority potential applicants. Hudson (1994) called on school districts to end "organizational process discrimination" where job search traditions result in the "tendency of employers to choose people like themselves to serve" as superintendents (p. 393).

winter and Dunaway (1997) examined the effects of job attributes, school level, and job information source on applicant attraction to principal positions described in recruitment brochures. The study participants $(N=168)$ were experienced elementary, middle, and high school teachers who role-played as applicants for a principal position. All teachers were from Kentucky and were working under the Kentucky Education Reform Act (KERA) which 
increased accountability and instructional leadership for principals.

The independent variables were: (a) school level (elementary, middle, high); (b) job information source (school site, central office); and job attributes (management, instructional leadership). The researchers randomly selected applicants from a large pool of teachers, and then randomly assigned them to treatment groups. The participants reacted to one of four different recruitment brochures that contained general information, job information, minimum qualifications, application procedures, and information about the principal selection process. The researchers held constant all brochure content except the job information source and job attributes.

The dependent variable was applicant reaction to a job described in a recruitment brochure and was an additive composite score composed of four items measured on 5-point Likert-type scales $(5=$ most favorable, $1=$ least favorable). The four items were: (a) overall attractiveness of the job, (b) likelihood of applying for the job, (c) likelihood of accepting an interview for the job, and (d) likelihood of accepting the job if offered. 
Winter and Dunaway (1997) assessed the data with a $2 \mathrm{x}$ $2 \times 3$ completely crossed, fixed-factor analysis of variance (ANOVA) which yielded 12 equal cells $(n=14)$. Results indicated a significant main effect for job attributes and a significant interaction effect for job attributes and school level. High school teachers preferred principal positions emphasizing school management while middle school and elementary teachers preferred principal positions emphasizing instructional leadership.

Young, Place, Rinehart, Jury, and Baits (1997) conducted a study to assess the usefulness of the similarity-attraction hypothesis as a theoretical framework for examining the effects of race and gender on teacher recruitment. The similarity-attraction hypothesis proposes that there is a positive relationship between perceptions of similarity and degree of attraction (Byrne, 1961). The participants $(N=240)$ were teachers enrolled in one of nine college of education programs in four states. The researchers used stratified random sampling to select the participant groups: White males $(n=60)$; White females ( $n$ $=60)$; Black males $(n=60)$; and Black females $(n=60)$. The independent variables were: applicant sex (male, female); (b) applicant race (White, Black); (c) recruiter sex (male, female); (d) recruiter race (White, Black); and 
(e) job attributes (economic, work environment, work itself). The participants viewed videotaped recruitment messages depicting recruiters role played by experienced educators: White males $(n=3)$; and Black males $(n=3)$; White females $(n=3)$; and Black females $(n=3)$. Each videotape emphasized different groupings of job attributes (economic, work environment, work itself). The dependent variable was applicant reaction to a teacher position described in the videotape. To assess the dependent variable, the researchers used a composite score composed of two items measured with 5-point Likert-type scales $(5=$ most favorable, 1 = least favorable $):(a)$ perceived probability of receiving the teacher position and (b) perceived probability of accepting the teacher position.

Young et al. (1997) used a between-within split-plot factorial analysis of variance (ANOVA) design with the three levels of job attributes serving as the within-groups factor. The between-subjects factors were: (a) race of teacher applicants (Black, White); (b) sex of teacher applicants (male, female); (c) race of school administrators (Black, White); and (d) sex of school administrators (male, female). Results provided limited support for the similarity-attraction hypothesis as a 
recruitment strategy for teachers. Partial support indicated that job applicants rated videotaped recruitment messages most favorably when the job applicant and the recruiter were of the same race. Results revealed no significance for applicant-recruiter same sex pairings. Additional analysis revealed significant job attributes for applicant race by recruiter sex interaction. Black applicants preferred jobs described by female recruiters that emphasized either work environment attributes or work itself attributes. White applicants preferred jobs described by male recruiters presenting recruitment messages which emphasized work environment attributes.

Responding to the shortage of research about principal recruitment, Pounder and Merrill (2001) conducted a study to provide information about the potential high school principal candidate as a decision maker in the job attraction process. This study examined which job attributes had the greatest influence on potential applicants for high school principal positions and applicant intentions to seek and accept a position. The researchers used job choice theory as a conceptual framework to examine candidates' perceptions and job intentions in seeking and accepting a high school principalship. 
Pounder and Merrill (2001) based their research on three job choice theories proposed by Behling, Labovitz, and Gainer (1968). The Objective Theory views candidates as economic beings selecting positions based on weighing the advantages and disadvantages of objective, measurable economical factors (i.e. salary, benefits, career advancement, educational opportunities). The Subjective Theory views candidates as psychological beings. The candidate views the position/organization in terms of meeting his psychological needs (i.e. perception of work environment, satisfaction of emotional needs, desire to achieve and influence others, etc.). The critical contact Theory postulates job candidates cannot differentiate between objective and subjective criteria, so they make decisions based on the recruitment process, the physical facility, the efficiency of the application process, or the professional networking/support for the promotional process/position.

The participants $(N=233)$ were high school assistant principals and middle school principals from a western state. These were appropriate participants because members of these groups were most often promoted to high school principals. A total of 170 usable surveys yielded a 73\% response rate. The participants reflected the 
disproportionate percentage of men $(n=120)$ versus women $(n=50)$ in secondary principalships nationally.

The independent variables were job attributes that defined and described a high school principalship based on the Job Choice Theory concept and school context scale for each job attribute (objective, subjective, critical content). The dependent variable was candidate rating of the influence each attribute had on their attraction to a high school principalship. Also, they rated the influence of school context items on their attraction to the high school principalship. Relevant literature, job descriptions, and feedback from a panel of experts (high school principals and assistant principals) identified the job attributes.

A panel of experts (principals, assistant principals, and superintendents) validated the instrument. Factor analysis reduced variables to subjective (desire to achieve/improve education); objective (salary, benefits); critical contact (professional network); and school context scales. Analysis also revealed a work itself scale (dilemmas/problems, time demands, external relations, management tasks, and fiscal management). Principal component analysis revealed three items for the dependent variable: perceived job attractiveness, probability of 
seeking a high school principalship, and probability of accepting a high school principalship. Coefficient alpha for the composite scale was .91 .

Bivariate correlations and multiple regression analysis determined the relationship between the dependent variables and the independent variables (demographic characteristics). Results revealed that the perceived probability of being offered a principalship was a positive significant predictor of job attraction and intention to pursue the job. Also positively significant were the variables desire to achieve, time demands, and salary/benefits. All Beta values were positive indicating that the more one favorably viewed the attribute, the more one was likely to be attracted to seek and accept the position. Results indicated that potential candidates were most attracted to high school principalships due to a desire to achieve and influence or improve education (subjective factor), followed by salary and benefits (objective theory). Applicants were least attracted to work factors such as: time demands, evening and weekend work, balancing work and family demands, and work related problems (e.g. student discipline, union grievances.)

Responding to the perceived shortages of school superintendents in Ohio, Howley, Pendarvis, and Gibbs 
(2002) examined the conditions of the job that make it attractive or unattractive for principals. The participants $(N=508)$ were Ohio principals selected randomly for the study. The researchers identified principals for their study based on the common career path for the superintendency (teacher, principal, superintendent). The purposes of the study were: (a) to identify conditions associated with the superintendency which principals found attractive, (b) to identify conditions associated with the superintendency which principals found objectionable, (c) to identify characteristics of principals which predispose them to view aspects of the superintendency as attractive or objectionable, and (d) to identify the characteristics in the context of principals work which predispose them to review aspects of the superintendency as attractive or objectionable.

The participants rated 19 variables related to conditions which would affect a decision to pursue a superintendent position on 4-point Likert-type scales. Factor analysis reduced the variables to three: (a) making a difference, (b) hard job, and (c) extrinsic motivator. The instrument also included eliciting demographic information: age, gender, years as a teacher, years as an 
administrator, highest degree obtained, and experience as a coach. Also, the participants responded to six items measuring localists (place-bound) and cosmopolitan (careerbound) commitments of principals. The researchers inputted contextual data salient to the analyses (rural, nonrural, school size, school SES, and total per pupil expenditure). Descriptive statistics analyzed each variable.

The results indicated four conditions most appealing (the chance to have a greater impact, the anticipated satisfaction associated with making a difference, the opportunity to implement creative personal ideas, the anticipated satisfaction associated with the ability to provide support to school and district staff). Results also revealed four conditions least appealing (increased burden of local, state, and federal mandates, the need to be accountable for outcomes beyond one's control, low levels of board support, excessive pressure to perform). Howley et al. (2002) identified significant predictors through a series of multiple regressions. The independent variables were characteristics of principals or of their schools. The dependent variable was superintendent condition (making a difference, hard job, extrinsic motivator). Results indicated that making a difference was not important in their decision to pursue a 
superintendency. Results yielded a small significance for hard job. Only one variable, years as a teacher, had a significant effect on hard job. Principals with less teaching experience rated the superintendency as more difficult than those with more teaching experience. The extrinsic motivator scale was significant but only explained a small amount of variance (3.7\%). A principal was more likely to view salary and benefits associated with the superintendency as important if he or she held cosmopolitan commitments. The influence of school context features on the three conditions for superintendency was non-significant.

Overall, hard job had the most influence on principal decisions to accept a position as a superintendent. The principals rated the increased burden of superintendent responsibilities for local, state, and federal mandates and the need to be accountable for outcomes that are beyond their control as objectionable features of the superintendency. The researchers asserted a new direction for the superintendency should be to reinvest the position "with sufficient authority and efficacy to once again make its attainment the aspiration of those educators with the greatest talent for leadership" (p.11). 
Responding to the issue of fewer applicants for principal vacancies, winter and Morganthal (2002) conducted a study with assistant principals rating of high school principal jobs varied by student achievement classifications, school location, and participant current school assignment. The study took place in Kentucky where school reform legislation mandates site-based school councils hire principals, and state standardized test scores determine school achievement classifications which result in school rewards or sanctions. The researchers selected school achievement as the primary independent variable based on its importance in school reform. The dependent variable was applicant ratings of high school principal vacancies prior to the initial employment interview.

The purpose of the study was to investigate the effects of school academic achievement (in need of assistance, progressing, meets goal); school location (inner city, suburban, rural); and participant school assignment (elementary, middle school, high school) on applicant ratings of high school principal positions. Participants in the study were $\mathrm{K}-12$ assistant principals $(N=189)$ randomly selected from 271 respondents to mailed instruments inviting participation (response rate 
$=77 \%)$. The population included 13 Kentucky school

districts with 63 assistant principals for each school level (elementary, middle, and high). All school levels were considered because assistant principals in Kentucky are certified K-12 and may apply at any school level. The ethnic distribution of the participants was: $86 \%$ White American, 13\% African American, and 1\% Asian with gender represented by $54 \%$ male and $46 \%$ female.

Winter and Morganthal (2002) conducted a factorial experiment using a $3 \times 3 \times(3 \times$ S) fixed-factor betweenwithin ANOVA design. The job description instrument operationalized the independent variables school achievement (in need of assistance, progressing, meets goal) and school location (inner city, suburban, rural). School achievement was the within-groups factor. A biographical data form operationalized the other independent variable school assignment (elementary, middle, high). A panel of experts $(n=6)$ and educators $(n=28)$ completing their principal certification program validated the job description instrument. A pilot study checked manipulations for school achievement and school location with $96 \%$ accuracy on both variables. Participant responses to a two-item additive composite rating of the job operationalized the dependent variable (job rating). The 
items were (a) "If offered, how likely would you be to accept an interview for the high school principal job described?" and (b) "If offered, how likely would you be to accept the high school principal job described?" The participants responded on 5-point Likert-type scales anchored by $1=$ not very likely to accept and $5=$ very likely to accept.

winter and Morganthal (2002) hypothesized that highperforming schools would receive higher job ratings than those schools that were progressing or in need of assistance. Also, they hypothesized that jobs at innercity locations would receive lower ratings than jobs at suburban or urban locations. ANOVA results revealed a significant main effect for school achievement and a significant two-way interaction for school achievement and school assignment. Omega-squared analysis revealed that the school achievement main effect accounted for $64 \%$ of the variance in applicant rating of the job. The school achievement by school assignment interaction explained 15\% of the variance in applicant rating of the job. Post-hoc tests revealed the mean score for jobs located at schools described as meets goal was significantly higher than the mean score for jobs located as schools described as progressing or in need of assistance. The mean score for 
jobs at schools described as progressing was significantly higher than the mean score for jobs located at schools described as in need of assistance. Across all school levels of job assignment, jobs at schools classified as meets goal received the highest ratings and those classified as in need of assistance received the lowest ratings. The study results indicated that school achievement had the largest influence in recruiting assistant principals for high school principal positions. Although not as significant as school achievement, there was a significant interaction between school achievement and school level. The researchers speculated the higher job ratings by participants at the elementary level might have resulted from other variables such as perceived job promotion, prestige, and increased pay.

Winter, Rinehart, and Muñoz (2002) conducted a study of the internal pool of principal certified personnel to evaluate potential applicants for principal vacancies. Recruitment theory (applicant characteristics associated with applicant attraction to the job), job satisfaction theory (job satisfaction levels impact personnel outcome), and self-efficacy theory (belief in one's capabilities to perform job responsibilities) framed the study. The researchers had six research objectives: (a) construct a 
profile of the principal certified personnel's demographic and personal characteristics, (b) use job attraction theory and self-efficacy theory as a framework to evaluate the participants' attraction to the job of principal, (c) evaluate the participants' satisfaction with specified facets of their current jobs compared to their expected satisfaction with those same job facets if they were to assume a position as principal, (d) identify reasons why the participants earned principal certification, (e) evaluate the participants' assessment of the changes in the job of principal that might make the job more attractive, and (f) have the district's principal certified personnel rate possible barriers to assuming a job as principal. The participants $(N=194)$ held principal certification but were currently in jobs other than the principalship in the $26^{\text {th }}$ largest school district in the United States. Two questionnaires assessed the participants' background information, current and expected job satisfaction, and job likelihood. The participants responded to a five-part questionnaire which assessed: (a) background information, (b) current and expected job satisfaction scales, (c) reasons for earning principal certification, (d) changes in the job of principal that might make the job more attractive, and (e) barriers to 
pursuing the job of principal. The researchers used 5point Likert-type scales to measure current and expected job satisfaction $(1=$ Not at All Satisfied, $5=$ Extremely Satisfied), degree of importance for earning principal certification ( $1=$ Not at All Important, $5=$ Extremely Important), and likelihood changes in job of principal would make it more attractive $(1=$ Not at All Likely, $5=$ Very Likely). A 5-point agreement scale (1 = Strongly Disagree, 5 = Strongly Agree) assessed ratings of barriers to pursuing the job of principal. The researchers assessed job likelihood with the participants responding to a principal job description identical to the one used in the school district and by using two-item composite score for job likelihood. The two items were: (a) "If offered, how likely would you be to accept an interview for the principal job described?" And (b) "If offered, how likely would you be to accept the principal job described?"

The independent variables were: (a) demographic characteristics (age, gender, ethnicity, marital status, number of dependent children, year of principal certification, number of times interviewed, current job held, highest degree held, number of times offered a job as principal); and (b) self-rating of the capability to do the job of principal (self-efficacy). The dependent variables 
were: (a) participant rating of the principal job, (b) the two-item composite score for job likelihood (c) expected job satisfaction, (d) reasons for earning a principal certificate, (e) the likelihood of changing the job would make it more attractive, and (f) self-reported ratings of participant capabilities to do the job also served as the dependent variable with gender and ethnicity as independent variables.

Descriptive statistics (frequencies, percentages, measures of central tendency) analyzed personal and demographic data. Results indicated that the average age of the participants was 50 and that $71 \%$ earned administrative certification more than five years ago. This suggested that the participants were near retirement age and were not actively pursing a principalship. Independent samples t-tests measured job likelihood and self-efficacy which revealed no significant differences between males and females or whites and minorities with respect to likelihood to accept a job or the self-reported capability to do the job.

One-way analysis of variance (ANOVA) assessed current job held (assistant principal, school counselor, teacher, other) and the dependent variables. A Tukey post-hoc test analyzed the ANOVA results of significant group mean 
differences. Results indicated that assistant principals and counselors rated the principal job significantly higher than did teachers and others. Teacher attraction to the job was moderate. Multiple regression analysis revealed two significant predictor variables. Self-reported capability to do the job accounted for $30.9 \%$ of the variance in job likelihood. As self-reported capability to do the job (self-efficacy) increased, job likelihood also increased. Age had a negative relationship with job likelihood accounting for $4.3 \%$ of the variance. As age increased, job likelihood decreased. Paired-sample t-tests indicated that the participants mostly earned principal certification to expand career options and to assume a greater leadership role in the district. The highest rating for recommended changes in the job of principal was to assign some principal job duties to other personnel. The highest rated impediments to pursing a principalship were current job satisfaction and inadequate authority to do the job given the high stakes accountability demanded of the principal.

Summary

Job attributes were significant variables in the $\mathrm{K}-12$ education recruitment research. Teacher attraction to jobs was influenced by organizational characteristics (e.g. pay, 
type of school, location) and job attributes (e.g. subjective, intrinsic, work context). Inexperienced teacher applicants were more likely to respond to job opportunities than experienced teachers. However, both experienced and inexperienced teachers responded favorably to recruitment messages inclusive of intrinsic and work context job attributes rather than economic attributes. winter and Morganthal (2002) conducted a study of high school principal recruitment using school achievement as a variable which was the first empirical investigation of this factor in $\mathrm{K}-12$ education recruitment literature. Results revealed that school achievement (based on state assessment scores) had the largest influence (compared to other variables of school location and school level) in recruiting assistant principals for high school principal positions.

Howley et al. (2002) contributed to the need for empirical research in recruitment of $\mathrm{k}-12$ school superintendents. The researchers identified the difficulty of the job (hard job) as having the most influence on principal decisions to accept a position as a superintendent. Their study proposes that job redesign may be the solution to the superintendent job applicant 
shortages. Winter and Morgenthal (2002) found similar results relative to principalship.

Higher Education Recruitment Research

The importance and challenges of organizational recruitment are not unique to the private sector or $\mathrm{K}-12$ education. Although limited empirical research exists on post-secondary education faculty recruitment, a pressing need to recruit talented faculty emerged in this literature review. Potential increases in faculty retirements and in student enrollments are predictive of qualified faculty shortages (Winter \& Muñoz, 2001). Effective recruitment of college faculty members is paramount in colleges in student recruitment, graduation rates, and potential research monies. Early research in post-secondary institutions focused on the economic factors of salary and benefits and work conditions (Freeman \& Carpenter, 1983). Recognizing a need for higher education to attract qualified students for doctoral programs, Young, Galloway, and Rinehart (1990) investigated the effects of doctoral program recruitment brochures on prospective doctoral students. Included in higher education recruitment literature is the unique challenges of hiring qualified faculty for community and technical colleges (Winter \& Muñoz, 2001). Recent literature also focused on the applicant perspective in the 
recruitment process. Factors which influenced applicant decisions to accept college faculty positions included college locations, job assignments, and job satisfaction (Matier, 1991; Winter, 1998; Winter and Muñoz, 2001).

Young, Galloway, and Rinehart (1990) investigated the effects of college recruitment brochures on graduate students. The participants $(N=48)$ were experienced teachers taking graduate education courses at a Midwestern university.

The independent variables were: (a) gender (male, female) and (b) recruitment brochure content (subjective, objective, critical contact). Three separate recruitment brochures operationalized the independent variables. The objective perspective reflected economic incentives associated with graduating from the doctoral program including market advantages, salary growth, placement services, and placement rates. The subjective perspective associated with the doctoral program participation included psychological and developmental dimensions such as individual instruction, professional growth, and network opportunities. The critical contact perspective associated with the doctoral program emphasized the program requirements such as minimum GRE and GPA, residency requirements, and graduation requirements. The dependent 
variable was a composite score of participant reactions to a brochure measured on 6-point Likert-type scales $(1=$ least favorable, 6 = most favorable). The items were: (a) probability of attending and (b) probability of graduating from the doctoral program described in the brochure.

Young et al. (1990) used a split-plot factorial design with one between subjects factor (male, female) and three within-subjects factors (subjective, objective, critical contact). An analysis of variance (ANOVA) revealed no main effects for gender, no interaction effect between gender and brochure content, and a main effect for theoretical perspective. A post hoc test revealed a significant mean score difference in critical contact. Teachers reacted more favorably to recruitment brochure content emphasizing the critical contact perspective than to recruitment brochure content emphasizing the subjective or objective perspective.

Matier (1991) examined the factors influencing prospective faculty members with firm offers to accept positions at research universities. Matier assessed the relative weight and importance placed on tangible, intangible, and non-work related benefits in the job decision process. Location of the university (rural, urban) was also a factor. 
The participants $(N=182)$ had offers to join faculty (assistant, associate, or full professors) at either Wyandot or Manada, two research universities. To assess the factors influencing the decisions to accept positions, the participants completed a questionnaire and participated in a 20-minute follow-up interview. The questionnaire and interview yielded 33 factors which were assigned to one of three groups: (a) intangible, (b) tangible, and (c) nonwork related. These became the independent variables in the study. The participants indicated location of university preference by choice of urban (Wyandot) or rural (Manada). The dependent variable was applicant enticement to accept a job offer from the university.

Matier (1991) used descriptive statistics to compare factors between rural and urban job offer enticements. A second analysis determined the relative importance of each factor in the decision-making process. The researcher squared the individual scores to differentiate the relative difference between the scores for accepting a position at either Wyandot or Manada. Results indicated that intangible factors were the most significant factors in the job decision-making process, regardless of whether the university was urban or rural. The participants identified the most important intangible factors in the decision- 
making process as: (a) the job assignment (teaching/ opportunities; (b) reputation of the institution; (c) reputation of the department; (d) reputation and congeniality of associates; (e) research opportunities; and (f) rapport with department leaders. The tangible benefit of teaching/research load was the remaining common factor. The results also indicated that non-work related factors were the least important factors influencing the decision to accept the university offer, regardless of university location.

winter (1998) conducted a study which applied marketing and advertising theory to the recruitment of college business faculty. The participants $(N=180)$ in this study were business professionals pursuing masters of business administration (MBA) degrees. The researcher selected equal number of male $(n=90)$ and female $(n=90)$ participants. All participants role-played as applicants reacting to jobs described in formal recruitment advertisements for community college faculty positions. The independent variables were: applicant sex (male, female); instructional programs (academic transfer, career education, compensatory education); and job attributes (intrinsic, extrinsic, and work context). 
The dependent variable was an additive composite rating of applicant reactions to jobs described in faculty recruitment advertisements. Winter (1998) operationalized the dependent variable with a composite score of four items using 5-point Likert-type scales ( 5 being more favorable than 1). The four items were: (a) overall attractiveness of the job, (b) likelihood of applying for the job (c) likelihood of accepting an interview for the job, and (d) likelihood of accepting the job if offered.

Winter (1998) used a $2 \times 3 \times 3$ factorial analysis of variance design (ANOVA) and found significant statistical effects for instructional programs, an interaction between sex and job attributes, and an interaction between sex, instructional programs, and job attributes. The researcher conducted an analysis of simple effects. Two simple effects were significant. For advertisements describing academic programs, women rated jobs containing intrinsic job attributes higher than jobs described with extrinsic attributes, and men rated jobs described with extrinsic attributes higher than jobs described with intrinsic attributes. Also, both male and female applicants rated jobs described as academic transfer most favorably. Winter and Kjorlien (2000) conducted a study about recruiting faculty for business department vacancies at 
community colleges. The participants $(N=136)$ were business professionals completing their MBA degree at two large public universities in the midwest. A recruitment simulation required the participants to role-play the part of applicants for a community college business faculty position. The participants completed three tasks: (a) completion of a biographical data sheet, (b) review of a simulated faculty position announcement, and (c) completion of an evaluation of the position announcement. Each participant responded to one of four faculty position announcements created for the study.

The independent variables were job mobility (relocation required, relocation not required); recruiter background (business, education); and applicant gender. The dependent variable was a composite rating for applicant reaction to a job described in a faculty position announcement. Applicant rating was operationalized by 5point Likert-type scales $(5=$ most favorable, $1=$ least favorable). A summed composite score of the four evaluation items measured applicant reaction to the job descriptions. The evaluation items were: (a) overall attractiveness of the job, (b) likelihood of applying for the job, (c) likelihood of accepting an interview if 
offered, and (d) likelihood of accepting the job if offered.

winter and Kjorlien (2000) analyzed the data with a 2 $\times 2 \times 2$ completely crossed fixed-factor analysis of variance (ANOVA) procedure. Results indicated, across all levels of applicant gender and recruiter background, the participants rated the position more favorably when it did not require relocation. Also, across all levels of applicant gender and job mobility, the participants rated the position more favorably when the recruiter had a background similar to the background of the applicant (business background).

Winter and Kjorlien (2000) continued investigating recruitment of community college business administration faculty members by applying a factorial analysis to Barber's (1998) applicant attraction model and Byrne's (1971) similarity-attraction hypothesis. Again, the participants $(N=136)$ role-played applicants for business faculty positions. Also, the participants reviewed and evaluated one of four simulated position announcements. The independent variables were (a) 11 personal characteristics (gender, spousal income, age, race, marital status, current job satisfaction, etc.); (b) recruiter background (similar, dissimilar); and (c) relocation (yes, 
no). The composite rating for applicant reaction to a faculty position served as the dependent variable. The same Likert-type scales used in the previous study measured the dependent variable.

Winter and Kjorlien (2000) used stepwise multiple regression to analyze the data. The results revealed that the most significant predictor was applicant current job satisfaction. As applicant rating of current job satisfaction decreased, the rating of the position increased. Other significant results indicated that the applicant rating of the job increased as the spousal income decreased. Results also indicated applicant ratings of the job were more favorable when the background of the recruiter was similar to the applicant and the position did not require relocation.

Winter and Muñoz (2001) investigated the association between personal characteristics of applicants and their job ratings for business faculty positions. The participants $(N=194)$ were business professionals completing master of business administration degrees at a large midwestern research university. The researchers randomly selected the participants who responded to simulated recruitment advertisements for business college faculty positions. The participants completed: (a) a 
biographical data form, (b) a job satisfaction instrument, and (c) a rating of a job for a community college business faculty position described in an advertisement. The researchers used Schwab's (1982) employment process model and Schwab, Rynes, and Aldag's (1987) general model of job search and evaluation to frame this study. According to Schwab (1982), the job applicant searches for organizations (employment opportunities) as the organization searches for employees (job openings). Schwab et al.'s (1987) model emphasized the association between applicant personal characteristics and applicant job choice decisions.

The independent variables were: (a) applicant demographic characteristics (gender, race, marital status, employment status, age, number of dependent children, years resident in area, years work experiences, years business work experience, hours worked per week, years job tenure, intrinsic satisfaction, extrinsic satisfaction, willingness to consider job); and (b) applicant personal satisfaction with facets of their current jobs. Composite scores from the short form of the Minnesota Satisfaction Questionnaires (MSQ) for intrinsic and extrinsic job facets of participant current positions evaluated job satisfaction. The participants responded to the MSQ on 5-point Likert-type scales $(1=$ very dissatisfied, 5 = very satisfied $)$. 
The dependent variable was participant rating of a business faculty job described in a simulated recruitment advertisement. A job evaluation instrument operationalized participant rating: (a) likelihood of applying for the job, (b) likelihood of accepting an interview, and (c) likelihood of accepting the job if offered. The participants evaluated the simulated advertisement on 5point Likert-type scales $(1=$ not very likely, $5=$ very likely).

A correlation design analyzed the data using ordinary least squares stepwise multiple regression. The correlations revealed significance with several variables: (a) martial status, (b) hours worked per week, (c) age, (d) total work experience, and (c) number of dependent children. Marital status and hours worked per week resulted in the strongest correlations and factored into the stepwise multiple regression equation. The results revealed that marital status explained 5\% of the variance in applicant ratings of job advertisements. Attraction to the job increased when the participants were not married. Hours worked per week explained $3 \%$ of the variance in applicant rating of the job advertisement. As the hours per week increased so did applicant attraction to the job. The researchers concluded that knowing personal 
characteristic of job applicants associates with applicant attraction to job vacancies increases organization recruitment potential.

Summary

Two important factors emerged in the limited number of higher education research studies. First, research emphasizing the applicant perspective increased the identification of determinants of applicant job attraction to college faculty positions. The reviewed studies indicated the increased hiring potential for variables emphasizing the applicant perspective including: (a) work location, (b) teaching discipline, (c) marital status, economic factors, (e) job design, (f) research opportunities, (g) hours worked per week, and (h) reputation of the university. The other contribution to this research was the identification of theoretical contexts such as recruitment-as-job-marketing theory (Winter, 1998) and the similarity-attraction theory (Winter \& Kjorlien, 2000).

Models and Theories

To conceptualized recruitment research and provide a framework for future research, researchers developed models and theories to delineate processes and outcomes in recruitment practices. In the more recent recruitment 
research literature, the recruitment process focused on the applicant perspective rather than from the organizational perspective. Recruitment models and theories included how the applicant made decisions about job choices often based on personal needs and issues. Four recruitment models and two theories contributed significantly to the focus of this research and will be discussed in this section. Others have been included in previous sections due to their contributions there, but they will be mentioned in this section summary.

Wanous (1980) investigated the selection and entry of newcomers to the organization in his analysis of realistic job previews (RJPS) in 13 experimental studies. In three studies, realistic job previews were presented at the preentry stage. At entry stage, three other studies presented RJPs. The remaining seven studies presented RJPs at the post entry stage. RJP methods of presentations included: (a) a work-sample test, (b) audiovisual, (c) oral presentations, and (d) booklets. Five studies found that RJPs had no negative effect on newcomers or on job acceptance. In nine studies, results indicated that job survival was longer for recruits who received RJPs. Wanous (1980) concluded from the analysis that "ineffective recruitment can affect either the job performance of 
newcomers (and thus involuntary turnover) or it can affect the job satisfaction or organizational commitment of newcomers (and thus voluntary turnover). The primary impact of recruitment, however, is on the latter, not the former (p. 83).

Wanous (1980) proposed a matching model as a framework of the processes linking RJPs to employee adjustment and employment stability. Based on the Minnesota Theory of Work Adjustment (TWA), this model included the match between individual preferences for job rewards (needs) and perceptions of available job rewards (rewards) result in job satisfaction and employment stability. Wanous (1980) introduced into this framework RJPs as increasing the needs-rewards process. Applicants who received RJPS experienced better matches between work-related needs and job rewards. A strong need-reward match increased job satisfaction and organizational commitment, and it negatively affected employee actions to secure another job. Because the Wanous (1980) model proposed a framework for realistic recruitment, the matching model is included in this study (Figure 1).

Wanous (1980) introduced two new constructs to his matching model. He included (a) comparison of present job to others and (b) organizational commitment. Both need- 
rewards and comparison of present job to others influenced job satisfaction in the model. Also, organizational commitment demonstrated a relationship with job satisfaction. The accuracy-of-job-information component included the RJP process as the premise underlying the model. Wanous (1980) concluded that the matching model proposed an effective method of identifying factors influencing both voluntary and involuntary turnover.

Schwab, Rynes, and Aldag (1987) developed a model of the job search and choice process which structured their review of relevant literature. The researchers identified two basic factors influencing job search and job choice factors: (a) individual characteristics of those seeking employment and (b) labor market conditions. They hypothesized that job seeker methods used are a function of personal characteristics: (a) labor force status (employed, unemployed); (b) occupational preferences and training; and (c) cognitive abilities (decision anxiety, memory capacity). In addition to individual characteristics, Schwab et al. (1987) emphasized that the labor market influences job choice decisions with variables such as unemployment rates, organizational climate (rules, goals, customs), and unemployment benefits. 
Following the decision to seek a job, Schwab et al. (1987) proposed an evaluation stage in the model which addressed two factors referred to as the content and process aspects of evaluation. Both content and process aspects of job evaluation are dependent variables in the studies. In the content or search stage, the job seeker evaluates the source used to acquire information about the job vacancy (recruiter, advertisement, employment agency). At this stage, the job seeker decides to accept, reject and renew search, or reject and withdraw from the labor force. Also relevant to the search stage is the intensity of search. Job seekers evaluate whether or not the job meets minimum standards, personal goals, and is comparable to other job offers. In the process stage, the job seeker conceptualizes outcomes in two ways: (a) obtained employment (yes, no); and (b) the quality of obtained employment (wage level, job satisfaction, tenure). Schwab et al. (1987) concluded that employment outcomes are the result of decisions made by both job seekers and employers (a two-way process).

Rynes and Barber (1990) developed a recruitment model from the organization's perspective. Previous recruitment theory research framed the applicant attraction model which was based on studies from the fields of economics, human 
resource management, industrial psychology, organizational behavior, and sociology. The model contained the following components: (a) contingencies that affect attracting applicants, (b) strategies for attracting applicants, (c) human resources practices that affect applicant attraction, and (d) outcomes of the applicant attraction strategies. Contingencies affect the selection of an attraction strategy which recruiters must consider in the recruitment process. The researchers identified the following contingencies: (a) labor market conditions (supply of workers relative to demand); (b) vacancy characteristics (position level, embeddedness, incumbents, position attractiveness, skill requirements); (c) organizational characteristics (ability to pay, business strategy, culture and values, organizational demographics); (d) phase of the attraction process (application, interview, screening); and (e) legal considerations (salary regulation, equal employment opportunity) .

In the second component, Rynes and Barber (1990) identified three strategies for attracting applicants: (a) altering recruitment practices, (b) modifying employment inducements, and (c) targeting nontraditional applicants. More recruitment literature exists about recruitment practices than about the other recruitment strategies. 
Recruitment practices in the studies included: (a) organizational representative characteristics (e.g., personality, knowledge, credibility); (b) the recruitment message content; (c) recruitment source; and recruitment timing. The other influences on applicant attraction to an organization were improving employee inducements (pecuniary, nonpecuniary) and targeting individuals considered to have skills and characteristics different from traditional applicants. Age, gender, work experience, and country of origin classified were factors used to classified individuals as non-traditional applicants.

In the third component of the model, Rynes and Barber (1990) described how attraction strategies have an interaction with other human resource practices. First, they limit potential strategies that organizational representatives might select (e.g., an organization regards equity as a priority over monetary incentives). Second, when an organization changes an attraction practice this way it affects other human resources practices (e.g., attracting non-traditional applicants may precipitate funding more employee training).

In the fourth component of the model, Rynes and Barber (1990) described the applicant attraction outcomes of the attraction strategies. In previous research studies, these 
outcomes served as the dependent variables. Outcomes cast as dependent variables included the decision to apply for the job and the decision to accept an interview for the job. Applicant strategies influenced attraction outcomes related to pre-employment and post-employment quantity and quality of individuals attracted to an organization. Also, they influenced monetary and time efficiency in the applicant attraction efforts and applicant decision-making process .

Mauer, Howe, and Lee (1992) applied principles, theories, and practices of marketing management to examine engineering recruitment as a process of "job marketing." The study focused on six hypotheses which investigated specific recruitment issues: (a) recruiter behaviors, (b) applicant response to the recruitment process, (c) similarities in applicant and recruiter traits, (d) realistic job information preview, (e) person-organization fit, and (f) applicant needs in pre-interview stage. Mauer, et al. (1982) defined the recruitment-as-jobmarketing theory as:

A process where the buyer/applicant must make a cognitive demanding purchase decision to enter into a long-term and dynamic exchange relationship with the seller/employer. From the employer's perspective, the job marketing goal is to facilitate the exchange process in order to maximize human capital concerns gained for position offerings by filling jobs with the 
greatest possible number of best qualified applicants. (p. 808)

The participants $(N=242)$ were engineering students (chemical, civil, electrical, mechanical, others) from 20 universities who completed questionnaires referring to previous interviews. The researchers developed the questionnaire items from focus group interviews with graduating engineering students. Factor analysis revealed seven factors: (a) employment environment/rewards (b) job/skills match, (c) interview performance, (d) interview information measures, (e) compensation/benefits, (f) job/career information, and (g) security/success. The researchers assessed applicant satisfaction with the recruitment procedure and information gained at the three stages of the recruitment process (pre-interview, interview, job tour) with 6-point Likert-type scales.

The independent variables in the study were: (a) preinterview information, (b) interview procedures, (c) information provided in the interview, and (d) interview outcomes. The dependent variables in the study were: (a) overall response to the recruitment process and (b) likelihood of accepting the job if offered. Three Likertscale items measured overall responses to the recruitment process: (a) the recruitment process increased interest in 
the employer, (b) he/she was satisfied with information obtained about potential job responsibilities, and (c) relative to other employers, this process was conducted well. Response to a fill-in-the blank statement measured likelihood of job acceptance on a 100-point scale: "If offered a job the firm I interviewed last, the chances of me taking the job with them are out of a hundred".

Mauer, et al. (1992) used multiple regression procedures and analysis of variance (ANOVA) to analyze the data. Results indicted that positive applicant perceptions of recruiter interpersonal skills and objective job information (employment/environmental rewards, job/skills, compensation/benefits, job/career information) positively impacted overall perceptions of the recruiting processes and intention to accept a job offer. This finding supported the importance of recruiter interpersonal skills and behavior suggested by the recruitment-as-job-marketing theory.

Smither, Reilly, Millsap, Pearlman, and Stoffey (1993) contributed to the research of recruitment-as-a-jobmarketing theory by conducting two studies investigating the practical importance of applicant satisfaction with recruitment practices and strategies. The researchers based their research on three reasons for organizations to 
consider job applicant reactions to selection procedures:

(a) applicants are viewed as customers and organizations as suppliers in competition for available jobs, (b) applicant reactions may be related to litigation regarding selection procedures, and (c) applicant reactions may indirectly affect the actual validity and utility of a selection procedure.

In Study 1, the participants were newly hired entrylevel managers $(N=110)$ and recruiting managers $(N=44)$ from a large corporation. First, the entry-level managers completed cognitive ability tests which included measures of logical reasoning, integrative process, inductive reasoning, and vocabulary and math tests. Second, entrylevel managers and recruiting managers rated descriptions of tests or procedures in terms of whether the management jobs were likely to predict employment success. The participants responded to two statements: (a) "Applicants who perform well on this type of test (selection procedure) are more likely to perform well on entry management jobs than applicants who perform poorly on the test." and (b) "The actual content of this type of test (selection procedure) is clearly related to entry management jobs." The researchers measured responses on 5-point Likert-type scales $(1=$ strongly disagree, $5=$ strongly agree $) . A$ 
factor analysis indicated that the two statements measured perceived job relatedness.

The independent variables were: (a) test description (construct, no construct); and (b) cognitive tests (business context, no business context). The dependent variable was perceptions of new managers and recruiting managers. A series of t-tests and analysis of variance (ANOVA) analyzed the data. Results indicated that newly hired entry-level managers and recruiting managers judged simulations, interviews, and cognitive tests related to concrete information (vocabulary, standard written English, mathematical word problems) to be more job related than personality, biographical data, and cognitive tests with relative abstract items (quantitative comparisons, letter sets). Because the concrete information received more favorable ratings for applicants, the findings in study 1 supported the recruitment-as-job-marketing theory.

In Study 2, the participants $(N=460)$ were applicants for civil service jobs in a state government. The applicants completed a questionnaire assessing their reactions to a professional civil service exam just taken. The 35-item questionnaire assessed: (a) face validity and predictive validity of the examination, (b) knowledge of results, (c) the likelihood of improving previous 
examination scores, (d) affective reaction to taking the exam, and (e) organizational attractiveness.

One month after completing the first questionnaire, and following the receipt of civil services test scores, the participants completed a second questionnaire. This one measured applicant perceptions concerning the procedural and distributive justice of the examination process and the likelihood of applicant recommendation that others apply for employment with the state government agency. Results indicated that applicants perceiving the recruitment process as being fair were more likely to recommend the employer to others. In study 2, the results also indicated that organizational representatives who focused on applicants and responded to applicant needs during the recruitment process were more successful in recruiting than organizations who did not consider the applicant as customer in the recruitment-as-job-marketing theory.

winter (1996) investigated reactions of job applicants to job messages in formal position advertisements. The purpose of the study was to propose a recruitment practices model to attract experienced educators. The participants were experienced female teachers $(N=136)$ randomly selected from graduate education courses at a large 
midwestern university and randomly assigned to treatment conditions. The subjects role-played applicants for a teaching position.

The independent variables were: (a) job attributes (intrinsic, work context); (b) job message tone (personal, impersonal); and (c) stimulus to apply (personal call, information packet, control). Intrinsic job attributes included higher order job needs such as sense of accomplishment (Maslow, 1943), whereas extrinsic job attributes related to lower level job needs such as salary and job security (Maslow, 1943). The applicants reacted to jobs described in 12 formal position advertisements with format and length (210 words) held constant across treatment conditions. The researcher conducted two pilot studies to develop job attribute content, check manipulation of job message tone, and check manipulation of stimulus to apply. Content validity for job attributed included a panel of experts, operational definitions of intrinsic and extrinsic job attributes, and a Q-sorting procedure for assigning attributes to categories. Coefficient alpha for the job evaluation items forming a composite score was .93 .

The dependent variable was applicant rating of a job described in a position advertisement. The evaluation 
instrument had 5-point Likert-type scales ( 5 being more favorable than 1) which measured four items forming a composite score. The items measured were: (a) overall attractiveness to the job, (b) likelihood of applying for the job, (c) likelihood of accepting an interview for the job, and (d) likelihood of accepting the job if offered. Winter (1996) used a $2 \times 2 \times 3$ completely crossed, fixed-factor analysis of variance (ANOVA) which yielded twelve equal cells $(n=14)$. All main effects were significant. Results revealed that applicants reacted more favorably to jobs described in advertisements with intrinsic attributes, a personal tone, and a phone call as the stimulus to apply.

Winter (1996) proposed a model for recruiting experienced educators. The model details six steps in the process: (a) set recruitment objectives, (b) profile target applicants, (c) specify recruitment practices, (d) match recruitment and marketing practices (e) construct recruitment practices, and (f) implement and evaluate. This study provided a useful model for educational recruitment practices, and an effective assessment of recruitment-as-job marketing theory for educational organizations. 
Summary

Other contributions to the recruitment models and theories research have been reviewed in previous sections of this literature review. The expectancy theory, initially defined by Vroom (1964), was the framework of the Rynes and Lawler (1983) study which examined how individuals combine information about job characteristics and probabilities of receiving job offers in decisions to pursue job vacancies. Pounder and Merrill (2001) used job choice theory (Behling, Labovitz, \& Gainer, 1968) as a conceptual framework to examine candidates' perceptions and job intentions in seeking and accepting a high school principalship. The job choice theory has three dimensions: (a) objective theory (candidate weighs job choice decisions on economic factors); (b) subjective theory (candidate weights job choice decisions in terms of his psychological needs); and (c) critical contact theory (candidate weighs job choice decisions on the recruitment process. The similarity-attraction theory served as a framework for Young, Place, Rinehart, Jury, and Baits (1997) study which assessed the effects of race and gender on teacher recruitment. The similarity-attraction theory proposes that there is a positive relationship between perceptions of similarity and degree of attraction (Byrne, 1961). The 
combination of recruitment models and theories enables researchers to determine appropriate variables, processes, and frameworks in their recruitment research.

\section{Research Methods}

Recruitment research studies primarily reflect the use of two research designs to investigate organizational recruitment. In both the private and education sectors, the two prevalent research methods are the experimental design and the correlation design. The experimental design utilizes analysis of variance (ANOVA) as the statistical procedure for analyzing data. The experimental approach involves having potential job applicants rate recruitment variables in actual or simulated situations. Experimental designs in recruitment studies cast as independent variables job attributes, interviewer or recruiter characteristics, and recruitment sources. Applicant job rating is the usual dependent variable. Examples of the rating items include: likelihood of applying for the job, likelihood of accepting a job interview, and likelihood of job acceptance.

The second method is the correlation design which uses multiple regression as the statistical procedure for analyzing data. The correlation design involves having job applicants rate job-related factors, usually on surveys or 
questionnaires, which become independent variables. In this design study, the participants rate their reactions to the job and the recruitment practices which serve as the dependent variables. In correlation design studies, the researcher predicts the amount of variance explained relative to such dependent variables as likelihood of applying for the job, likelihood of accepting an interview for the job, likelihood of job acceptance.

\section{Summary}

Recruitment research in the past three decades focused on recruiters, recruitment sources, and realistic job previews. From these studies, researchers identified variables that are important in the job applicant's decision-making process. Effects of the organization's recruiter had strong influence on the applicant's decision to accept a job offer (Rynes, 1991). Studies indicated that variables such as interviewer's behaviors and characteristics are significant in the applicant expecting to receive a job offer and to accept one (e.g. Alderfer \& McCord, 1970; Rogers \& Sincoff, 1978; Harris \& Fink, 1978). Private sector researchers identified recruitment sources effects variables as referrals from current organization employees, direct applications or walk-ins, newspaper or professional journal advertisements, rehires, and 
employment agency referrals (Ullman, 1966; Gannon, 1971; Decker \& Cornelius, 1979; Breaugh, 1981; Caldwell \& Spivey, 1983; and Taylor \& Schmidt, 1983). From the research studies on recruitment sources effects, researchers investigated variables affecting employee performance and recruitment sources. As a result, accurate sources of information regarding the job emerged in the private-sector recruitment research. Variables in the research included types of information received in the interview (positive, negative). Wanous was the leading researcher in the area of realistic job previews, and he furthered his studies to include methods of measuring individual differences as a significant variable in employee reactions to job characteristics. Wanous (1974) found that employees know little about the organizations at entry, and significant employee attitudes towards intrinsic factors affect employee performance after one year of employment.

Private sector research provided the framework for the more recent $\mathrm{k}-12$ educational research studies. As in the private sector, the recruiter was viewed as having an effect on the job applicant's decision to apply for a position and to accept a job if offered. Most educational research studies focused on teacher recruitment (Winter, 1996; Winter, 1998). However, some recent studies 
investigated k-12 principal recruitment (Pounder \& Merrill, 2001 and Winter \& Morganthal, 2002). K-12 education research identified job attributes as a significant variable in teacher and administrator attraction to positions. Applicant reactions to recruitment videos and job advertisements measured recruitment sources effects on decisions regarding job attractiveness and willingness to pursue and accept vacant job positions. Most of the findings in $\mathrm{K}-12$ education research were consistent with findings in private sector recruitment research. The next chapter contains a description of the research design for this study and the planned analytical procedures. 
CHAPTER III

METHODOLOGY

Methods

The purpose of this study was to examine variables that influence elementary, middle, and high school teachers to consider a career as a school counselor. The variables examined were counselor job facets and personal characteristics of the participating teachers. Counselor job facets are important to examine because they represent how school reform has transformed the work of the school counselor, and the increasing shortages of applicants as the school counseling profession moves from service providers to part of the leadership team for school reform initiatives (Dollarhide, 2003). The link between school counseling programs in the last decade and student academic achievement especially with "at risk" students contributes to the new and critical role counselors play in accountability for school and student success (Sink \& Stroh, 2002). As with other school administrators (principal, assistant principal) in school reform states, counselors are faced with accountability pressures. The 
often complex and ambiguous role of the school counselor contributes to frustration and disappointments associated with job facets and to the lack of sufficient numbers of applicants for school counseling vacancies (Portman, 2002). This study provided data to inform school districts about aspects of the job of counselor that might aid district recruiters in attracting teachers into the counseling profession.

\section{Theoretical Framework}

The theoretical framework for this study was the Rynes and Barber (1990) applicant attraction model reviewed in Chapter II (see p. 181). This model postulates that job vacancy characteristics are among the most salient factors influencing applicant attraction to position vacancies, and applicant decisions to pursue a job such as the decision to accept an interview for the position. In accordance with the above postulate, the researcher cast counselor job facets as independent variables of interest and applicant rating of the job as the focal dependent variable.

\section{Research Advancements}

This study contributed to research advancements because it addressed the recruitment of school counselors. The research advancements were: 
The first empirical study on counselor recruitment.

2. The first empirical study involving a counselor recruitment simulation.

3. The first empirical study involving counselor recruitment conducted in a state undergoing systemic school reform.

4. The first empirical study to compare potential applicant satisfaction in the current position as teacher with the potential applicant expected satisfaction in the job of school counselor.

5. The first attempt to assess counselor job attraction among individuals (i.e., teachers) not yet in the profession. 6. The first study to address counselor job attraction across school levels (elementary, middle, high) .

The research methodology used to achieve the above advancements follows.

Participants and Sampling Procedures The participants $(N=553)$ were elementary, middle, and high school certified teachers in the Jefferson County Public Schools in Louisville, Kentucky. The researcher 
chose the school sites for data collection to ensure diversity relative to such factors as socio-economic status of school, ethnicity of teachers, and years of teaching experience. The Jefferson County Public Schools serves $98,000 \mathrm{~K}-12$ students, and of those, $64 \%$ are at-risk (classified as having qualified for a free or reduced lunch). Elementary, middle, and high school teachers reflect a population of 5,874 with $15 \%$ African American and 85\% other. The study sample is similar to these demographic factors and is reported in Chapter IV. The sample size was based on the assumptions of a maximum of 31 predictor variables and Stevens' criterion (1992, p. 125) of 15 participants per predictor variable. Each study participant completed demographic information, a counselor survey, and role-played as job applicants by evaluating a counselor job by rating the position as depicted in a simulated school counselor job description.

\section{Research Design}

The first phase of the analysis was to perform group mean comparisons involving demographic variables as independent variables, and a two-item composite rating of a counselor position depicted in a simulated job description as the dependent variable. The data related to the third rating item on the job evaluation, concerning a JCPS 
orientation session, will be reported as descriptive information only. The procedures used to perform this analysis were the independent-samples t-test (e.g., gender as the grouping variable) and analysis of variance (e.g., ethnicity as the grouping variable).

The second phase of this study involved two-group comparisons to compare participant job satisfaction with specified job facets (e.g., special education, paperwork support of testing and assessment). Participants rated their current teaching jobs with their expected job satisfaction and then rated those same facets as if the participants were to assume a job as a school counselor. The analytical procedure used to perform this analysis was the paired-samples t-test (Sheskin, 1997).

The third phase of this study involved a correlation design (Campbell \& Stanley, 1963) with hierarchical multiple regression analysis (Cohen \& Cohen, 1983) as a procedure. Personal characteristics of the participants (age, gender, number of dependent children, ethnicity, education, current school enrollment, current school level, current school CATS level, years of teaching experience, years of teaching experience in JCPS) served as control variables (i.e., covariates) and entered into the regression equation first. 
The purpose of the control variables was to isolate variance in the dependent variable not attributable to the predictor variables of interest (Edwards, 1985).

Participant ratings of counselor job facets were the predictor variables of interest and entered the regression equation second. The rationale for the above order of variable entry was that the study participants possessed their demographic characteristics prior to experiencing job facets in a work setting. The dependent variable for the regression analysis was a composite rating of a counselor job as depicted in a simulated counselor job description. Additional information about the independent variables, dependent variable, and variable measurement and operationalization is in the following sections.

\section{Independent Variables}

One phase of the research involved hierarchical multiple regression analysis (Stevens, 1992). The control variables for the regression included age, gender (one dummy variable), number of dependent children, ethnicity (five dummy variables), highest degree earned, school enrollment, school assignment (two dummy variables), school classification based on the most recent CATS results (two dummy variables), years teaching experience, and years teaching experience in JCPS. Page 2 of the survey 
instrument (See Appendix B) operationalized the control variables.

The predictor variables of interest for the regression analysis, subject to a principle components analysis to assess the need for data reduction, were the job facets operationalized on the survey instrument (See Appendix B) .

Another phase of the study involved two-group comparisons requiring the participants to rate their current teacher job satisfaction with facets of their current jobs compared to their expected job satisfaction with those same job facets in the job of school counselor. In this analysis the independent variable was job satisfaction (current, expected) and the dependent variables were rating items. The researcher operationalized the above variables on the survey instrument (See Appendix B).

Primary Dependent Variable of Interest

The primary dependent variable of interest in this study was applicant rating of school counselor position as depicted in a simulated counselor job description (See page 11 of the survey in Appendix B). The rating was a two-item additive composite score with 5-point Likert-type scales (1 = very unlikely to accept, 5 = very likely to accept). The two rating items were: (a) "If offered, how likely would 
you be to accept an interview for the school counselor job described?" and (b) "If offered, how likely would you be to accept the school counselor job described?". In previous private-sector recruitment research (e.g., Rynes, 1991; Rynes \& Lawler, 1983) and education-sector recruitment studies (e.g., Young et al., 1989; Young et al., 1990; Young et al., 1997) the above rating items consistently rated with coefficient alphas of .80 or greater.

\section{Instruments}

The researcher developed the biographical data sheet, counselor survey, and counselor job description by consulting with an educational administration researcher who is developing similar instruments for empirical research on counselor recruitment. The biographical data sheet measured these variables: age, gender, number of dependent children, ethnicity, education, teaching area, current school enrollment, current school level, current school level as indicated on the Commonwealth Accountability Testing System (CATS), years of teaching experience, and years of teaching experience in JCPS.

In the second section, the researcher developed a 5point Likert-type scale to measure the participant interest in counselor job duties. The researcher derived survey items from reviewing the job duties assigned to counselors 
in JCPS and from reviewing the counselor standards used in the district. These job duties fell into one of three area: (a) academic (b) career, and (c) personal/social. The researcher asked participants to consider a career in school counseling and to rate their interest in performing job duties such as: "Assist students to acquire skills that contribute to effective learning in and out of school" (1 = Not at all Interested, 5 = Very Interested).

In a similar manner to the second section, in the third section participants rated their interest in counselor job facets at the current stage of their career. Items included: "The opportunity to participate with others in my school to make important decisions" ( 1 = Not at all Interested, 5 = Very Interested).

In the fourth section, the researcher developed a job satisfaction survey to measure current job satisfaction as a teacher and expected job satisfaction as a counselor using job characteristics derived from a large number of job satisfaction studies (e.g., Cranny, Smith, \& Stone, 1992: Hulin, Roznowksi, Hachiya 1985; Locke, 1976; Smith, Kendall, \& Hulin, 1969). The operational definition of job satisfaction adopted for this study was the one developed by Locke (1976): "Job satisfaction may be defined as a pleasurable or positive emotional state resulting from the 
appraisal of one's job or job experience" (p. 1300). The survey structure and some of the rating items were similar to the structure (e.g., comparing current job satisfaction with expected job satisfaction, use of a job evaluation instrument) and items on an administrator survey used in previous recruitment research (Winter, Rinehart, \& Muñoz, 2002). An example of a job-characteristic measured was "The opportunity to use my talents" for current job satisfaction $(1=$ Not at all Satisfied, $5=$ Extremely Satisfied) and for expected counselor job satisfaction (1 = Not at all Satisfied, 5 = Extremely Satisfied).

The fifth section consisted of three open-ended questions asking the participants to respond on provided spaces. These three questions were (a) "Based on what you know about school counseling, what would you identify as being the most rewarding aspects of working as a school counselor?", (b) "In your opinion, what are the greatest barriers preventing teachers from considering a career as a school counselor?", and (c) "What recommendations would you give to make the profession of school counseling more attractive to teachers?"

In the final section, the participants read a job description and then rated the job using rating scales. (The items, scales, and anchors were: (a) "If offered, how 
likely would you be to accept an interview for school counselor job described?" (1 = Very Unlikely to Accept, $5=$ Very Likely to Accept); (b) "If offered, how likely would you be to accept the school counselor job described?" $(1=$ Very Unlikely to Accept, 5 Very likely to Accept); and (c) If invited, how likely are you to attend a JCPS orientation session for teachers to learn about a career in school counseling?" ( 1 = Not likely to Accept, 5 = Very Likely to Accept) .

The researcher developed a counselor job description based on the actual content of the Jefferson County Public School Human Resource Department. The researcher used actual job descriptions to develop the job evaluation instrument to lend realism to the study. The job description used was modified to include common commonalities of job responsibilities from the JCPS elementary, middle, and high school job descriptions for a cross level survey instrument use in this study. Having the participants role-play as job applicants by reacting to a job depicted in a simulated job description was an approach used in previous research (Winter, Rinehart, \& Muñoz, 2002). The operational definition used in this study was the one developed by Barber (1998) and is stated verbatim on page 1 of Chapter I. 


\section{Pilot Study}

The researcher administered the instruments (Appendix

B) to a group of teachers $(N=24)$ employed in a JCPS middle school. The same participants completed the survey twice. The researcher asked the pilot participants to write the last four digits of their social security numbers in the upper right hand corner of the first page in order to code instruments to check test-retest reliability of the instruments and to assess coefficients of stability for the survey rating items. The researcher used the script in Appendix $\mathrm{C}$ to administer the instruments. Descriptive statistics for the pilot participants are in Table 1. The results of the reliability analysis (coefficient alpha) are in Table 2. The results of the test-retest reliability analysis are in Appendix D.

The data in Table 1 provide a profile of the teachers who participated in the pilot study. As can be seen from the results in Table 2 , the two-item composite score serving as the primary dependent variable of interest had a high level of internal consistency. Coefficient alpha for the composite scale was .9320 , well above the minimum $(.60)$ required for use of a composite score in statistical analysis (Nunnally \& Bernstein, 1994). 
The test-retest analysis (see Appendix D) resulted in revisions of the survey instrument. The criterion for retaining survey rating items was a coefficient of stability of .50 or greater. The coefficients of stability for most of the nine rating items derived from the ASCA (1996) national counselor professional job standards (see pages 3-4 of instrument in Appendix D) were far below the above decision criterion. The teacher-participants did not provide reliable ratings for these standards-based items, possibly because teachers are too far removed from counselor professional standards to be able to have an accurate or informed perception of job duties based on these standards. The decision taken based on this finding was to delete the standards-based rating items from the survey instrument.

A practical recruitment issue related to the deleted items is that professional standard content appears not to be useful during the early stages of recruiting teachers into the counseling profession. This type of information may be more useful during later stages of the recruitment process le.g., employment interview stage, site visit stage) or during new employee induction when an orientation about professional counselor standards might have more impact. 
A similar analysis resulted in deleting items 14 and 15 (see other Job Factors items 5 and 6 in Appendix D) from the "Other Counselor Job Factors" section of the original instrument. Relative to the current and expected job satisfaction items (see Appendix D), the decision criterion for retaining a job satisfaction item was existence of an acceptable coefficient of stability for both the current and the expected job satisfaction scales. Application of this criterion resulted in retaining seven of the 19 job satisfaction items assessed. The coefficients of stability for the job, rating items (see Appendix D) were acceptable. There were no other modifications to the instruments. Revised instruments, reflecting the deletions reported above, appear in Appendix E.

\section{Data Collection for This Study}

The researchers collected data for the actual study by administering the research instruments (see Appendix E) to teachers in the district prior to faculty meetings. The researcher followed a script (see Appendix C) and had the participants perform four tasks: (a) read an advised consent preamble, (b) complete a counselor survey 
Table 1

Descriptive Statistics for Pilot Participants $(N=24)$

\begin{tabular}{lrrrrr}
\hline Variable & $n$ & 8 & Mean & $S D$ & Range \\
\hline Age (Years) & & & 41.5 & 8.4 & $29-55$ \\
$\begin{array}{l}\text { Gender } \\
\quad \text { Male }\end{array}$ & 5 & 20.8 & & & \\
$\quad$ Female & 19 & 79.2 & & & \\
$\begin{array}{l}\text { Number of Dependent } \\
\text { Children }\end{array}$ & 24 & & 1.2 & 1.3 & $0-5$ \\
$\begin{array}{l}\text { Ethnicity } \\
\quad \text { Minority }\end{array}$ & 2 & 8.5 & & & \\
$\quad$ White & 22 & 91.2 & & &
\end{tabular}

Highest Degree Earned

$\begin{array}{lrc}\text { BS/BA } & 3 & 12.5 \\ \text { MS/MA } & 13 & 54.2 \\ \text { Masters +30 } & 6 & 25 \\ \text { Doctorate } & 2 & 8.3\end{array}$

School Enrollment

1,300

School Assignment

Elementary

Middle

$24 \quad 100.0$

High

School CATS Classification

In Needs of

Assistance

$24 \quad 100.0$

Progressing

Meets Goals

Work Experience:

Years of Teaching

Experience

11.3

9.1

$0-27$

Years of Teaching

Experience in JCPS

7.4

6.5

$0-26$ 
Table 2

Reliability Analysis - Pilot Study $(N=24)$

\begin{tabular}{lllclc}
\hline Item & $\begin{array}{l}\text { Scale } \\
\text { Mean if } \\
\text { Item } \\
\text { Deleted }\end{array}$ & $\begin{array}{c}\text { Scale } \\
\text { Variance } \\
\text { If Item } \\
\text { Deleted }\end{array}$ & $\begin{array}{c}\text { Corrected } \\
\text { Item-Total } \\
\text { Correlation }\end{array}$ & $\begin{array}{c}\text { Squared } \\
\text { Multiple } \\
\text { Correlation }\end{array}$ & $\begin{array}{c}\text { Alpha } \\
\text { If Item } \\
\text { Deleted }\end{array}$ \\
\hline 1. & 2.5417 & 1.737 & .877 & .769 & (a) \\
2. & 2.7083 & 2.129 & .877 & .769 & (a) \\
\hline
\end{tabular}

(a) Cannot compute coefficient alpha for a single item.

Item Code:

1. = likelihood of accepting an interview.

2. = likelihood of accepting a job offer.

Coefficient Alpha for composite score $=.9320$

questionnaire, (c) read a simulated counselor job description, and (d) evaluate the job described using the three rating items described earlier.

\section{Data Analysis}

The data analysis for the study involved computing both descriptive statistics and inferential statistics. 
Descriptive Statistics

The first phase of the data analysis involved computing descriptive statistics for the study participants. The descriptive statistics addressed participant characteristics and included: frequencies, percentages, means, standard deviations, and range statistics.

Inferential Statistics

The inferential statistical procedures for this study included the independent-samples t-test, analysis of variance, and the paired-samples t-test which is a repeated measures technique. The paired t-tests analyzed current job satisfaction with teaching and expected job satisfaction as a school counselor. Each participant gave a rating for both current and expected job satisfaction. The statistical method used to analyze predictors of job rating was hierarchical multiple regression with the control variables entered first and job facets entered second. The statistics computed in the correlation phase of the data included: a correlation matrix, beta coefficients, multiple-R, $R^{2}, \Delta R^{2}$, and adjusted- $R^{2}$. This study received approval from the University of Louisville Human Studies Committees and the JCPS Department of 
Accountability, Research, and Planning. A summary of the statistical findings is reported in Chapter IV. 


\section{CHAPTER IV}

\section{RESULTS}

This school counselor recruitment study utilized a correlation design (Campbell \& Stanley, 1963) with hierarchical multiple regression analysis (Cohen \& Cohen, 1983) as the primary analytical procedure. Personal characteristics of the participants (age, gender, number of dependent children, ethnicity, education, current school enrollment, current school level, current school CATS level, years of teaching experience, years of teaching experience in JCPS, years of teaching experience in Kentucky) served as the control variables (i.e., covariates) and entered into the regression equation first. The purpose of the control variables was to isolate variance in the dependent variable not attributable to the predictor variables of interest (Edwards, 1985). Entering into the regression equation second were participant ratings of counselor job facets, the predictor variables of interest. The rationale for the above variable entry order was that the participants possessed their demographic characteristics prior to experiencing job facets in a work 
setting. The dependent variable for the regression analysis was a composite rating of a counselor job as depicted in a simulated counselor job description.

The research involved a field survey (see Appendix E) with data collection occurring within Jefferson County Public Schools in Louisville, Kentucky. The researcher collected data at 15 school locations (see Appendix G). The schools represented all levels (elementary school, middle school, high school) and the district student demographic make-up in terms of such factors as race and socio-economic status. The schools at each level included six elementary schools, four middle schools, and five high schools. The number of participants $(N=553)$ exceeded the minimum sample $(N=465)$ identified using Steven's (1992) criterion of 15 participants per predictor variable.

\section{Descriptive Statistics}

Descriptive statistics for the study participants appear in Table 3. The teacher participants had a mean age of 40.9 with a range in ages from 21-69. Male participants were $30.9 \%$ of the population, and females comprised $69.1 \%$ of the population. The mean number of dependent children was one, and the range was 0-11 dependent children for the participants. Ethnicity included White American (82.8\%), 
Table 3

Descriptive Statistics for Participants $(N=553)$

\begin{tabular}{|c|c|c|c|c|c|}
\hline Variable & $n$ & 8 & Mean & $S D$ & Range \\
\hline Age (Years) & & & 40.9 & 10.8 & $21-69$ \\
\hline \multicolumn{6}{|l|}{ Gender } \\
\hline Male & 171 & 30.9 & & & \\
\hline Female & 382 & 69.1 & & & \\
\hline \multicolumn{6}{|l|}{ Number of Dependent } \\
\hline Children & & & 1.0 & 1.3 & $0-11$ \\
\hline \multicolumn{6}{|l|}{ Ethnicity } \\
\hline White & 458 & 82.8 & & & \\
\hline African American & 81 & 14.6 & & & \\
\hline Asian American & 2 & .4 & & & \\
\hline Native American & 1 & .2 & & & \\
\hline Hispanic American & 5 & .9 & & & \\
\hline Other & 6 & 1.1 & & & \\
\hline
\end{tabular}

Highest Degree

$\begin{array}{lrr}\text { BS / BA } & 106 & 19.2 \\ \text { MS /MA } & 276 & 49.9 \\ \text { Masters +30 } & 163 & 29.5 \\ \text { Doctorate } & 8 & 1.4\end{array}$

School Enrollment School Assignment

Elementary

$162 \quad 29.3$

Middle

11320.4

High

$278 \quad 50.3$

School Class.

Needs Assistance $89 \quad 16.1$

Progressing $\quad 350 \quad 63.3$

$\begin{array}{lll}\text { Meets Goal } & 114 & 20.6\end{array}$

Work Experience:

Years Teaching Experience

$\begin{array}{lll}12.9 & 9.8 & 1-38\end{array}$

Experience in JCPS

$10.4 \quad 9.2 \quad 1-38$

Experience in $\mathrm{KY}$

$11.8 \quad 9.6$

$1-38$ 
African American (14.6\%), Asian American (.4\%), Native American (.2\%), Hispanic American (.9\%), and other (1.1\%). Highest education degrees earned by participants included: BS/BA (19.2\%), MS/MA (49.9\%), Masters +30 (29.5\%), and Doctorate (1.4\%). School enrollment had a mean of $1,068.5$ students with a range of 420 to 1,850 students. School assignment included 162 elementary school teachers (29.3\%), 113 middle school teachers (20.4\%), and 278 high school teachers (50.3\%). In terms of the schools where the respondents were employed, the CATS scores classifications were: 89 "in needs of assistance" (16.1\%), 350 "progressing" (63.3\%), and 114 "meets goal" (20.6\%). Teacher work experience had a mean of 12.9 years with 10.4 years in JCPS, and 11.8 years in Kentucky.

Table 4 contains the frequencies, percentages, means, and standard deviations for the item addressing participant interest in attending a JCPS orientation session for teachers to learn about a career in school counseling. The teacher participants had a mean of 2.8 which is just below the midpoint on the 5-point scale for interest in attending an orientation session. The percentage of participants indicating a four or five on the scale was $36.5 \%$ of the participants $(n=202)$. One hundred and nine participants 
Table 4

Descriptive Statistics for Attending a Counselor Session $(N=553)$

If invited, how likely are you to attend a JCPS orientation session for teachers to learn about a career in school counseling?

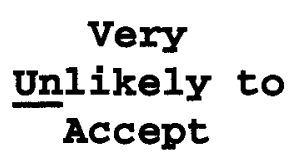

1

Frequency

Percent

Mean

(S.D)
179

73

99

93

109

$\begin{array}{lll}32.4 & 13.2 & 17.9\end{array}$

16.8

19.7

\author{
Very \\ Likely to \\ Accept
}

5

45

9

7


(19.7\%) indicated a five on the scale ("very likely to accept") .

\section{Group Mean Comparisons}

The procedures used to analyze differences in group mean scores, with the two-item composite for counselor job rating serving as the dependent variable, were the independent samples $t$-test and one-way analysis of variance (ANOVA). These analyses indicated there were no significant group mean differences relative to gender (male, female), school level (elementary, middle, high), or school classification (in needs of assistance, progressing, meets goal).

The one-way ANOVA with highest degree serving as the independent variable was significant $(\mathrm{p}<.05)$. There was one significant group mean difference. The mean for participants with a bachelors degree (BS/BA) $(M=6.0)$ as the highest degree earned was significantly higher than the mean for participants with masters degree +30 hours $(M=$ 51) as the highest degree earned. The Pearson correlation between age and job rating $(r=-.19)$ was significant $(\mathrm{p}<$ .0001 ) indicating as age increased, the score for job rating decreased. These data are consistent with the highest degrees earned data reported above in that job rating decreased as age and credentials increased. Older, 
more educated individuals rated the job lower than younger, less educated individuals.

\section{Reliability Analysis}

The teacher participants role-played as job applicants by reacting to a job depicted in a simulated job description. The two items were: (a) "If offered, how likely would you be to accept an interview for school counselor job described?" and (b) "If offered, how likely would you be to accept the school counselor job described?" The participants responded on 5-point Likert-type scales (1 = very unlikely to accept, 5 = very likely to accept). The statistical results in Table 5 indicated the means and variances changed little as each item was deleted from the composite score. The coefficients under the "Corrected Item Total Correlation" represent Pearson correlations between the two items. The inter-item correlation $(r=$ .9108 ) was high in magnitude (Cohen, 1988) which indicates a high degree of internal consistency.

In the "Squared Multiple Correlations Column," the $R^{2}$ values derived from multiple regression analyses. The results $\left(R^{2}=.8296\right)$ indicated that each item in the composite explained a high proportion of variance in the other item. These high $R^{2}$ values further supported the conclusion that the two items in the composite score were 
internally consistent. The procedure used to assess the reliability of the composite score serving as the dependent variable was coefficient alpha. Results of the analysis revealed the coefficient alpha for the composite score was .9531 , well above the minimum (.60) required for use of a composite score in statistical analyses (Nunnally \& Bernstein, 1994).

Table 5

Reliability Analysis for Participants ( $N=553)$

\begin{tabular}{|c|c|c|c|c|c|}
\hline Item & Scale & Scale & Corrected & Squared & Alpha \\
\hline & Mean if & Variance & Item-Total & Multiple & If Item \\
\hline & Item & If Item & Correlation & Correlation & Deleted \\
\hline
\end{tabular}
1. 2.6401
2.1040
.9108
.8296
(a)
2. 2.7902
2.2349
.9108
.8296
(a)

(a) Cannot compute coefficient alpha for a single item.

Item Code:

1. = likelihood of accepting an interview.

2. = likelihood of accepting a job offer.

Coefficient Alpha for composite score $=.9531$ 


\section{Paired t-Test Results}

The statistical procedure used to analyze current teacher job satisfaction and expected job satisfaction as a school counselor was the paired t-test which is a repeated measures technique. The results of the paired t-tests are in Table 6. The paired items were the seven job characteristics common to the jobs of teacher and counselor. Statistical significance ( $<<.001$ ) was found with the first six job characteristics: "The vacation time I have" ( $t=19.3)$, "The time I have to spend with my family" ( $t=12.0)$, "Extra income I can earn in the summer" $(t=3.7)$, "The hours I work per week" $(t=9.0)$, "The opportunity to experience varied activities on the job" ( $t$ $=4.7)$, and "The opportunity to serve others" $(t=5.7)$. In all cases, the participants rated satisfaction in the current job higher than expected satisfaction in the job of school counselor. The one job characteristic not statistically significant was "The recognition I receive for doing a good job" $(t=-.6)$.

Correlation and Regression Results

The first step in the inferential statistical analysis was to compute a correlation matrix for the control variables, predictor variables, and dependent variable to be examined in a hierarchical multiple regression analysis. 
The correlation matrix appears in Table 7 . The dependent variable in Table 7 is the composite score for participant rating of a counselor job description. Correlation coefficients in Table 7 with a magnitude of $.08(p<.05)$ or greater are statistically significant.

Table 6

Paired t-Test Results $(N=553)$

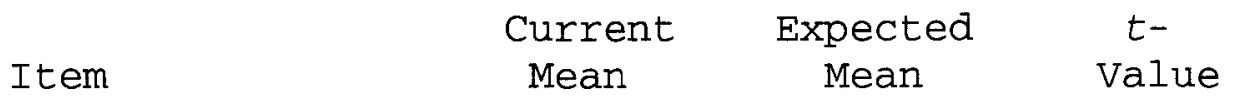

$\begin{array}{llll}\text { 1. }=\text { vacation time } & 4.3 & 3.2 & 19.3 * \\ \text { 2. = time with family } & 3.7 & 3.0 & 12.0 * \\ 3 .=\text { summer income } & 3.4 & 3.1 & 3.7 * \\ \text { 4. }=\text { hours per week } & 3.4 & 2.9 & 9.0 * \\ 5 .=\text { varied activities } & 3.7 & 3.4 & 4.7 * \\ 6 .=\text { serve others } & 4.2 & 3.9 & 5.7 * \\ 7 .=\text { recognition } & 3.3 & 3.3 & -.6\end{array}$

${ }^{*} \mathrm{p}<.0001$

Dummy coding served to render scores for nominal-scaled variables such as gender and ethnicity. The researcher eliminated ethnic groups with extremely low sample sizes. The resulting ethnicity variable consisted of two levels 
(White American, African American). The researcher entered an average composite rating of the seven current job satisfaction items as an additional control variable. A reliability analysis for the seven item composite score appears in Table 8.

The statistical procedure used to analyze the reliability of the seven job satisfaction items was coefficient alpha. The means and variances specified in Table 8 changed little as the researcher deleted items from the composite score. The Pearson correlations in the column "Corrected Item-Total Correlation" are correlations between the single job characteristic and the sum of the other six job characteristics. These seven correlations are similar and high in magnitude (Cohen, 1988) indicating internal consistency. In the Squared Multiple Correlation column, each $R^{2}$ value is a result of a multiple regression analysis where one item was cast as the dependent variable and the other six were cast as the predictor variables. The $\mathrm{R}^{2}$ statistics were similar in magnitude, suggesting internal consistency. Finally, in all cases deleting an item from the composite scale caused coefficient alpha to decrease. The decision was to retain all items. Coefficient alpha for the composite score was .8007 which 
Table 7

Correlation Matrix $(N=553)$

Variable

2

3

4

5

67

8

9

10

11

12

13

14

$15 \quad 16$

17

Dependent Variable

\section{Job rating}

N

Control Variables

2. Age
3. Gender
4. Dep. child
5. Ethnicity
6. Highest degree
7. School level
8. Core area
9. Elective area
10. Teaching exper
11. JCPS exper
12. Current satis
13. Decisions
14. ECE paperwork
15. Administration
16. Tests/assess
17. Counsel/mentor

$\begin{array}{rrrrr}-.19 & - & & & \\ -.05 & .02 & - & & \\ -.00 & .14 & -.07 & - & \\ -.09 & .05 & .03 & .06 & - \\ -.09 & .42 & .09 & .11 & .10 \\ .04 & .58 & -.36 & .04 & .02 \\ .00 & -.10 & .06 & -.08 & -.03 \\ .02 & .13 & -.15 & .08 & .32 \\ -.23 & .77 & .08 & .12 & .07 \\ -.26 & .66 & .10 & .10 & .04 \\ .07 & -.07 & -.06 & .02 & .06 \\ .42 & -.16 & .01 & -.02 & -.04 \\ .37 & -.10 & .03 & .03 & -.21 \\ .49 & -.13 & -.09 & -.01 & -.14 \\ .47 & -.12 & -.02 & -.00 & -.07 \\ .48 & -.18 & -.07 & -.01 & -.05\end{array}$

$-.02-$

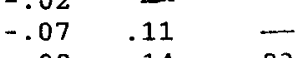

$\begin{array}{rrr}.08 & .14 & -.83 \\ .44 & -.02 & -.09\end{array}$

$\begin{array}{lll}.44 & -.02 & -.09 \\ .40 & -.04 & -.09\end{array}$

$\begin{array}{lll}.40 & -.04 & -.09 \\ .01 & -.02 & -.10\end{array}$

$\begin{array}{lll}-.03 & -.05 & -.05\end{array}$

$\begin{array}{lll}-.03 & -.05 & -.03 \\ -.06 & -.04 & -.07\end{array}$

$\begin{array}{rrr}-.06 & -.04 & -.07 \\ .01 & .05 & -.05\end{array}$

$\begin{array}{lll}-.04 & -.02 & -.01\end{array}$

$\begin{array}{lll}.09 & -.02 & .03\end{array}$

$\begin{array}{rrr}-.09 & - & \\ .09 & .89 & - \\ .12 & .09 & -.10 \\ -.00 & -.13 & -.16 \\ .09 & -.13 & -.13 \\ .05 & -.11 & -.10 \\ .00 & -.12 & -.13 \\ .06 & -.18 & -.17\end{array}$

-14
.16
.13
.15
.07

.39
.16
.56
.65 
exceeded the minimum (.60) recommended for use of a composite score for statistical analysis (Nunnally \& Bernstein, 1994).

Results of the hierarchical multiple regression analysis appear in Table 9. These results indicated one control variable and four predictor variables explained significant variance in the dependent variable (rating of a school counselor job). The standardized regression coefficients $(\beta)$ determined the relative contribution of the significant independent variables for explaining the variance in ratings of a school counselor job. The independent variable with the beta coefficient ( $\beta$ ) having the highest absolute value was the most significant independent variable. The data in Table 9 for Step 1 indicated that JCPS experience $(\beta=-.20, p<.01)$ explained significant variance in the dependent variable (job counselor rating) when controlling for the effects of other control variables. It was a negative coefficient. As teaching experience in JCPS increased, participant rating of a counselor job decreased. No other control variables were significant.

In Step 2, four predictor variables had a statistically significance impact on counselor job rating. 
Table 8

Reliability Analysis for Current Job Satisfaction Composite Score $(N=553)$

\begin{tabular}{lccccc} 
Item & $\begin{array}{c}\text { Scale } \\
\text { Mean if } \\
\text { Item } \\
\text { Deleted }\end{array}$ & $\begin{array}{c}\text { Scale } \\
\text { Variance } \\
\text { Deleted }\end{array}$ & $\begin{array}{c}\text { Corrected } \\
\text { Item-Total } \\
\text { Correlation }\end{array}$ & $\begin{array}{c}\text { Squared } \\
\text { Multiple } \\
\text { Correlation }\end{array}$ & $\begin{array}{c}\text { Alpha } \\
\text { If Item } \\
\text { Deleted }\end{array}$ \\
\hline 1. & 21.7626 & 20.3853 & .5869 & .4377 & .7673 \\
2. & 22.3051 & 18.6090 & .6394 & .5868 & .7538 \\
3. & 22.6425 & 20.6011 & .4120 & .1917 & .7981 \\
4. & 22.5962 & 18.1690 & .6423 & .5227 & .7527 \\
5. & 22.2960 & 20.0243 & .5524 & .3440 & .7714 \\
6. & 21.8476 & 21.6301 & .4826 & .3235 & .7845 \\
7. & 22.7204 & 20.2224 & .4455 & .3025 & .7921 \\
\hline
\end{tabular}

Item Code:

1. = vacation time

2. = time with family

3. = summer income

4. = hours per week

5. = varied activities

6. = serve others

7. = recognition

Coefficient Alpha for composite score $=.8007$ 
Table 9

Hierarchical Multiple Regression of Control Variables and Predictor Variables on Counselor Job Rating.

Variable $\quad \beta \quad \Delta R^{2}$

Step 1

$.08 * * * *$

Control Variables

JCPS Experience

Step 2

$.29 * * * *$

Predictor Variables

ECE Paperwork

Administration

$.09 *$

Testing/Assessment

$.23 * * * *$

Counsel/Mentor

${ }^{*} \mathrm{p}<.05,{ }^{* *} \mathrm{p}<.01, * * * \mathrm{p}<.001, * * * * \mathrm{p}<.0001$

Full Model: $R^{2}=.37[F(16,522)=18.9], \mathrm{p}<.0001$, Adjusted- $R^{2}=.35$ 
"The involvement with special education paperwork" $(\beta=.09$, $\mathrm{p}<.05)$, "The opportunity for me to perform administrative duties" $(\beta=.23, p<.0001)$, "The time I would spend in support of testing and assessment programs" $(\beta=.15, p<$ .001 ), and "The opportunity to provide counseling and mentoring to students" $(\beta=.23, \mathrm{p}<.0001)$ were the predictor variables that explained significant variance in the dependent variable (counselor job rating) when controlling for the effects of other independent variables. The full model, as indicated by the adjusted- $R^{2}$ statistic below Table 9, explained $35 \%$ of the variance in the rating of a counselor job. Cohen (1988) identified this as a large effect size.

Results From Open-ended Questions

The participants completed three open-ended questions for qualitative feedback on the school counselor survey (See Appendix F). Numbers in parentheses following responses indicated the frequency of that response item. School level (elementary, middle, high) determined response categories.

For elementary teachers, the most frequent response to the question "Based on what you know about school counseling, what would you identify as being the most 
rewarding aspects of working as a school counselor?" was: "Helping students and parents work through problems/crisis/emotional needs to enable them to make successful progress" (51). Listed next for elementary teachers was "Working with children in small groups and in the classroom" (21), and then "Placing at-risk, struggling students in programs that would benefit them the most" (18) .

To the second question, "In your opinion, what are the greatest barriers preventing teachers from considering a career as a school counselor?", "Excessive paperwork" (64) was the most frequent response by elementary teachers. Other responses include "Coursework/time/expense/additional education required for certification" (25) followed by "Lack of time spent counseling" (14).

The third question was: "What recommendations would you give to make the profession of school counseling more attractive to teachers?" Elementary teachers responded with "Require less paperwork" (40), "Allow time needed to be a counselor, not an administrator" (22), "Provide more time to meet, interact, and counsel kids in class visits" (21), and "Provide assistants" (18). 
Middle school teachers responded to the first question "Based on what you know about school counseling, what would you identify as being the most rewarding aspects of working as a school counselor?" with the most frequent response being "Working one-on-one with students, counseling and interacting in favorable situations to identify and provide help with their needs to become successful" (32). Next was "Seeing my involvement make a difference in students' progress/becoming more successful" (12).

To the second question, "In your opinion, what are the greatest barriers preventing teachers from considering a career as a school counselor?" middle school teachers listed "Excessive paperwork" (40) as the most frequent response. Additional responses to the second question included: "Extra work hours" (7), "Minimal pay" (5), and "Administrative duties" (5).

Middle school teachers responded to the third question, "What recommendations would you give to make the profession of school counseling more attractive to teachers?" with "Reduce paperwork" (13), "Allow more time for counseling" (7), and "Increase salaries to compensate for time on the job" (6).

High School teachers responded to the first question, 
"Based on what you know about school counseling, what would you identify as being the most rewarding aspects of working as a school counselor?" with "Mentoring/working with students" (84), followed by "Getting a student involved/successful in college career goals" (63). Also having a high frequency were "Getting to know students on a more personal/individual level" (38) and "Helping students make major decisions in dealing with problems" (28).

As with elementary and middle school teachers, high school teachers also responded to the second question most frequently with "Excessive paperwork" (92). Additional responses to the second question, "In your opinion, what are the greatest barriers preventing teachers from considering a career as a school counselor?" included: "Stress/long hours/extended year/less vacation" (57), "Time to complete the additional extensive coursework requirements for counseling while teaching" (46), "Lack of actual student interaction/counseling" (31), and "Universities often have difficulties providing certification classes in the time needed" (30).

High school teachers responded to the third question, "What recommendations would you give to make the profession of school counseling more attractive to teachers?" with 
"Allow more emphasis on actually counseling students" (61), "Reduce paperwork" (37), "Provide pay increase" (35), and "Hire someone to do tasks not in counselor job description $(\mathrm{ECE}) "(11)$. A discussion of the findings is in Chapter V. 


\section{CHAPTER V}

DISCUSSION, IMPLICATIONS AND CONCLUSION

This study addresses the problematic issue of recruiting sufficient numbers of counselors to staff public schools. The study took place in Kentucky, a school system undergoing systemic school reform. School counselors are essential players in school reform (Hughley, 2001) because they advise and counsel students on such important issues as: achieving academic success, overcoming adverse environmental and family conditions, adjusting to social structures in the school, preparing for successful careers, and becoming productive citizens.

Jefferson County Public Schools (JCPS), the site for this research, classifies school counselors as administrators. The educational administration literature contains few empirical studies about administrator recruitment despite the call by Pounder and Young (1996) for researchers to conduct such investigations. This study focuses on the potential attraction of teachers to a career as school counselor and is a tentative step towards filling 
the above gap in the educational administration literature. The researcher conducted this research by implementing a field survey, with teachers working at 15 schools in JCPS serving as the study participants. The data analysis, using descriptive statistics, independent group mean comparisons, paired t-tests, hierarchical multiple regression analysis, and open-ended question responses have implications for administrative practice and future research.

\section{Administrative Practice}

The intent of addressing the purpose and research questions described in Chapter I was to provide information to administrators and researchers about the degree of teacher attraction to a career as school counselor. The job of teacher is the position immediately preceding the job of counselor in that school counselors in JCPS must have teaching experience and counselor certification prior to assuming a job as school counselor. The data described in Chapter IV provide insights relative to the job of school counselor that may be useful in constructing recruitment practices that are attractive to teachers or restructuring the job of school counselor to make counseling a more attractive career option for teachers. The practical 
implications follow according to the procedure used to analyze the data.

\section{Descriptive Statistics}

Teacher surveys provided data to evaluate $\mathrm{k}-12$ public school teacher satisfaction with job facets in their current position compared to expected satisfaction with the same job facets in the position of school counselor. The teacher surveys also provided data to determine which demographic variables and counselor job facets are the most salient predictors of teacher rating of a school counselor position. Descriptive statistics show that the participants had a mean age of 40.9 , had a population comprised of $30.9 \%$ male and $69.1 \%$ female, had a mean number of one dependent child, had an ethnicity population of $82.8 \%$ White American, $14.6 \%$ African American, and $1.7 \%$ other. Highest degree earned by participants included: BS/BA (19.2\%), MS/MA (49.9\%), Masters+30 (29.5\%), and Doctorate (1.4\%). Other demographic data included school enrollment, which had a mean of 1,068.5. School assignment included 162 elementary schools teachers (29.5\%), 113 middle school teachers (20.4\%), and 278 high school teachers (50.3\%). The kentucky accountability scores classifications (CATS) were: 89 "in needs of assistance" (16.1\%), 350 "progressing" (63.38), and 
114 "meets goal" (20.6\%). Teacher work experience had a mean of 12.9 years with a mean of 10.4 years in JCPS, and 11.8 years in Kentucky.

The above demographic profile of the teacher participants is consistent with $\mathrm{K}-12$ JCPS teacher demographics. JCPS $\mathrm{K}-12$ teacher demographics includes $85 \%$ White American, 15\% African American, 21\% males, and 79\% females (Greer, 2004). This information indicates the study sample is representative of the teachers in the district and suggests the study results may be generalized to the total population of JCPS teachers.

The principal descriptive data of interest are in Table 4 which contains the frequencies, percentages, means, and standard deviations for the item addressing participant interest in attending a JCPS orientation session for teachers to learn about a career in school counseling. The teacher participants had a mean of 2.8 which is just below the midpoint on the 5-point scale for interest in attending an orientation session. The percentage of participants indicating a four or five on the scale was $36.5 \%$ of the participants, and the percentage of participants indicating a five on the scale was $19.7 \%$

The interest among the study participants in learning 
more about becoming a school counselor appears evident from the data. Given the increasing demand for school counselors and the increasing shortages of school counselors (American School Counseling Association, 1991; Towner-Larsen, Granello \& Sears, 2000), this study indicates a strong interest among a meaningful percentage of teachers with respect to acquiring more information about a career as a school counselor. It appears an orientation session could be a useful counselor recruitment device for JCPS.

Low counselor visibility and role ambiguity contribute to a lack of clarity concerning the job responsibilities and overall profession of a school counselor (Aubrey, 1993). Classroom teachers spend the majority of their day teaching students in the classroom and often have little understanding of the job of a school counselor (Johnson, 2000). In addition, the role of a school counselor has become more complex due to school reform initiatives (Yerkes \& Guaglianone, 1998) such as those occurring in JCPS since the Kentucky Educational Reform Act (KERA) of 1990. With $36.5 \%$ of the participants indicating a four or a five on the scale ("If invited, how likely are you to attend a JCPS orientation session for teachers to learn more about a career in school counseling?"), school districts, such as 
JCPS, may want to include specific information about the roles and responsibilities of a school counselor in this orientation session. Opportunities for interested teachers to learn more about the school counseling profession might include experiences such as discussions and job shadowing experiences with current school counselors.

\section{Group Mean Comparisons}

Analysis of group mean score differences, with the twoitem composite for counselor job rating serving as the dependent variable, were the independent samples t-test and one-way analyses of variance (ANOVA). These analyses indicated that there were no significant group mean differences relative to gender (male, female), school level (elementary, middle, high), or school classification (in needs of assistance, progressing, meets goal). These findings indicate it would not be a useful strategy to target teachers for school counselor job recruitment with respect to gender, school level, or school classification. The one-way ANOVA with the highest degree serving as the independent was significant $(p<.05)$. The mean for participants with a bachelors degree $(M=6.0)$ as the highest degree earned was significantly higher than the mean for participants with masters degree +30 hours $(M=5.1)$ as 
the highest degree earned. The Pearson correlation between age and job rating $(r=-.19)$ was significant $(p<.0001)$ indicating as age increased, the score for job rating decreased. This correlation corresponds with the above highest degree earned data in that job rating decreased as age and credentials increased. These data indicate that teachers who are younger and have only a bachelors degree rate the school counselor job the highest. The practical implication for school districts is that recruitment for school counselors should target teachers who are younger and who do not have advanced degrees. It appears older individuals who are more entrenched in their careers may be less viable for counselor recruitment.

\section{Paired t-Test Results}

Paired t-tests analyzed current teacher job satisfaction and expected job satisfaction as a school counselor. The paired items were the seven job characteristics common to the jobs of teacher and counselor. Statistical significance $(p<.05)$ was found with the first six job characteristics: "The vacation time I have" $(t=$ 19.3), "The time I have to spend with my family" $(t=12.0)$, "Extra income I can earn in the summer" ( $t=3.7)$, "The hours I worked per week" $(t=9.0)$, and "The opportunity to 
experience varied activities on the job" $(t=5.7)$. The one characteristic not significant was "The recognition I receive for doing a good job" $(t=-.6)$. The results indicate that the participants rated their current satisfaction with the six job factors as teachers higher than they did their expected job satisfaction as a school counselor.

The implications of the t-tests relative to recruiting school counselors may be that teachers perceive there will be less vacation time, less family time, and more work hours per week as a school counselor. Currently the work year is 187 days for teachers and 215 days for middle and high school counselors and 195 days for elementary counselors. Teachers work a seven-hour day as compared to counselors who work an eight-hour day. In addition, the counselor job description often does not reflect the local school assignment of counselor job duties. Burnham and Jackson (2000) conducted a study of the actual job practices of school counselors. Those job practices revealed that counselors spend $13 \%$ to $65 \%$ of their day on non-guidance duties including: student records, scheduling, transcript, office sitting, lunchroom supervision, hall and restroom supervision, bus duty, clubs and organization sponsoring, 
athletic supervision, and homeroom supervision (p. 46). These job responsibilities are in addition to the job description as a school counselor and require the counselor to spend more time after the school day and less time for family and vacations.

Teachers also are more satisfied with their current opportunities to earn extra income during the summer than their anticipated satisfaction with that opportunity as a school counselor. Often teachers are employed in various employment opportunities including teaching summer school and writing curricula. Counselors have a longer work year and do not find the same opportunities for employment as teachers. JCPS employs approximately 50 teachers for summer school programs and no counselors ( $\mathrm{P}$. Taylor, personal communication, February 24, 2004). JCPS counselors are paid on a salary schedule IV, grade 9 , teacher salary with an index of 1.056 for beginning counselors (the index increases with years of experience). In kentucky, administrators are paid on teacher salary (where they are on years of experience). The index is multiplied by a teachers daily rate and then multiplied by the number of days worked for a total yearly salary ( $R$. Merrick, personal communication, February 25, 2004). Implications for districts include 
compensation for counselors for additional job responsibilities or a restructuring of those additional responsibilities so that the job is more attractive.

The participants also rated their current satisfaction with experiencing varied activities on the job and serving others higher than their expected satisfaction as a school counselor with those same job factors. Implications for recruiting school counselors might include addressing the previously mentioned counselor role ambiguity and low visibility found in schools. With the diversity of responsibilities assigned to the school counselor, there exists no clear-cut sense of a counselor job description (Aubrey, 1993). Defining the counselor's job and ensuring that building principals do not infringe on that job description by adding additional duties should be considered as a district policy.

\section{Hierarchical Multiple Regression}

Hierarchical multiple regression analysis examined the control variables, predictor variables, and dependent variable. The dependent variable was the composite score for participant rating of a counselor job description. The researcher entered an average composite rating of the current job satisfaction items as an additional control 
variable.

The results of the hierarchical multiple regression analysis (See Table 9) indicated that one control variable and four predictor variables explained significant variance in the dependent variable (job rating of a school counselor). The standardized regression coefficients ( $\beta$ ) determined the relative contribution of significant independent variables for explaining the variance in ratings of a school counselor job. JCPS experience explained significant variance in the dependent variable (counselor job rating) when controlling for the effects of the other control variables. It was a negative coefficient indicating that as teaching experience in JCPS increased, participant rating of a counselor job decreased. Teachers who are more experienced have less attraction to a job as a school counselor. This is useful information for recruitment of administrators in that it assists recruiters in identifying a specific group of teachers who might be interested in a career as a school counselor.

In Step 2, four predictor variables had a statistically significant impact on counselor job rating. "The involvement with special education paperwork", "The opportunity for me to perform administrative duties", "The 
time I would spend in support of testing and assessment programs", and "The opportunity to provide counseling and mentoring to students" were the predictor variables that explained significant variance in the dependent variable (counselor job rating) when controlling for the effects of other independent variables. The combination of the above variables explained $35 \%$ of the variance in the dependent variable (job rating) which is a large effect size (Cohen, 1988) .

The knowledge of how teachers scored on these variables appears to be highly useful in identifying teachers who are most interested in a career as a school counselor. With this information, districts, such as JCPS, might design school counselor recruitment media and orientation sessions which promote these variables to attract teachers to the job of a school counselor. "The opportunity to provide counseling and mentoring to students" $(\beta=.23, p<.001)$ was one of two variables which explained the most variance in the dependent variable (job rating). This information identifies teaching and mentoring students as a job factor which is most important to teachers in considering a career as a school counselor.

"The opportunity for me to perform administrative 
duties" $(\beta=.23, p=.0001)$ was the other job factor which explained the most variance in the dependent variable (job rating). This information suggests that teachers are attracted to a career as a school counselor because it affords them the opportunity to perform administrative duties. JCPS classifies the job of a counselor as a school administrator; however, research indicates that the role of a school counselor remains undefined (Sink \& Stroh, 2003) and school counselors are often unable to join the administrative leadership team because they are burdened with paperwork, clerical record keeping, student supervision, and testing responsibilities (McCormick, 2003). Dollarhide (2003) suggests the context of counseling leadership should emphasize building comprehensive counseling programs, having opportunities to be visible and accessible, and being politically astute so that the mission of the school is communicated to stakeholders. This research might provide a focus for profiling the job of school counselor to have administrative and leadership opportunities in the school.

"The time I would spend in support of testing and assessment programs" $(\beta=.15, p<.001)$ was significant indicting that teachers are in support of student assessment 
programs. This would seem that to indicate that teachers support assessment activities even though the above research identifies the burden of testing responsibilities is a barrier for counselor job attractiveness. This might suggest that leadership of assessment programs could attract teachers to consider a career as a school counselor as long as there was sufficient support for relief from test administration and clerical responsibilities. Open-Ended Questions

Teachers across all school levels (elementary, middle, high) consistently identified the responsibilities of providing counseling services to students as the most rewarding aspects of working as a school counselor. Based on the responses to the first open-ended question, JCPS recruiters should consider emphasizing in their recruitment media the National Counselor Standards (ASCA, 1996), which shape the Jefferson County Comprehensive Guidance Program Standards (JCPS, 2000). These standards are designed to support students in three areas of skill development: academic, career, and personal/social. Teachers identified specific rewards to the job of a school counselor from the descriptors of each of these skill development areas. JCPS recruiters should emphasize such counselor job 
responsibilities as: assisting students in acquiring skills to be successful in school careers, or life; providing students with an understanding of the connection between school and the world of work and family; and helping students to set goals and to achieve those goals. In addition to recruitment media designed from these job responsibilities, orientation sessions to learn more about a school counselor job should emphasize these skill development standards so as to recruit prospective counselors.

In a similar manner to the first question, teachers across all school levels (elementary, middle, high) frequently identified the same greatest barriers preventing them from considering a career as a school counselor. Those barriers included excessive paperwork, additional work hours, lack of time spent counseling students, and time/expense required to earn a counseling certification. In addition, teachers responded to the third question requesting recommendations to make the profession of school counseling more attractive to teachers by removing the barriers identified in the second question.

JCPS recruitment administrators might want to consider a central office guidance leadership program which educates 
building principals in defining the role and responsibilities of a school counselor based on the JCPS and National Counseling Standards. In a school system undergoing state mandated reform with school accountability for student success, leadership from school counseling programs could increase student and school success. Counseling programs could meet the needs of increasing numbers of at-risk students and of students who do not meet basic academic performance standards. However, barriers of excessive paperwork and non-guidance activities prevent counselors from adequately providing services to students in a reform environment. The school counselor role should be transformed to one of providing student services based on counseling standards in order to attract qualified teachers to the counseling profession.

\section{Future Research}

As noted in the Theoretical Framework section of Chapter III, the framing device for this study was the Rynes and Barber (1990) applicant attraction model. This model hypothesizes that job vacancy characteristics are among the most salient influences on applicant outcomes such as the number and quality of job applicants attracted to the position vacancy. Researchers using the Rynes and Barber 
(1990) model as a framing device follow the directionality of variable relationships suggested by the model by casting vacancy characteristics (i.e., job facets) as independent variables hypothesized to impact measures of applicant outcomes cast as a dependent variable in the analysis. In this research, job facets were independent variables in a multiple regression analysis with job rating cast as the dependent variable. The composite dependent variable measure consisted of two ratings of applicant outcomes: likelihood of accepting an interview for the job and likelihood of accepting the job if offered. As discussed above, this approach rendered significant findings. The recommendation following from this result is that researchers studying the school counselor recruitment context should continue using the Rynes and Barber model (1990) as a framing device.

This study addressed the attraction of teachers to a career as a school counselor. Researchers have yet to cast the position of practicing counselor as the focal position in recruitment investigations. Future studies might cast practicing counselors in the role of simulated applicants for position vacancies to determine factors that make the job attractive or unattractive as a means of improving 
school counselor recruitment strategies and restructuring the job to make it more attractive to potential job applicants or individuals already in the job.

The use of the recruitment simulation technique (Rynes \& Lawler, 1983; Rynes \& Miller, 1983; Young \& Heneman, 1986; Young et al., 1989; Young et al., 1993; Young et al., 1997) in this study also rendered a significant result. The recommendation emanating from this success is that researchers continue the use of the recruitment simulation method in education studies.

Future research might also investigate the extent to which principals define counselor job responsibilities of a nonguidance nature. In this study site, the school system adopted the ASCA standards and specified a job description. However in practice, counselors are required to perform nonguidance responsibilities not in their job descriptions or reflected in the counselor standards. Teacher perceptions of these nonguidance responsibilities are identified in this study as barriers to a job as a school counselor. Additional research might also explore the possibility of increasing counselor job satisfaction by implementing electronic systems to reduce clerical tasks and paperwork. To increase teachers entering certification 
programs, there is a need for future research in the

alignment of the counselor certification process, district and state expectations for counselor certification, and university admission standards and program requirements for counselor certification.

Conclusion

This is the first empirical study about counselor recruitment. The purpose of this study was to address factors that may influence teacher attraction to a career as a school counselor. The three objectives for this study were met, and information from this research study could assist school districts in attracting quality teachers to a career as a school counselor.

The first objective was to determine if teachers differed in their ratings of a counselor position with respect to their demographic characteristics. The only significant demographic variable was JCPS years of teaching experience. The more years of JCPS teaching experience a participant had, the less interested the teacher had in considering a job as a school counselor. School districts might consider this information as recruitment administrators design counselor recruitment media to attract less experienced teachers. Although less tenure is usually 
associated with age, it cannot be assumed as so in this study. Age was not a significant demographic variable in the regression analysis indicating that teachers who enter the teaching profession in JCPS years later than a teacher who enters in their early twenties might be interested in a career as a school counselor. Designing recruitment media and counselor orientation sessions which consider JCPS years of experience as a factor in recruitment could attract potential applicants for a school counseling job.

The second objective was to evaluate $\mathrm{K}-12$ public school teachers' satisfaction with job facets in their current teaching position compared to expected satisfaction with the same job facets in the position of school counselor.

Teachers rated satisfaction in their current job higher than expected satisfaction in the job of school counselor on the first six variables: vacation time, time with family, summer income, hours per week, varied activities, and opportunities to serve others. Recognition for doing a good job was not significant.

This information could be very beneficial for school districts due to the perceptions of teachers about the job of a school counselor. Teachers may be discouraged from pursuing counselor certification or attending an orientation 
session to find out more information on the job of a school counselor if they perceive counselor job facets less attractive than those same job facets in their current position as a teacher. This information combined with the teacher identifications of barriers/recommendations in the open-ended questions indicates a teacher perception of the role of the school counselor to be one that is not attractive.

School districts should improve this image of the counseling job by aligning the job responsibilities with the national standards. Non-guidance job responsibilities assigned by principals interfere with counseling services to students. In a reform environment, schools need counselors to provide the leadership necessary to school reform efforts (Hughley, 2001). When counselors are burdened with noncounseling responsibilities, they are unable to provide leadership to student academic achievement (McCormick, 2003). In the open-ended questions, teachers indicated that the greatest attraction to a career as a school counselor is providing counseling services to students. That perception should be a reality in the schools if districts are going to attract quality teachers from the classroom to the counselor's office. 
The third objective was to determine which teacher demographic variables (control variables) and counselor job facets (predictor variables) are the most salient predictors of teacher rating of a school counselor position. The four predictor variables of significance were ECE Paperwork, Administration/Testing/Assessment and Counsel/Mentor. These detected factors identified from the teachers surveyed would be useful in designing recruitment media and orientation sessions. This information should also be considered in the district's review of the school counselor's job responsibilities. The responses to the open-ended questions support these data in that teachers perceive the job of school counselor as rewarding when they have the opportunity to provide counseling and mentoring to students. Rated as significant as counseling students was the job factor opportunity for teachers to perform administrative duties as counselors. This has potential implications for the role of counselors in leadership to school reform initiatives. If the school counselor is to be responsible for student academic achievement, then counselors should have opportunities to develop programs based on ASCA standards. If the role of the counselor is to remove institutional and environmental barriers (Stone, 2003) so that students will 
achieve academic, personal, and social success, then counselors should have the opportunity to focus on counseling programs. JCPS might consider directing principals to focus counseling job responsibilities on student services and to reduce the assignment of nonguidance responsibilities.

The task of investigating potential applicants for school counselor positions has barely begun. This study demonstrates the utility of the simulation technique and the use of existing recruitment models as framing devices. It is hoped other researchers will use the research approaches demonstrated in this study to expand the body of knowledge about counselor recruitment. The demand for school counselors is expected to increase more than any other occupation by the year 2005 (The Bureau of Labor Statistics, 1996). With the projected increase in the need for school Counselors (Towner-Larsen, Franello, \& Sears, 2000), school districts must address the recruitment practices and job responsibilities of school counselors if schools are to adequately meet the demands. Counselors are essential to the delivery of a quality educational program, and research about counselor recruitment deserves far greater research attention than currently exits. 


\section{REFERENCES}

Adkins, C. L., Russell, C. J., \& Werbel, J. D. (1994). Judgments of fit in the selection process: The role of work value congruence. Personnel Psychology, 47, 605623.

Alderfer, C. P., \& McCord, C. G. (1970). Personal and situational factors in the recruitment interview. Journal of Applied Psychology, 54, 337-385.

Aubrey, R. F. (1993). Excellence, school reform, and counselors. In J. Carlson \& J. Lewis (Eds.), Counseling the adolescent: Individuals, family, and school interventions ( $2^{\text {nd }}$ ed.) (pp. 221-236). Denver, CO: Love Publishing.

Barber, A., E. (1998). Recruiting employees: Individual and organizational perspectives. Thousand Oaks, CA: Sage Publications.

Behling, O., Labovitz, G., \& Gainer, M. (1968). College Recruiting: A theoretical base. Personnel Journal, 47, $13-19$.

Berlo, D. K., Lemmert, J. B., and Mertz, R. J. (1969). Dimensions for evaluating the acceptability of message sources. Public Opinion Quarterly, 33, 563-576.

Breaugh, J. A. (1981). Relationships between recruiting sources and employee performance, absenteeism, and work attitudes. Academy of Management Journal, 24, 4227 . 
Breaugh, J. A. (1983). Realistic Job Previews: A critical appraisal and future research directions. Academy of Management Review, 8, 612-619.

Breaugh, J. A., \& Mann, R. B. (1984). Recruiting source effects: A test of two alternative explanations. Journal of Occupational Psychology, 57, 261-267.

Bretz, R. D., Jr., Rynes, S. L., \& Gerhart, B. (1993). Recruiter perceptions of applicant fit: Implications for individual career preparation and job search behavior. Journal of Vocational Behavior, 43, 310327 .

Byrne, D. (1971). The attraction paradigm. New York: Academic Press.

Bureau of Labor Statistics. (1996). Occupations that have it all: High earnings, fast growth, and large numbers of openings. Occupational Outlook Quarterly, 48.

Burnam, J. J. \& Jackson, C. M. (2000). School Counselor roles: Discrepancies between actual practice and existing models. Professional School Counseling, 4, 41-49.

Cable, D. M., \& Judge, T. A. (1996). Person-organization fit, job choice decisions, and organizational entry. Organizational Behavior and Human Decision Processes, $67,294-311$.

Caldwel1, D. F., \& Spivey, W. A. (1983). The relationship between recruiting source and employee success: An analysis by race. Personnel Psychology, 36, 67-72. 
Campbell, D. T., \& Stanley, J. C. (1963). Experimental and quasi-experimental designs for research. Chicago: McNally.

Cohen, J., \& Cohen, P. (1983). Applied multiple regression/correlation analysis for the behavioral sciences. Hillsdale, N.J: Lawrence Erlbaum.

Costa, P. T., Jr., \& McCrae, R. R. (1992). Revised NEO personality inventory (NEO-PI-R) and NEO five-factor (NEO-FFI) inventory professional manual. Odessa, FL: PAR.

Cranny, C. J., Smith, P. C., \& Stone, E. F. (1992) Job satisfaction: How people feel about their jobs and how it affects their performance. New York: Lexington Books.

Davis, R. E., \& Craig, L. (1986). Recruiting for school counselor preparation programs. Paper presented at The Annual Meeting of the Southern Association of Counselor Education and Supervision.

Decker, P. J., \& Cornelius, E. T. III (1979). A note on recruiting sources and job survival rates. Journal of Applied Psychology, 64, 463-464.

Dollarhide, C. T. (2003). School counselors as program leaders: Applying leadership contexts to school counseling. Professional School Counseling, 6, 304308 .

Dugoni, B. L., \& Ilgen, D. R. (1981). Realistic job previews and adjustment of new employees. Academy of Management Journal, 24, 579-591.

Eckels, W. (2002). Human Resources Manual. Jefferson County Public Schools, Louisville, KY. 
Education Trust. (2001). Transforming school Counseling. retrieved March 2, 2001 from

http://www. edtrust.org/main/ school-counseling. Asp

Edwards, A. L. (1985). Multiple regression and the analysis of covariance. New York: W. H. Freeman and Company.

Fischer, C. D., Ilgen, D. R., \& Hoyer, W. D. (1979). Source credibility, information favorability, and job offer acceptance. Academy of Management Journal, 22, 94103.

Freeman, R. A., \& Carpenter, R. (1983). RN recruitment advertisements: An experimental study of nurses' responses to ad content. Journal of Health Care Marketing, 3, 7-12.

Good, G. E. (1992). New and early professionals: Observations and implications. The Counseling Psychologist, 82-88.

Guion, R. M. (1976). Recruiting, selection, and job placement. In M. D. Dunnette (Ed.), Handbook of industrial and organizational psychology. Chicago: Rand McNally.

Gannon, M. J. (1971). Sources of referral and employee turnover. Journal of Applied Psychology, 55, 226-228.

Goldberg, L. R. (1990). An alternative "description of personality": The Big-Five factor structure. Journal of Personality and Social Psychology, 59, 1216-1229.

Harn, T. J., \& Thorton, G. C. III. (1985). Recruitercounseling behaviors and applicant impressions. Journal of Occupational Psychology, 58, 57-65. 
Harris, M. M., \& Fink, L. S. (1987). A field study of applicant reactions to employment opportunities: Does the recruiter make a difference? Personnel Psychology, 40, 765-784.

Herriot, P., \& Rothwell, C. (1981). Organizational choice and decision theory: Effects of employers' literature and selection interview. Journal of Occupational Psychology, 54, 17-31.

Howley, A., Pendarvis, E. (2002). Recruiting and retaining rural school administrators. Office of Education Research and Improvement. (ERIC Document Reproduction Service No. EDO-RC-02-7)

Howley, A., \& Pendarvis, E., \& Gibbs, T. (2002). Attracting principals to the superintendency: Conditions that make a difference to principals. Education Policy Analysis Archives, 10, 1-18.

Hudson, M. J. (1991). How educators get top jobs: Understanding race and sex differences in the old boy network. Lanham, MD: University Press of America.

Hudson, M. J. (1994). Women and minorities in school administration: Re-examining the role of informal job contact systems. Urban Education, 28, 386-398.

Hughey, K. F. (2001). Effective leadership: Lessons from football and business. Professional School Counseling, 4(5), ii-iii.

Hulin, C. L., Roznowski, M., \& Hachiya, D. (1985).

Alternative opportunities and withdrawal decisions: Empirical and Theoretical discrepancies and an integration. Psychological Bulletin, 97, 233-250. 
Jefferson County Public Schools. (2000). Kindergarten through grade twelve comprehensive guidance program. [brochure\}. Louisville, KY.

Johnson, L. S. (2000). Promoting professional identity in an era of education reform. Professional School Counseling, 4, 31-40.

Judge, T. A., \& Bretz, R. D., Jr. (1992) Effects of work values on job choice decision: Journal of Applied Psychology, 77, (3) 261-271.

Judge, T. A., \& Cable, D. M. (1997). Applicant personality, organizational culture, and organization attraction. Personnel Psychology, 50, 359-394.

Kentucky Department of Education. (1996). Experienced and new counselor standards. [brochure]. Frankfort, KY.

Klaus, J. (2003). High School guidance counselors. The Catalyst, 3, 1-3.

Legislative Research Commission. (1994). The Kentucky Education Reform Act. [pamphlet].

Liden, R. C., \& Parsons, C. K. (1986). A field study of job applicant interview perceptions, alternative opportunities, and demographic characteristics. Personnel Psychology, 39, 109-122.

Locke, E. A. (1976). The nature and causes of job satisfaction. In M. D. Dunnette, (Ed.), Handbook of industrial and organizational psychology (pp. 12971349). Chicago: Rand McNally.

McCormick, P. (2003). Opening windows. High School Counselor, p. 6-9. 
Matier, M. W. (1991). Recruiting faculty: Complementary tales from two campuses. Research in Higher Education, $32,31-44$.

Mauer, S. D., Howe, V., \& Lee, T. W. (1992). Organizational recruiting as marketing management: An interdisciplinary study of engineering graduates. Personnel Psychology, 45, 807-833.

Meglino, B. M., Ravlin, E. C., \& DeNishi, A. S. (1997). When does it hurt to tell the truth? The effect of realistic job reviews on employee recruiting. Public Personnel Management, 26, 413-422.

National Association of Elementary School Principals and National Association of Secondary School Principals. (1998). Is there a shortage of qualified candidates for openings in the principalship? Educational Research Service.

Nunnally, J. C., \& Bernstein, I. H. (1994). Psychometric Theory ( $3^{\text {rd }}$ ed.). New York: McGraw-Hill.

O'Reilly, C. A., III, Chatman, J. A., \& Caldwell, D. F. (1991). People and organizational culture: A profile comparison approach to assessing person-organization fit. Academy of Management Journal, 34, 487-516.

Paisley, P. O., \& McMahon, G. (2001). School counseling for the $21^{\text {st }}$ century: Challenges and opportunities. Professional School Counseling, 5, 106-114.

Pérusse, R., Goodnough, G. E., \& Noel, C. J. (2001). Professional School Counseling, 5, 49-55. 
Portman, T. A. (2002). "The opportunity was there!" A qualitative study of early-entrant school counselors. Professional School Counseling, 5, 61-69.

Pounder, D. G., \& Young, I. P. (1996). Recruitment and selection of educational administrators: Priorities for today's schools. In $\mathrm{K}$. Leithwood (Ed.), A. W. Hart (Section Ed.), The International Handbook of Educational Leadership (pp. 279-308). Netherlands: Kluwer.

Powell, G. N. (1984). Effects of job attributes and recruiting practices on applicant decisions: A comparison. Personnel Psychology, 37(4), 721-732.

Powell, G. N. (1996). Recruiters' and applicants' awareness of the other party's postinterview evaluations. Psychological Reports, 79(3), 1363-1369.

Quaglieri, P. L. (1982). A note on variations in recruiting information obtained through different sources. Journal of Occupational Psychology, 55, 53-55.

Ravlin, E. C., \& Meglino, B. M. (1987). Effects of values on perception and decision making: A study of alternative work values measures. Journal of Applied Psychology, 72, 666-673.

Reilly, R. R., Brown, B., Blood, M. R., \& Malatesta, C. Z. (1981). The effects of realistic previews: A study and discussion of the literature. Personnel Psychology, 34(4), 823-834.

Reilly, R. R., Tenopry, M. L., \& Sperling, S. M. (1979). Effects of job previews on job acceptance and survival of telephone operator candidates. Journal of Applied Psychology, 64, 218-220. 
Rogers, D. P., \& Sincoff, M. Z. (1978). Favorable impression characteristics of the recruitment interviewer. Personnel Psychology, 32, 495-504.

Rynes, S. L. (1991). Recruitment, job choice, and posthire consequences: A call for new research directions. In M. D. Dunnett and L. Hough (Eds.), Handbook of Industrial and Organizational Psychology $\left(2^{\text {nd }}\right.$ ed., pp. 399-444). Palo Alto, CA: Consulting Psychologist Press.

Rynes, S. L., \& Barber, A. E. (1990). Applicant attraction strategies: An organizational perspective. Academy of Management Review, 15, 286-310.

Rynes, S. L., \& Gerhart, B. (1990). Interviewer assessments of applicant "fit": An exploratory investigation. Personnel Psychology, 43, 13-35.

Rynes, S. L., Heneman, H. G., III, \& Schwab, D. P. (1980). Individual reactions to organizational recruiting: A review. Personnel Psychology, 33, 529-542.

Rynes, S. L., \& Lawler, J. (1983). A policy-capturing investigation of the role of expectancies in decisions to pursue job alternatives. Journal of Applied Psychology, 68, 620-631.

Rynes, S. L., \& Miller, H. E. (1983). Recruiter and job influences on candidates for employment. Journal of Applied Psychology, 68, 147-154.

Scheel, M. J. (2003). Proposal for the transformation of the school counselor training program. Counseling Psychology, 1-4 from http: //tc.unl.edu/counselorpsych/proposal.html 
Schmitt, N., \& Coyle, B. W. (1976). Applicant decisions in the employment interview. Journal of Applied Psychology, 61, 184-192.

School Counselors: Emerging Vanguards of Student Safety and Success. Policy Services (2000) from http://www.ael.org/rel/policy/coun2000.htm

Schwab, D. P. (1982). Recruiting and organizational participation. In K. Rowland and G. Ferris (Eds.), Personnel Management (pp. 103-128). Boston: Allyn and Bacon.

Schwab, D. P., Rynes, S. L., \& Aldag, R. J. (1987). Theories and research on job search and choice. Research in Personnel and Human Resources Management, $5,129-166$.

Schwab, R. (2001). Testimony of Richard Schwab, Dean of the Neag School of Education. Retrieved from http: //www. govrel. unconn. edu/educat01.htm

Sheskin, D. J. (1997). Handbook of parametric and nonparametric statistical procedures. New York: CRC Press.

Sink, C. A., \& Stroh, H. R. (2003). Raising achievement test scores of early elementary school students through comprehensive school counseling programs. Professional School Counseling, 6, 350-363.

Smith, P. C., Kendall, L. M., \& Hulin, C. L. (1969). The measurement of satisfaction in work and retirement: $A$ strategy for the study of attitudes. Chicago: Rand McNally. 
Smither, J. W., Reilly, R. R., Millsap, R. E., Pearlman, K., \& Stoffey, R. W. (1993). Applicant reactions to selection procedures. Personnel Psychology, 46, 4976.

Stevens, J. (1992). Applied multivariate statistics for the social sciences. ( $2^{\text {nd }}$ ed.). Hillsdale, NJ: Lawrence Erlbaum Associates.

Stone, C. (2003). The new counselor: agent of change. The College Board Review, 199, 45-47.

Swaroff, P. G., Bass, A. R., \& Barclay, L. A. (1985). Recruiting Sources: Another look. Journal of Applied Psychology, 70, 720-728.

Taylor, M. S., \& Bergmann, T. J. (1987). Organizational recruitment activities and applicants' reactions at different stages of the recruitment process. Personnel Psychology, 40, 261-285.

Taylor, M. S., \& Schmidt, D. W. (1983). A process-oriented investigation of recruitment source effectiveness. Personnel Psychology, 36, 343-354.

Tirozzi, G. (2001). More Minorities needed to head schools. NASSP Bulletin, 33(5), 13-14.

Towner-Larsen, R., Granello, D. H., \& Sears, S. J. (2000). Supply and demand for school counselors: Perceptions of public school administrators. Professional school Counseling, 3, 270-276.

Ullman, J. C. (1966). Employee referrals: prime tool for recruiting workers. Personnel, 43, 30-35. 
Vandenberg, R. J., \& Scarpello, V. (1990). The matching model: An examination of the processes underlying realistic job previews. Journal of Applied Psychology, 75, 60-67.

Vroom, V. H. (1964). Work and motivation. New York: Wiley.

Wanous, J. P. (1973). Effects of a realistic job preview on job acceptance, job attitudes, and job survival. Journal of Applied Psychology, 58, 327-332.

Wanous, J. P. (1974). Individual differences and reactions to job characteristics. Journal of Applied Psychology, $59,616-622$.

Wanous, J. P. (1975). Tell it like it is at realistic job previews. Personnel, 52, 50-60.

Wanous, J. P. (1976). Organizational entry: From naïve expectations to realistic beliefs. Journal of Applied Psychology, 61, 22-29.

Wanous, J. P. (1977). Organizational entry: Newcomers moving from outside to inside. Psychological Bulletin, 84, 601-618.

Wanous, J. P. (1978). Realistic job previews: Can a procedure to reduce turnover also influence the relationship between abilities and performance? Personnel Psychology, 31, 249-258.

Wanous, J. P. (1980). Organizational entry: Recruitment, selection, and socialization of newcomers. Reading, MA: Addison-Wesley.

Weitz, J. (1956). Job expectancy and survival. Journal of Applied Psychology, 40, 245-247. 
Whiston, S. C. (2002). Response to the past, present, and future school counseling: Raising some issues. Professional School Counseling, 5, 148-155.

Whitaker, K. (2001). Where are the principal candidates? Perceptions of superintendents. NASSP Bulletin, $85(625), 82-92$.

Wiggins, J. D. (1984). Personality-environmental factors related to job satisfaction of school counselors. The Vocational Guidance Quarterly, 169-177.

Winter, P. A. (1996). Recruiting experienced educators: A model and a test. Journal of Research and Development in Education, 29, 163-171.

Winter, P. A. (1998). Community college faculty recruitment practices: The effects of applicant sex, instructional programs, and job attributes. Community College Journal of Research and Practice, 22, 187-201.

Winter, P. A., \& Dunaway, D. M. (1997). Reactions of teachers, as applicants, to principal recruitment practices in a reform environment: The effects of job attributes, job information source, and school level. Journal of Research and Development in Education, 30, 144-153.

Winter, P. A., \& Kjorlien, C. L. (2000). Community college faculty recruitment: Predictors of applicant attraction to faculty positions. Community college Review, 28(1), 23-40.

Winter, P. A., \& Morganthal, J. R. (2002). Principal recruitment in a reform environment: effects of school achievement and school level on applicant attraction to the job. Educational Administration Quarterly, 38, 319-340. 
Winter, P. A., \& Muñoz, M. A. (2001). Community college business faculty recruitment: Association between personal characteristics and applicants' ratings of the job. Community College Journal of Research and Practice, 25, 639-651.

Winter, P. A., Rinehart, J. S., \& Muñoz, M. A. (2002). Principal recruitment: An empirical evaluation of a school district's internal pool of principal certified personnel. Journal of Personnel Evaluation, 16, 129 141.

Yerkes, D. M. \& Guaglianone, C. L. (1998). Where have all the high school administrators gone? Thrust for Educational Leadership, 10-14.

Young, I. P., Galloway, C. M., \& Rinehart, J. (1990). The effects of recruitment brochure content and gender of the reactor for doctoral programs in educational administration. Educational Administration Quarterly, $26,168-182$.

Young, I. P., \& Heneman, H. G., III. (1986). Predictors of interviewee reactions to the selection interview. Journal of Research and Development in Education, 19, $29-36$.

Young, I. P., Place, A. W., Rinehart, J. S., Jury, J. C., \& Baits, D. F. (1997). Teacher recruitment: A test of the similarity-attraction hypothesis for race and sex. Educational Administration Quarterly, 33, 86-106.

Young, I. P., Rinehart, J. S. \& Henneman, H. G. III (1993). Effects of job attributes categories, applicant job experience, and recruiter sex on applicant job attractiveness ratings. Journal of Personnel Evaluation in Education, 55-66. 
Young, I. P., Rinehart, J. S., \& Place, W. (1989). Theories for teacher selection: Objective, subjective and critical contact. Teaching and Teacher Education, 5, $329-336$.

Zaharia, E. S., \& Baumeister, A. A. (1981). Job preview effects during the critical initial employment period. Journal of Applied Psychological, 66, 19-22. 


\section{SCHOOL COUNSELOR SURVEY \\ Preamble}

You are being invited to answer the attached questionnaire designed to provide information about a career in school counseling. This study is being conducted by Dr. Paul A. Winter and Beverly Keepers, and is sponsored by the Department of Leadership, Foundations, and Human Resource Education at the University of Louisville and Jefferson County Public Schools.

Your participation in this study is voluntary. If you agree to participate, you will complete this survey questionnaire. The survey should take approximately 15 minutes to complete. You may decline to answer any questions. There are no risks or benefits for your participation; however, the knowledge gained may benefit school counselors and help promote the career of school counselors. The information you provide will be used to examine the impact of various factors related to school counseling that may contribute to individuals entering or leaving the profession.

Your completed survey will be stored at the Department of Leadership, Foundations, and Human Resource Education. Individuals from the Department of Leadership, Foundations, and Human Resource Education and the Human Studies Committee may inspect these records. In all other respects, however, the data will be held in confidence to the extent permitted by law. Should the data be published, your identity and the identity of your institution will not be disclosed.

Please remember that your participation in this study is voluntary. By completing this questionnaire, you are voluntarily agreeing to participate and are acknowledging that all your present questions have been answered in language you can understand and all future questions will be treated in the same manner. You may decline to participate without being subject to any penalty or losing benefits to which you are otherwise entitled.

If you have any questions about this study, you may contact the principal investigator, Dr. Paul A. Winter, at (502) 852-0617. If you have any questions about your rights as a research participant, you can contact the University Human Studies Committees at (502) 852-5188. You will be given the opportunity to discuss any questions about your rights as a research participant, in confidence, with a member of the committees. These are independent committees composed of members of the University community, staff of the institutions, as well as, lay members of the community not connected with these institutions. The Committee has reviewed this study. Thank you for considering this request for your assistance.

Sincerely,

Paul A. Winter

Beverly C. Keepers 
INSTRUCTIONS: Please check or provide the below information that applies best to you. Your responses are anonymous and confidential.

\section{DEMOGRAPHIC DATA}

Your Age in Years:

Your Gender: Male Female

Number of Dependent Children

Ethnicity:
African-American
White American
Asian American
Native American
Hispanic American
Other (Please Specify)

\section{Education:}

Highest Degree Earned:

$\mathrm{BS} / \mathrm{BA}$ MS/MA Masters +30 hours Doctorate

Area of Teaching Certification (College Major)

\section{Current Job:}

Approximate Enrollment of Your School

Current School Assignment:

Elementary Middle School High School

Your school's classification based on the most recent CATS results:

In Need of Assistance Progressing Meets Goal

\section{Work Experience:}

Years of Teaching Experience

Years of Teaching Experience in JCPS

Please continue on to next page. 


\section{COUNSELOR JOB DUTIES}

A list of general school counselor job duties appears below. Please use the rating scales to indicate your interest in performing the counselor duties described below. The scales range from a low of 1 (Not at all Interested) to a high of 5 (Very Interested). Please circle the number which best indicates your interest.

\section{In considering a career in school counseling, I would rate my interest in performing the following duties as:}

\section{Academic Development Job Duties}

1. Assist students to acquire skills that contribute to effective learning in and out of school. ............

2. Aid students in completing school with the knowledge needed to pursue post-high school options, including college........

3. Inform students about the relationship between academics and the world of work, home, and community. .

\section{Career Development Job Duties}

4. Help students acquire the ability to make informed decisions about the world of work..............

5. Aid students in developing strategies to achieve future career success. ... .

\section{Not at all}

Interested

\section{Very}

Interested

5

5

45

5

4

5

Please continue on to next page. 


\section{Appendix A}

\section{Counselor Performance Responsibilities}

(a) Elementary School Counselor

1. Plans, implements and evaluates a developmental, preventative guidance program which enhances the school consolidated plan.

2. Provides individual, small group, and classroom guidance and counseling for students, parents, and staff to promote student success in academics, career, and personal/social development.

3. Assumes responsibility for administration of the school in the absence of the Principal.

4. Collaborates with staff to assist the district's compliance with federal, state, and local school mandates.

5. Coordinates and interprets state and district testing programs in the school.

6. Directs the maintenance of the permanent record system and provides such records to parents or legal guardians upon request.

7. Promotes positive school-community relationships through active participation in school and civic organizations and functions. 
8. Coordinates the health programs and services for the local school.

9. Plans for and provides orientation, transition, and school programs information to students, parents, and staff.

10. Coordinates services and programs for the strengthening of parenting skills.

11. Collaborates with staff in placing students in the most appropriate instructional program and classroom setting.

12. Refers to and consults with district, local, and state resources and agencies in order to promote student success.

13. Duties may include performance of health services, for which training will be provided. 14. Performs other duties as assigned by the Principal.

(b) Middle School Counselor

1. Plans, implements, and evaluates a developmental, preventative guidance program which enhances the school consolidated plan.

2. Provides individual, small group and classroom guidance and counseling for students, parents, and 
staff to promote student success in academics, career, and personal/social development.

3. Collaborates with staff on the master schedule and placing students in the most appropriate instructional program and classroom setting.

4. Develops and implements orientation programs for the transition of students from one level/program to another, i.e., elementary to middle and middle to secondary school.

5. Directs the maintenance of the school permanent record system and assists parents, students, and teachers in interpreting record data.

6. Works to improve student attendance by counseling students, contacting parents and making referrals to in-district and outside resources.

7. Collaborates with staff to assist the district's compliance with federal, state and local mandates at the school level.

8. Consults with and provides inservice for parents and teachers regarding student progress, special needs and abilities, and preventive approaches to discipline. 
9. Assists with the referral of students to the district's optional, alternative programs and community agencies.

10. Duties may include performance of health services, for which training will be provided. 11. Performs other duties as assigned by the Principal.

(c) Secondary School Counselor

1. Plans, implements, and evaluates a developmental, preventative guidance

program which enhances the school consolidated plan. 2. Provides individual, small group, and classroom guidance and counseling for students, parents, and staff to promote student success in academics, career, and personal/social development.

3. Registers, orients, and schedules all secondary students into appropriate classes and makes necessary schedule adjustments to meet individual needs. 4. Directs the maintenance of the local school permanent record system and interprets permanent record data to parents, students and teachers.

5. Certifies students' progression towards graduation; e.g., calculates accumulated credits, grade point averages, and class standings; records 
test information and determines promotion and retention decisions.

6. Collaborates with staff to address the district's compliance with federal, state, and local school mandates.

7. Consults with students, parents, and teachers, regarding student progress, special needs and abilities, and preventive and positive approaches to discipline.

8. Works to improve student attendance by counseling students, contacting parents and making referrals to in-district and outside resources.

9. Coordinates and interprets the state and district testing programs in the school.

10. Coordinates the referral of all students to the district's optional, alternative, G.E.D., and Independent Study programs and to community agencies. 11. Provides recommendations to colleges, post-secondary schools, scholarship sources, and employers; assists in the maintenance of the College Entrance Testing Program, and provides scholarship and financial aid information to students. 12. Duties may include performance of health services, for which training will be provided. 
13. Performs other duties as assigned by the Principal. 
Appendix B

Counselor Survey Instrument 
In considering a career in school counseling, I would rate my interest in performing the following duties as:

\section{Not at ali}

6. Give students insights about the

relationship between personal qualities,

education, and the world of work. .....

Personal/Social Development Job Duties

7. Assist students in acquiring interpersonal skills needed to understand and respect self and others. .............

8. Inform students about how to set and achieve goals. ..............

9. Convey insights to students about safety and survival skills. . . . . . . .

\section{Interested}

1
Very Interested

5

\section{OTHER COUNSELOR JOB FACTORS}

INSTRUCTIONS: Please use the scales below to rate your interest in a school counseling career. The scales range from a low of 1 (Not at all Interested) to high of 5 (Very Interested). Please circle the number indicating your response.

At this stage of your career, how would you rate your interest in a career as a school counselor relative to the job duties described below?

Not at All

Interested
Very

Interested

10. The opportunity to participate with others in my school to make important decisions. . . .

Please continue on to next page. 
At this stage of your career, how would you rate your interest in a career as a school counselor relative to the job duties described below?

\section{Not at All}

Interested

11. The involvement with Special Education paperwork. .............

12. The opportunity for me to perform administrative duties. ..........

13. The time I would spend in support of testing and assessment programs. . . . . . . .

14. My involvement to perform health services and to provide health services and training. ...........

15. My involvement in implementing federal, state and local educational mandates. ....

16. The opportunity to provide counseling and mentoring to students. .........
2

2

2

2
Very

Interested

5

5

5

5

5

5

Please continue on to next page. 


\section{CURRENT AND EXPECTED JOB SATISFACTION}

There are two sets of rating scales for the job characteristics described below. The scales range from a low of 1 (Not at All Satisfied) to a high of 5 (Extremely Satisfied). The scales to the left relate to your satisfaction with your current job. The scales to the right relate to your expected job satisfaction if you were to assume a position as a school counselor. Please circle the one number for each scale that reflects your opinion best regarding current and expected job satisfaction.

\section{CURRENT JOB SATISFACTION}

In my current job, I rate my satisfaction with the below job characteristics as...

\section{Job Characteristics}

\section{Not at All \\ Satisfied}

1. The opportunity to use my talents...

2. My salary.......

3. The work climate...

4. The freedom to make my own decisions....

5. The sense of achievement I experience on the job. ..

6. The opportunity to try my own way of doing things.........

$\begin{array}{lllll}1 & 2 & 3 & 4 & 5 \\ 1 & 2 & 3 & 4 & 5 \\ 1 & 2 & 3 & 4 & 5 \\ 1 & 2 & 3 & 4 & 5 \\ 1 & 2 & 3 & 4 & 5\end{array}$

Extremely

Satisfied

\section{EXPECTED COUNSELOR JOB SATISFACTION}

If I were a counselor, I would expect to rate my satisfaction with the below job characteristics as. .

\section{Not at All \\ Satisfied \\ Extremely \\ Satisfied}




\section{CURRENT JOB SATISFACTION}

In my current job, I rate my satisfaction with the below job characteristics as. . .

\section{Job Characteristics}

\section{Not at All \\ Satisfied}

Extremely

Satisfied

7. The vacation time

I have. .......

1

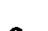

2

8. Income I receive from extra-service pay...

$\begin{array}{lllll}1 & 2 & 3 & 4 & 5\end{array}$

9. The time I have to spend with my family. .

2

$3 \quad 4 \quad 5$

\section{Extra income I can} earn in the summer.

11. My overall job security. ..

12. The hours I work per week.......

13. The opportunity to advance in my career. .......

14. The hours I work per year. . 1

\section{EXPECTED COUNSELOR JOB SATISFACTION}

If I were a counselor, I would expect to rate my satisfaction with the below job characteristics as. . .

$\begin{array}{cc}\text { Not at All } & \begin{array}{c}\text { Extremely } \\ \text { Satisfied }\end{array}\end{array}$

Not at All
Satisfied

Satisfied

$\begin{array}{lllll}1 & 2 & 3 & 4 & 5 \\ 1 & 2 & 3 & 4 & 5 \\ 1 & 2 & 3 & 4 & 5 \\ 1 & 2 & 3 & 4 & 5 \\ 1 & 2 & 3 & 4 & 5 \\ 1 & 2 & 3 & 4 & 5 \\ 1 & 2 & 3 & 4 & 5 \\ 1 & 2 & 3 & 4 & 5\end{array}$

Please continue on to next page. 


\section{CURRENT JOB SATISFACTION}

In my current job, I rate my satisfaction with the below job characteristics as. ..

\section{Job Characteristics}

\section{Not at All}

Satisfied

Extremely

Satisfied

\section{EXPECTED COUNSELOR JOB SATISFACTION}

If I were a counselor, I would expect to rate my satisfaction with the below job characteristics as. . .

$\begin{array}{cc}\text { Not at All } & \text { Extremely } \\ \text { Satisfied } & \text { Satisfied }\end{array}$

15. The opportunity to experience varied activities on the job.........

6. The opportunity to serve others......

17. The way school policies are implemented. . .

18. The opportunity to give directions to students. ......

19. The recognition I receive for doing a good job.....

.

1

$\begin{array}{llll}2 & 3 & 4 & 5\end{array}$

3

4

5

1

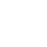

$\begin{array}{llll}2 & 3 & 4 & 5\end{array}$

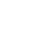




\section{ADDITIONAL QUESTIONS}

Instructions: Please consider the working conditions that generally exist for school counselors and respond to the questions posed below about a career as school counselor.

1. Based on what you know about school counseling, what would you identify as being the most rewarding aspects of working as a school counselor?

2. In your opinion, what are the greatest barriers preventing teachers from considering a career as a school counselor?

3. What recommendations would you give to make the profession of school counseling more attractive to teachers?

Please continue on to next page. 
INSTRUCTIONS: Please read the following job description for a school counselor position and rate the job using the rating scales provided on the following page. Circle the one number on each rating scale that applies best to you. In rating the job, assume you are at a point of time in the future when you have earned counselor certification.

\section{SCOPE OF RESPONSIBILITIES}

The counselor reports to the school principal and is responsible for the development of a guidance program implements district guidance plans. Counselors provide systematic and ongoing individual and group counseling services related to the academic, social, vocational and personal development of students. Counselors provide information, consultation, coordination, testing and referral services to meet the needs of students, parents and staff. The counselor implements federal, state and local educational and title mandates on behalf of the school.

\section{PERFORMANCE RESPONSIBILITIES}

1. Plans, implements and evaluates a developmental, preventative guidance program which enhances the school improvement plan.

2. Provides individual, small group, and classroom guidance and counseling for students, parents, and staff to promote student success in academics, career, and personal/social development.

3. Collaborates with staff to assist the district's compliance with federal, state, and local school mandates.

4. Coordinates and interprets state and district testing programs in the school.

5. Directs the maintenance of the permanent record system and provides such records to parents or legal guardians upon request.

6. Promotes positive school-community relationships through active participation in school and civic organizations and functions.

7. Coordinates the health programs and services for the local school.

8. Provides orientation and school program information to students, parents, and staff for successful transition to the next level of education or career-related services.

9. Coordinates services and programs for strengthening of parenting skills.

10. Collaborates with staff in placing students in the most appropriate instructional program and classroom setting.

11. Refers to and consults with district, local, and state resources and agencies in order to promote student success.

12. Duties may include performance of health services, for which training will be provided.

13. Performs other duties as assigned by the Principal.

\section{MINIMUM QUALIFICATIONS}

1. Master's Degree with major in guidance and counseling

2. Certification in guidance and counseling by the Kentucky Department of Education.

3. Teaching experience 
1. If offered, how likely would you be to accept an interview for school counselor job described?

\author{
Very \\ Unlikely To \\ Accept
}

1

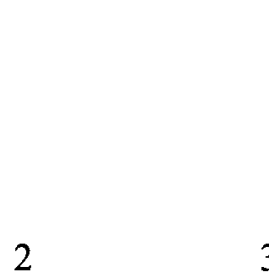

3

4

Very

Likely To

Accept

5

2. If offered, how likely would you be to accept the school counselor job described?

\author{
Very \\ Unlikely To \\ Accept
}

1

2

3

4

3. If invited, how likely are you to attend a JCPS orientation session for teachers to learn about a career in school counseling?

\author{
Very \\ Unlikely To \\ Accept
}

\author{
Very \\ Likely To \\ Accept
}

5 


\section{Appendix C}

\section{Pilot Data Collection Script}

"Good morning colleagues. Thank you for agreeing to participate in this research. This is a pilot to the study designed to test the survey instruments for use in the actual research study. In order to assess the reliability of these instruments, it requires that you complete the instruments twice. I will return on November 4 at 7:30 am, prior to the beginning of your professional development activities, for the second completion. (Start passing out surveys. )

To determine the reliability of these instruments, I will need to match your first responses on the survey taken today with those responses you will give on November 4 . In order to facilitate the matching of responses, I will need an indication of which two surveys match. Therefore, I am asking you to place the last four digits of your social security number in the upper right hand corner of the first page of the survey. Please record those numbers at this time.

Before completing the survey, let's briefly review its contents. The survey begins with a preamble assuring confidentiality and explaining the purpose of the study. Page 2 contains anonymous demographic data. Pages 3-5 ask 
for your ratings of counselor job duties. Pages 6-8 ask for you to rate your current satisfaction with teacher job factors and your expected satisfaction with those same job factors in the job of school counselor. Page 9 has some open-ended questions for your response. Page 10 has a counselor job description and page 11 has items to rate the job described.

Please go back to page 1 and complete the survey. Do not write your name on the instrument as the data is confidential. When you are finished, please hold up the survey and I will collect it. Again, thank you for your participation."

Study Data Collection Script

Good afternoon colleagues. Thank you for agreeing to participate in this research study. I am asking your assistance this afternoon in completing a survey to gain possible insights about the interest of teachers in pursuing a career as school counselors. Participation is anonymous, confidential, and should take only 15 minutes. (Start passing out surveys.)

Before completing the survey, let's briefly review its contents. The survey begins with a preamble assuring confidentiality and explaining the purpose of the study. Page 2 contains anonymous demographic data. Page 3 asks 
for your ratings of counselor job duties. Pages 4-5 ask for you to rate your current satisfaction with teacher job factors and your expected satisfaction with those same job factors in the job of school counselor. Page 6 has some open-ended questions for your response. Page 7 has a counselor job description and page 8 has items to rate the job described.

Please go back to page 1 and complete the survey. Do not write your name on the instrument as the data is confidential. When you are finished, please hold up the survey and I will collect it. Again, thank you for your participation." 


\section{Counselor Job Duties}

(assists students to......)

1. acquire learning skills .20

2. prepare for post-secondary .47

3. know academics and work relationship .14

4. make informed decisions $-10$

5. develop strategies for success .12

6. gain insights/self and work .14

7. acquire interpersonal skills .65

8. set and achieve goals .05

9. learn safety and survival skills .53

\section{Other Job Factors}

1. make important decisions $\quad .73$

2. be involved with Special Education $\quad .68$

3. perform administrative duties $\quad .71$

4. spend time on testing .61

5. perform health services .48

6. implement federal, state, local .48

7. provide counseling, mentoring .64 
Reliability Analysis (continued)

Item Number

Reliability Coefficient

\section{Current Satisfaction}

1. use talents

.72

2. salary .58

3. work climate

4. make decisions

5. sense achievement

6. try own way of doing

7. vacation time

8. income from extra service

9. time with family

10. income earned in summer

11. job security

12. hours worked per week

13. advance in career

14. hours worked per year

15. experience activities on job

16. serve others

17. school policies implementation

18. give direction to students

19. recognition for job well done 
Reliability Analysis (continued)

Item Number

Reliability Coefficient

\section{Expected Satisfaction}

1. use talents

.34

2. salary

.48

3. work climate

.35

4. make decisions

5. sense achievement

6. try own way of doing

.38

7. vacation time

.64

8. income from extra service

9. time with family

10. income earned in summer

11. job security

12. hours worked per week

13. advance in career

14. hours worked per year

15. experience activities on job

16. serve others

17. school policies implementation

18. give direction to students

19. recognition for job well done 
Reliability Analysis (continued)

Item Number

Reliability Coefficient

Job Ratings

1. interview

.64

2. job

.64

\section{Attend Session}

1. orientation session

.76 
Appendix E

Revised Instruments 


\section{SCHOOL COUNSELOR SURVEY}

\section{Preamble}

You are being invited to answer the attached questionnaire designed to provide information about a career in school counseling. This study is being conducted by Dr. Paul A. Winter and Beverly Keepers, and is sponsored by the Department of Leadership, Foundations, and Human Resource Education at the University of Louisville and Jefferson County Public Schools.

Your participation in this study is voluntary. If you agree to participate, you will complete this survey questionnaire. The survey should take approximately 15 minutes to complete. You may decline to answer any questions. There are no risks or benefits for your participation; however, the knowledge gained may benefit school counselors and help promote the career of school counselors. The information you provide will be used to examine the impact of various factors related to school counseling that may contribute to individuals entering or leaving the profession.

Your completed survey will be stored at the Department of Leadership, Foundations, and Human Resource Education. Individuals from the Department of Leadership, Foundations, and Human Resource Education and the Human Studies Committee may inspect these records. In all other respects, however, the data will be held in confidence to the extent permitted by law. Should the data be published, your identity and the identity of your institution will not be disclosed.

Please remember that your participation in this study is voluntary. By completing this questionnaire, you are voluntarily agreeing to participate and are acknowledging that all your present questions have been answered in language you can understand and all future questions will be treated in the same manner. You may decline to participate without being subject to any penalty or losing benefits to which you are otherwise entitled.

If you have any questions about this study, you may contact the principal investigator, Dr. Paul A. Winter, at (502) 852-0617. If you have any questions about your rights as a research participant, you can contact the University Human Studies Committees at (502) 852-5188. You will be given the opportunity to discuss any questions about your rights as a research participant, in confidence, with a member of the committees. These are independent committees composed of members of the University community, staff of the institutions, as well as, lay members of the community not connected with these institutions. The Committee has reviewed this study. Thank you for considering this request for your assistance.

Sincerely,

Paul A. Winter

Beverly C. Keepers 
INSTRUCTIONS: Please check or provide the below information that applies best to you. Your responses are anonymous and confidential.

\section{DEMOGRAPHIC DATA}

Your Age in Years:

Your Gender: Male Female

Number of Dependent Children

Ethnicity:
African-American
White American
Asian American
Native American
Hispanic American
Other (Please Specify)

\section{Education:}

Highest Degree Earned:

$\mathrm{BS} / \mathrm{BA}$ MS/MA

Masters +30 hours

Doctorate

Area of Teaching Certification (College Major)

\section{Current Job:}

Approximate Enrollment of Your School

Current School Assignment:

Elementary Middle School

High School

Your school's classification based on the most recent CATS results:

In Need of Assistance Progressing

Meets Goal

\section{Work Experience:}

Years of Teaching Experience

Years of Teaching Experience in JCPS 


\section{COUNSELOR JOB FACTORS}

INSTRUCTIONS: Please use the scales below to rate your interest in a school counseling career. The scales range from a low of 1 (Not at all Interested) to high of 5 (Very Interested). Please circle the number indicating your response.

At this stage of your career, how would you rate your interest in a career as a school counselor relative to the job duties described below?

\section{Not at All}

Interested

1. The opportunity to participate with others in my school to make important decisions....

2. The involvement with Special Education paperwork. ............

3. The opportunity for me to perform administrative duties. . . . . . . .

4. The time I would spend in support of testing and assessment programs.

5. The opportunity to provide counseling and mentoring to students.

\section{1}

1

1

1

1
2

2

2

2

2

\section{Very}

\section{Interested}

4

5

5

5

5

5 


\section{CURRENT AND EXPECTED JOB SATISFACTION}

There are two sets of rating scales for the job characteristics described below. The scales range from a low of 1 (Not at All Satisfied) to a high of 5 (Extremely Satisfied). The scales to the left relate to your satisfaction with your current job. The scales to the right relate to your expected job satisfaction if you were to assume a position as a school counselor. Please circle the one number for each scale that reflects your opinion best regarding current and expected job satisfaction.

\section{CURRENT JOB SATISFACTION}

In my current job, I rate my satisfaction with the below job characteristics as. . .

\section{Job Characteristics}

1. The vacation time

I have. .......

2. The time I have to spend with my family.

\section{Not at All \\ Satisfied}

\section{Extremely \\ Satisfied}

\section{$\sqrt{2}$}

3

4

5

\section{EXPECTED COUNSELOR JOB SATISFACTION}

If I were a counselor, I would expect to rate my satisfaction with the below job characteristics as. . .

\section{Not at All \\ Satisfied}

\section{Extremely \\ Satisfied}

3. Extra income I can

earn in the summer. .

1

2

3

4

5

$\begin{array}{lllll}1 & 2 & 3 & 4 & 5\end{array}$

$\begin{array}{lllll}1 & 2 & 3 & 4 & 5 \\ 1 & 2 & 3 & 4 & 5\end{array}$

4. The hours I work

per week. ......

1

2

45

1

$\begin{array}{llll}2 & 3 & 4 & 5\end{array}$

\section{The opportunity} to experience varied activities on the job.........

$\begin{array}{lllll}1 & 2 & 3 & 4 & 5\end{array}$

$\begin{array}{lllll}1 & 2 & 3 & 4 & 5\end{array}$




\section{CURRENT JOB SATISFACTION}

In my current job, I rate my satisfaction with the below job characteristics as. . .

\section{Job Characteristics}

6. The opportunity to serve others. .....

7. The recognition I receive for doing a good job.....

\section{Not at All}

Satisfied

\section{Extremely}

Satisfied

(20)

3

4

5

\section{EXPECTED COUNSELOR JOB SATISFACTION}

If I were a counselor, I would expect to rate my satisfaction with the below job characteristics as. . .

\section{Not at All}

Satisfied

\section{Extremely}

Satisfied

1

2

3

4

5

1

2
4

5

Please continue on to next page. 


\section{ADDITIONAL QUESTIONS}

Instructions: Please consider the working conditions that generally exist for school counselors and respond to the questions posed below about a career as school counselor.

1. Based on what you know about school counseling, what would you identify as being the most rewarding aspects of working as a school counselor?

2. In your opinion, what are the greatest barriers preventing teachers from considering a career as a school counselor?

3. What recommendations would you give to make the profession of school counseling more attractive to teachers? 


\section{COUNSELOR JOB EVALUATION}

INSTRUCTIONS: Please read the following job description for a school counselor position and rate the job using the rating scales provided on the following page. Circle the one number on each rating scale that applies best to you. In rating the job, assume you are at a point of time in the future when you have earned counselor certification.

\section{SCOPE OF RESPONSIBILITIES}

The counselor reports to the school principal and is responsible for the development of a guidance program implements district guidance plans. Counselors provide systematic and ongoing individual and group counseling services related to the academic, social, vocational and personal development of students. Counselors provide information, consultation, coordination, testing and referral services to meet the needs of students, parents and staff. The counselor implements federal, state and local educational and title mandates on behalf of the school.

\section{PERFORMANCE RESPONSIBILITIES}

1. Plans, implements and evaluates a developmental, preventative guidance program which enhances the school improvement plan.

2. Provides individual, small group, and classroom guidance and counseling for students, parents, and staff to promote student success in academics, career, and personal/social development.

3. Collaborates with staff to assist the district's compliance with federal, state, and local school mandates.

4. Coordinates and interprets state and district testing programs in the school.

5. Directs the maintenance of the permanent record system and provides such records to parents or legal guardians upon request.

6. Promotes positive school-community relationships through active participation in school and civic organizations and functions.

7. Coordinates the health programs and services for the local school.

8. Provides orientation and school program information to students, parents, and staff for successful transition to the next level of education or career-related services.

9. Coordinates services and programs for strengthening of parenting skills.

10. Collaborates with staff in placing students in the most appropriate instructional program and classroom setting.

11. Refers to and consults with district, local, and state resources and agencies in order to promote student success.

12. Duties may include performance of health services, for which training will be provided.

13. Performs other duties as assigned by the Principal.

\section{MINIMUM QUALIFICATIONS}

1. Master's Degree with major in guidance and counseling

2. Certification in guidance and counseling by the Kentucky Department of Education.

3. Teaching experience 
1. If offered, how likely would you be to accept an interview for school counselor job described?

\author{
Very \\ Unlikely To \\ Accept
}

1

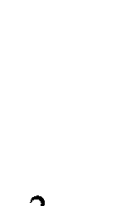

2

\author{
Very \\ Likely To \\ Accept
}

5

2. If offered, how likely would you be to accept the school counselor job described?

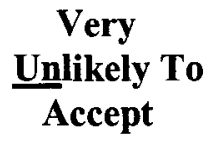

1

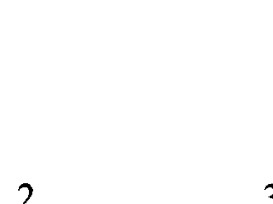

3

4

4




\section{Appendix F}

\section{Responses to Open-Ended Questions}

\section{Elementary School}

1. Based on what you know about school counseling, what would you identify as being the most rewarding aspects of working as a school counselor?

Helping students and parents work through problems/crisis/emotional needs to enable them to make successful progress (51)

Working with children in small groups and in the classroom (21)

Placing at-risk, struggling students in programs that would benefit them most (18)

Getting the chance to meet and know all students through monthly rotation of class visits and lessons (10)

Being able to teach children social skills at an early age in order to impact them for a lifetime (5)

Being able to participate in decisions that affect the entire school (4)

Exiting students who no longer need ECE services (3)

Don't know (3)

Completing ECE paperwork (1)

2. In your opinion, what are the greatest barriers preventing teachers from considering a career as a school counselor?

Excessive paperwork (64)

Coursework/time/expense/additional education required for certification (25) 
Lack of time spent counseling (14)

Administrative duties, responsibilities not related to counseling (14)

ECE paperwork/meetings/testing/scheduling (12)

Student behavior problems, upset parents/referrals (11)

Insufficient pay (8)

Two many teaching responsibilities to pursue a counseling career/would rather teach (6)

Being able to relate to at-risk kids and having to not take the job home with you (1)

Lack of time in the classroom (1)

Having a family (1)

Long work hours (1)

3. What recommendations would you give to make the profession of school counseling more attractive to teachers?

Reduce paperwork (40)

Allow time needed to be a "counselor" not an administrator (22)

Provide more time to meet, interact, counsel kids in class visits (21)

Provide assistants (18)

Provide more pay (14)

Assign ECE testing to ECE chairpersons/qualified testing personnel so counselor can spend more time with students (10)

Educate at in-service, provide more information and explain the duties, show positive aspects and impact that can be 
made in the counseling profession (testimonials from veteran counselors) (6)

Work with students/teachers to receive free tuition/discounted student loans/experience in lieu of college credits (6)

Small group, individual guidance, mentoring (3)

Reduce the amount of time dealing with discipline (2)

Provide more than one counselor at a school (2)

Middle School

1. Based on what you know about school counseling, what would you identify as being the most rewarding aspects of working as a school counselor?

Working one-on-one with students, counseling and interacting in favorable situations to identify and provide help with their needs to become successful (32)

Seeing my involvement make a difference in students' progress/becoming successful (12)

Working with students on career guidance, college and vocational information with interest on to high school

None (5)

2. In your opinion, what are the greatest barriers preventing teachers from considering a career as a school counselor?

Too much paperwork (19)

Extra work hours (7)

Insufficient pay (5)

Too many administrative duties (5)

Spending the extra time getting college courses needed while having to work as a teacher at the same time (5) 
Vague job description, lack of knowledge about counseling variations from school to school/being trained one way by university and employed by school system to do another job (5)

High stakes testing (4)

Leaving core content teaching (3)

ECE paperwork (2)

Not being able to counsel students (2)

Serving large numbers of students (2)

Short vacation (2)

Cost of additional schooling (1)

None (1)

3. What recommendations would you give to make the profession of school counseling more attractive to teachers?

Reduce paperwork (13)

Allow more time for counseling (7)

Increase salaries to compensate for time on the job (6)

Take away testing responsibilities (3)

Limit counseling responsibilities, lower student/counselor ratio (3)

Set similar hours/vacation time as teachers (3)

Hire secretary/clerk for paperwork (2)

Divide ECE paperwork from guidance services (1)

Provide more information to education majors in early years (1) 
Give the job the respect it deserves (1)

Unsure (1)

High School

1. Based on what you know about school counseling, what would you identify as being the most rewarding aspects of working as a school counselor?

Mentoring/working with students (84)

Getting a student involved/successful in college/career goals (63)

Getting to know students on a more personal/individual level (38)

Helping students make major decisions in dealing with problems (28)

Seeing students becoming successful (14)

Working with parents, families, and communities (13)

Making sure that students meet their needs toward graduation (9)

Earning extra pay (8)

Assisting borderline, at-risk students to stay in school (6)

Taking home less paperwork (6)

Helping students get scholarships (4)

Helping improve school environment (4)

Assisting teachers/adults (3)

None (3)

Getting out of the classroom (2) 
Assisting an individual who appreciates your efforts (1) Helping administrators

Being recognized by parents and students (1)

2. In your opinion, what are the greatest barriers preventing teachers from considering a career as a school counselor?

Excessive paperwork (92)

Stress/long hours/extended year/less vacation (57)

Time to complete the additional extensive coursework requirements for counseling while teaching (46)

Lack of actual student interaction/counseling (31)

Difficulties in universities providing certification classes in the time needed (30)

Scheduling (21)

Finding money for tuition (20)

Doing administrative duties (19)

Dealing with difficult, dissatisfied parents/teachers (12) Not enough openings/job opportunities (10)

Leaving the classroom (10)

Dealing with problems/discipline (10)

Low salary (9)

ECE/meetings/paperwork (8)

Lack of interest (7)

Testing responsibilities (5)

Finding the job of counselor difficult to do well because of the student/counselor ratio (5) 
Lack of knowledge of job requirements (4)

No opinion (4)

Bad reputation, negative interactions (3)

Participating in the selection process (1)

Changing schools (1)

Coaches want to continue to coach (1)

Number of dropouts (1)

3. What recommendations would you give to make the profession of school counseling more attractive to teachers?

Allow more emphasis on actually counseling students (61)

Reduce paperwork (37)

Provide pay increase (35)

Hire someone to do other tasks not in counselor job description (ECE) (11)

Minimize student-counselor ratio (11)

Provide orientation to let teachers know what is required/expected of a counselor (10)

No opinion (10)

Eliminate unnecessary coursework/classes (9)

Require fewer administrative tasks/responsibilities (9)

Provide more counselors in the building (8)

Decrease scheduling requirements (8)

Have JCPS pay part of the tuition to become a counselor (7) 
Provide more support/better system for decisions dealing with behavior (6)

Hire clerks to do paperwork (5)

Provide grants/tuition reimbursement for university work (4)

District and uniform job responsibilities across the district (3)

Psychology classes at university level (3)

Remove degree status, one less degree, allow degree without testing ( 3 )

Require shorter work days (3)

Provide scholarships-paid days off for study purposes (2)

Require non-mandatory class/PD credit or college credit to explore counseling as a lateral move (2)

Advertise positions more (2)

Change slating process (2)

Implement district's Developmental Counseling Program (1)

Make it a position a teacher could be promoted to without certification (1)

Provide opportunities for schooling toward a degree after school/weekends (1)

Require a one-year program for certification (1)

Hire a testing coordinator (1)

Require student to have at least four annual appointments with a counselor (1)

Provide better communication between teachers and counselors (1)

Make it a program that is possible for a working mother (1) 
Appendix G

\section{Data collection Sites}

Elementary Schools

Dunn Elementary

Fern Creek Elementary

Englehard Elementary

Greathouse Shyrock Elementary

Sanders Elementary

Minors Lane Elementary

Middle Schools

Newburg Middle School

Meyzeek Middle School

Lassiter Middle School

Iroquois Middle School

High Schools

Waggener High School

Southern High School

Pleasure Ridge Park High School

Shawnee High School

Seneca High School 
CURRICULUM VITAE

NAME :

Beverly Keepers

ADDRESS :

1712 Golden Leaf Way

Louisville, Kentucky 40245

DOB :

Louisville, Kentucky - March 24, 1948

EDUCATION

$\&$ TRAINING :

B.A., English and Theatre Western Kentucky University

1967-1970

M.A., English

University of Louisville

1972-1975

Rank I

Administration and Supervision

University of Louisville

1972-1982

Ph.D., Educational Administration

University of Louisville

2000-2004

AWARDS :

Teacher Award, Louisville Community

Foundations (\$1,200 grant), 1985

Kentucky Dept. of Education's Pilot Writing Project Grant $(\$ 18,400), 1986$

Butler High School's Teacher of the Year,1987

Jefferson County Stand Up Award for

Outstanding Student Publications, 1988

Kentucky Educational Leadership Institute

(selected as participant), 1992

NEA/NFIE Southeast Learning for Tomorrow

Program (selected as participant), 1992 
Oxford International Round Table on School Principalship and Superintendency, oxford University, Oxford, England, August 1997 Heuser Technology Grant $(\$ 125,000)$ to network building, provide collaboration with $\mathrm{U}$ of $\mathrm{L}$ Speed Scientific School, 1998 Outstanding High School Principal, JCPS, 1998

PROFESSIONAL SOCIETIES :

\author{
Kentucky Institute for Women in School \\ Administration, 1989-Present \\ Jefferson County Association for School \\ Administrators, President, 1995-96 \\ Kentucky Association of Secondary School \\ Principals, 1988-Present \\ Kentucky Association of Secondary School \\ Principals Board Member, Region 7, 1999- \\ Present \\ National Association for Secondary School \\ Principals, 1988-Present \\ National Association for Secondary School \\ Principals Urban Schools Committee, 1997- \\ Present \\ Women in School Administration (Member, 1989- \\ Present; Nominating Committee 1995-96; At \\ Large Member, 1996-97; \\ International Network of Performing and \\ Visual Arts School Board Member, Membership \\ Chair, 1998), 1989 - Present \\ Jefferson County Principals Association \\ (Executive Board 1993-99, \\ 2003-04, Chairperson 1996-97) \\ Life Membership in PTSA, 1996 \\ 15th District PTSA Board Member, 1996-98 \\ Kosair Children's Hospital, Board Member, \\ 1996-Present \\ Leadership Louisville (Class of 1995) \\ Bingham Fellows (Class of 1997)
}

PUBLICATIONS: "Manual Principal Shares Advice on Preparing for the PSAT" Business First, February 25, 2000 
"Implementing Drug Awareness Programs in Performing Arts Schools", Network of Performing and Visual Arts Schools Conference, Miami, Florida (1990) "Principal Support for Writing Portfolio Assessment," National Council of Teachers of English Conference (1992) "The Kentucky Education Reform Act: Implications for Arts Magnet Schools," The International Network of Performing and Visual Arts Schools Conference (October 25, 1996, Louisville, KY)

"Performance Assessment: Implementing KIRIS Strategies in Interdisciplinary Magnet Programs" Magnet Schools of America Conference, Miami, Fla. (March 7-9, 1997) "Principal Support for School to Career Programs in the Arts" - International Network of Performing and Visual Arts School Conference, Las Vegas, Nevada (October 1997) Introduction of Speaker and Forum Moderator "Succeeding in School Reform Forum" presented by Ruby Payne. National Association of Secondary Schools Conference, San Antonio, TX (Feb. 5, 2000)

Panel Presenter - Urban Schools Committee Forum "To Redesign or Not to Redesign: That is the Question", National Association of Secondary Schools Conference, San Antonio, TX (Feb. 7, 2000)

INVITED PRESENTATIONS:

"Jazz Your Class with the Arts," Jefferson County Teachers Arts Conference (1990) "Creating and Implementing a Sexual Harassment Policy in Your School" Jefferson County Public Schools Administrators Retreat (August 1995, Gheens Academy, Louisville) "Breaking In: Arts Jobs of the $90^{\prime} \mathrm{s}, "$ Kentucky Arts Council's ARTS CONNECTIONS Conference (December $8 \& 9$, 1995, Lexington, Kentucky) 
"KERA and Shared Decision Making: A

Principal's Perspective," The Oxford Round Table on Education Policy: The School Principalship and Superintendency. (July 28August 1, 1997, Oxford, England)

"Strategies for Increasing Math Assessment Scores from High Performance Schools of CATS", (February 16, 2000)

"Touchdown 2014 Fourth Annual High School Restructuring Showcase" KY Department of Education and KY Association of School Administrators, (February 15-17, 2000) 